NBER WORKING PAPER SERIES

BRIDE PRICE AND FEMALE EDUCATION

\author{
Nava Ashraf \\ Natalie Bau \\ Nathan Nunn \\ Alessandra Voena
}

Working Paper 22417

http://www.nber.org/papers/w22417

\author{
NATIONAL BUREAU OF ECONOMIC RESEARCH \\ 1050 Massachusetts Avenue \\ Cambridge, MA 02138 \\ July 2016, Revised March 2018
}

\begin{abstract}
We thank Martha Bailey, Marianne Bertrand, David Baqaee, Sam Bazzi, St'ephane Bonhomme, Melissa Dell, Esther Duflo, Raquel Fernández, Ingvil Gaarder, Murat Iyigun, Kelsey Jack, Simone Lenzu, Kenneth Leonard, Corinne Low, Neale Mahoney, Cecilia Machado, Bryce Millett Steinberg, Magne Mogstad, Suresh Naidu, Ben Olken, Claudia Olivetti, Tommaso Porzio, Al Roth, Aloysius Siow, Chris Udry, Glen Weyl and participants at various seminars and conferences for helpful comments. Eva $\mathrm{Ng}$, Parina Lalchandani, and Poulod Borojerdi provided excellent research assistance. The views expressed herein are those of the authors and do not necessarily reflect the views of the National Bureau of Economic Research.
\end{abstract}

NBER working papers are circulated for discussion and comment purposes. They have not been peerreviewed or been subject to the review by the NBER Board of Directors that accompanies official NBER publications.

(C) 2016 by Nava Ashraf, Natalie Bau, Nathan Nunn, and Alessandra Voena. All rights reserved. Short sections of text, not to exceed two paragraphs, may be quoted without explicit permission provided that full credit, including (C) notice, is given to the source. 
Bride Price and Female Education

Nava Ashraf, Natalie Bau, Nathan Nunn, and Alessandra Voena

NBER Working Paper No. 22417

July 2016, Revised March 2018

JEL No. I21,I25,O53,O55,Z1,Z13

\begin{abstract}
$\underline{\text { ABSTRACT }}$
Although it is well known that traditional cultural practices can play an important role in development, we still have little understanding of what this means for development policy. To improve our understanding of this issue, we examine how the effects of school construction on girls' education vary with a widely-practiced marriage custom called bride price, which is a payment made by the husband and/or his family to the wife's parents at marriage. We begin by developing a model of educational choice with and without bride price. The model generates a number of predictions that we test in two countries that have had large-scale school construction projects, Indonesia and Zambia. Consistent with the model, we find that for groups that practice the custom of bride price, the value of bride price payments that the parents receive tend to increase with their daughter's education. As a consequence, the probability of a girl being educated is higher among bride price groups. The model also predicts that families from bride price groups will be the most responsive to policies, like school construction, that are aimed at increasing female education. Studying the INPRES school construction program in Indonesia, as well as a similar program in Zambia, we find evidence consistent with this prediction. Although the program had no discernible effect on the education of girls from groups without bride price, it had large positive effects for girls from groups with a bride price. The findings emphasize the importance of the marriage market as a driver of educational investment and provide an example of how the cultural context of a society can be crucial for the effectiveness of development policy.
\end{abstract}

Nava Ashraf

Department of Economics

London School of Economics

Houghton Street

London WC2A 2AE

United Kingdom

n.ashraf1@lse.ac.uk

Natalie Bau

Department of Economics

University of Toronto

150 St. George Street

Toronto, ON M5S 3A3

natalie.bau@utoronto.ca
Nathan Nunn Department

of Economics Harvard

University 1805

Cambridge St Cambridge,

MA 02138 and NBER

nnunn@fas.harvard.edu

Alessandra Voena

Department of Economics

University of Chicago

1126 East 59th Street

Chicago, IL 60637

and NBER

avoena@uchicago.edu 


\section{Introduction}

Increasingly, researchers and policy-makers are recognizing the importance of culture for economic development (World Bank, 2015; Collier, 2017). However, we continue to have a far more limited understanding of what traditional practices imply for development policy and whether the efficacy of development programs is related to the particular cultural context in which they are enacted. Although development policies generally have not been tailored to specific cultural settings, there is growing recognition that one-size-fits-all strategies may not be optimal and that there may be benefits to understanding a society's cultural context when designing policies (Rao and Walton, 2004; World Bank, 2015).

In an attempt to gain a better understanding of whether the success of development programs can depend on cultural context, we revisit one of the best-studied historical development projects, the Sekolah Dasar INPRES school building program of the 1970s in Indonesia, as well as a similar, but more recent, school-construction program that took place in Zambia starting in the late 1990s. We show that whether the programs were successful in increasing female education depended critically on the traditional marriage customs of the local population. Specifically, we document the importance of the custom called bride price (or sometimes called bride wealth), which is a transfer from the groom and/or his family to the bride's parents upon marriage. The payment, which is often greater than a year's income and takes the form of money, animals, or commodities, is widely practiced in many regions of the world, including Southeast Asia and sub-Saharan Africa (Anderson, 2007a). In both settings, we find that the effect of school construction on overall female education is undetectable, but among the ethnic groups that practice the bride price, it is large and positive.

We begin our analysis by modeling the relationship between the marriage market and education. Our model provides a framework for understanding the relationships between the practice of bride price, the parents' decision of whether to educate their daughter, and how the latter is affected by a policy, like school construction, that reduces the cost of education. In the model, imperfectly altruistic parents choose whether to educate their children. After the educational investment takes place, men and women match in a frictionless marriage market based on their educational attainments, which are complementary in the marital output function. The bride price is the marital transfer to women, which is appropriated by the bride's parents in cultures with bride price customs, and it is larger for educated women in equilibrium. Hence, the practice of bride price provides an additional monetary incentive for parents to invest in their daughters' education. This mechanism is particularly important when daughters cannot credibly commit to paying back their parents ex post for educational investments, 
as in our setup (Becker, 1993; Gale and Scholz, 1994). As a result, female education rates are higher in bride societies. Moreover, such societies are also more responsive to a decrease in the cost of schooling, as long as overall female education rates are low, as is common in developing countries. Importantly, in our framework, when educated women are scarcer than educated men, transferable utility ensures that the equilibrium education decision of a boy's parents does not depend on the presence of a bride price custom.

The model delivers six testable predictions. First, complementarity ensures that matching is assortative by education in both bride price and non-bride price ethnic groups. Second, in equilibrium, educated women command higher bride price payments. Third, girls' education is higher among bride price ethnic groups. Fourth, the average innate ability of girls enrolled in school is lower among bride price ethnic groups. The fifth and most important prediction states that, in a developing-country context with low education rates, policies that decrease the cost of schooling result in a greater increase in girls' education for bride price ethnic groups. Sixth, in contrast to the girls' case, boys' average educational attainment, the average quality of enrolled boys, and the responsiveness of male education to policies that reduce the cost of education are no different for bride price and non-bride price ethnic groups.

Our empirical analysis is guided by the predictions of the model, and culminates with the heterogeneity analysis of the effects of two large school construction programs in our two countries of interest. We focus on Indonesia and Zambia because they have sub-national variation in bride price practices and have also recently experienced large-scale school construction projects. In both countries, the value of bride price payments is quantitatively important today and is correlated with traditional ethnic customs. In Indonesia, average payments among ethnic groups that practice bride price are $80 \%$ of per capita GDP, while this figure is $205 \%$ in Zambia. ${ }^{1}$

We begin by testing the first prediction and find a strong positive relationship between the education of grooms and that of brides. Moreover, we find that, consistent with the model, this relationship is similar for couples from bride price and non-bride price ethnic groups.

Turning to the second prediction, we then examine the relationship between the bride's education and the value of the bride price she commands at marriage. Within Indonesia, we find that completing primary school is associated with a $58 \%$ increase in the bride price payment, completing junior secondary is associated with a further $67 \%$ increase, and completing college is associated with another $86 \%$ increase. These relationships are very robust and remain strong even when conditioning on a

\footnotetext{
${ }^{1}$ As we discuss below, the Zambian sample is taken from the poor suburbs of the capital city Lusaka, and thus is not necessarily nationally representative.
} 
large set of observable characteristics, including the groom's education. In Zambia, we find the same patterns in the data. In addition, we collect information on whether people are aware of the relationship between education and bride price payments and what their perceptions of the reason behind this positive relationship are - e.g., whether the relationship is causal or spurious. The data collected indicate that the relationship between the bride's education and the amount of bride price received is widely known and that the parents view it as causal. ${ }^{2}$

We then turn to the prediction of the model that states that the average level of education is higher for women belonging to bride price ethnic groups (prediction 3), and that, as a result, the average ability of enrolled, female students from bride price ethnic groups is lower than the average ability of enrolled students from non-bride price ethnic groups (prediction 4). We find that prediction 3 holds in both Indonesia and Zambia. Female enrollment rates are 4.1-4.9 percentage points higher for bride price groups in Indonesia relative to non-bride price groups and 1.2-2.1 percentage points higher in Zambia. Using Indonesian data, we test prediction 4 by examining students' test scores in the national Ebtanas exam. We find that the average test score for female students belonging to bride price ethnic groups is about 0.07 standard deviations lower than for female students belonging to non-bride price ethnic groups.

We then turn to prediction 5, which is the penultimate prediction of the model and the focus of the paper. The prediction suggests that school construction policies that decrease the costs of schooling should have a larger effect on the education of girls from bride price ethnic groups. We first study the Indonesian Sekolah Dasar INPRES school-construction program, during which 61,807 primary schools were constructed between 1974 and 1980. The seminal paper studying this program, in line with its objective of measuring the effect of education on wages, only examines a sample of males (Duflo, 2001). In contrast, we study the impact of the program on girls' schooling. We first confirm that there appears to be no effect of this program on female education, consistent with the small effects found in Breierova and Duflo (2002). We then show that this average effect masks important heterogeneity that depends on a group's marriage custom. We observe a positive impact of the program on female education only among girls from ethnic groups that traditionally engage in bride price payments. Among these ethnic groups, adding one school every 1,000 school-aged children in a given district raises female primary school completion rates by 2.5 percentage points. Sensitivity and robustness checks show that this finding, and the previous ones, are not driven by

\footnotetext{
${ }^{2}$ In our survey, the most common explanation proffered for this relationship was that a higher bride price was due to a moral obligation on the part of the groom's family to compensate the bride's family for the greater educational investments they had made in their daughter. This view is consistent with anthropological accounts of the perceived role of bride price by local populations (e.g., Dalton, 1966; Moore, 2016).
} 
other important cultural factors that may be correlated with bride price, such as women's traditional role in agricultural production, matrilineality, polygyny, or the practice of Islam.

We corroborate these results by studying another nation-wide school expansion program that took place in Zambia in the late 1990s and early 2000s. Using newly-collected data from the Zambia Ministry of Education, we find the same patterns as in Indonesia. Among ethnic groups that traditionally practice bride price, school construction has a large and statistically significant effect on female education. Building an additional school per square kilometer in a given district raises female primary school completion rates by 4.2 percentage points. However, among ethnic groups that do not traditionally practice bride price, school construction does not have a detectable effect.

We then turn to testing for alternative explanations for the higher responsiveness of bride price families to schooling opportunities for their daughters. One possibility is that bride price parents are more responsive because they tend to either be wealthier, have fewer children, or simply value girls more. Examining each of these alternative explanations, we find that none are able to explain the larger effect of school construction on female education among bride price ethnic groups. We find no evidence that bride price families are wealthier, have fewer children, or have more positive attitudes towards females. Another possibility is that the returns to education are different for bride price and non-bride price ethnic groups. Again, we find no evidence in support of such an explanation. In both countries, the relationship between income and education is similar for women from bride price and non-bride price ethnic groups.

The final part of the analysis considers the implications of bride price for the education of males, which is the sixth prediction of the model. Consistent with the model, we do not observe the same patterns for males as we do for females. We find no evidence of the same relationships between bride price and either education, the average ability of those enrolled in school, or the responsiveness of education to the school-construction programs.

Our findings build on and advance the literature examining the economic effects of culture (e.g. Fernandez, 2007; Fernandez and Fogli, 2009; Algan and Cahuc, 2010; Fernandez, 2011; Atkin, 2016; Bau, 2016; Jayachandran and Pande, 2017; Lowes, 2017). In particular, we show that important large-scale development policies can have very different effects on different ethnic groups depending on the cultural tradition of bride price. This finding reinforces the idea that the cultural and historical contexts have persistent and non-obvious effects that matter for the success of development programs. Hence, taking these elements into account is important for evaluating treatment effects and for designing effective policies. 
We interpret the economic mechanism behind the heterogeneity in the effect of school construction by ethnic group as evidence of the role of the marriage market in driving educational choices and hence how households respond to education reforms. While marriage outcomes are generally considered an important component of the returns to education, especially for women (Goldin, 2006; Chiappori et al., 2017), it is typically difficult to empirically observe them and to identify their actual impact. In this paper, we study the marriage market returns to education as reflected in the value of the bride price and show that they have sizable effects on parents' decisions to educate daughters, particularly in response to policies that reduce the cost of schooling. In doing so, we also advance the understanding of the economics of marriage markets in developing countries. In particular, dowry has received a considerable amount of attention in the economics literature (Botticini and Siow, 2003; Anderson, 2003, 2007b; Arunachalam and Naidu, 2015; Anderson and Bidner, 2016), but bride price has been the subject of few studies, despite the fact that the practice is widespread and the payments are often large in magnitude (Anderson, 2007a; Bishai and Grossbard, 2010).

By exploring the role of the bride price as a payment from the younger to the older generation, our results also add to the literature on the relationship between human capital investments and intergenerational transfers. Cultural practices like patrilocal residence, inheritance, son preference, and polygyny have been shown to play an important role in such investments (Jacoby, 1995; Levine and Kevane, 2003; Tertilt, 2005, 2006; Gaspart and Platteau, 2010; La Ferrara and Milazzo, 2011; Bau, 2016; Jayachandran and Pande, 2017). In our framework, the practice of bride price allows parents to partake in the returns that their daughters accrue from education, and hence it helps to complete the intergenerational contract between parents and daughters. Importantly, this interpretation adds a new perspective to the growing policy debate about whether bride price should be discouraged or even banned (e.g., Wendo, 2004; Mujuzi, 2010), suggesting that arguments for the elimination of the practice should be considered with an understanding of the effect of this practice on female education.

The paper is structured as follows. We begin by providing an overview of the custom of bride price (section 2). This is followed by our model of the marriage market with premarital educational investments and bride price (section 3). We then bring the model to the data, testing the model's first predictions about marriage, bride price, and education (section 4). We then turn to the primary prediction of the model, which is about the heterogeneous response to education policies that is generated by the custom of bride price (section 5). In this section, we also explore alternative explanations for our findings and examine the model's predictions for males. We then provide a discussion of the significance and importance of our findings (section 6). Lastly, we conclude in 
section 7 .

\section{The Bride Price Custom}

\subsection{Overview and variation}

The payment of a bride price at the time of marriage is a custom that is widespread throughout sub-Saharan Africa and many parts of Asia today. The practice also has a long history, dating at least as far back as 3000 BCE, having been practiced by the Ancient Egyptians, Mesopotamians, Hebrews, Aztecs, and the Incas (Anderson, 2007a, pp. 152-153). Historically and today, the magnitude of the bride price is typically sizeable. It is common for the value of the bride price to be in excess of a year's income (Anderson, 2007a).

Our analysis requires measures of the traditional marriage customs of different ethnic groups. One of the data sources that we use is George Murdock's (1967) Ethnographic Atlas, which provides information on transfers made at marriage, categorizing ethnic groups as engaging in one of the following practices (Murdock, 1981, pp. 92-93): ${ }^{3}$

1. Bride price: Also known as bride wealth. A transfer of a substantial consideration in the form of goods, livestock, or money from the groom or his relatives to the kinsmen of the bride.

2. Token bride price: A small or symbolic payment only.

3. Bride service: A substantive material consideration in which the principal element consists of labor or other services rendered by the groom to the bride's kinsmen.

4. Gift exchange: Reciprocal exchange of gifts of substantial value between the relatives of the bride and groom, or a continuing exchange of goods and services in approximately equal amounts between the groom or his kinsmen and the bride's relatives.

5. Exchange: Transfer of a sister or other female relative of the groom in exchange for the bride.

6. Dowry: Transfer of a substantial amount of property from the bride's relatives to the bride, the groom, or the kinsmen of the latter.

7. No significant consideration: Absence of any significant consideration, or giving of bridal gifts only.

\footnotetext{
${ }^{3}$ Among the 1,265 ethnic groups examined in the Ethnographic Atlas, bride price is traditionally practiced by $52 \%$ globally, although this does not reflect the population weights of the different ethnic groups. The next most common custom is for there to be no dominant practice, which is the case for about $22 \%$ of societies.
} 
Table 1: Distribution of marriage customs

\begin{tabular}{|c|c|c|c|c|c|c|c|c|}
\hline & \multicolumn{2}{|c|}{ (1) } & \multicolumn{2}{|c|}{$(2)$} & \multicolumn{2}{|c|}{ (3) } & \multicolumn{2}{|c|}{ (4) } \\
\hline & \multicolumn{4}{|c|}{ Indonesia } & \multicolumn{4}{|c|}{ Zambia } \\
\hline & \multicolumn{2}{|c|}{$\begin{array}{c}\text { Ethnographic } \\
\text { Atlas only }\end{array}$} & \multicolumn{2}{|c|}{$\begin{array}{c}\text { All } \\
\text { Sources }\end{array}$} & \multicolumn{2}{|c|}{$\begin{array}{c}\text { Ethnographic } \\
\text { Atlas only }\end{array}$} & \multicolumn{2}{|c|}{$\begin{array}{c}\text { All } \\
\text { Sources }\end{array}$} \\
\hline & Number & Share & Number & Share & Number & Share & Number & Share \\
\hline Bride Price & 14 & 0.48 & 23 & 0.52 & 8 & 0.38 & 11 & 0.37 \\
\hline Bride Service & 2 & 0.07 & 4 & 0.09 & 7 & 0.33 & 12 & 0.40 \\
\hline Token Bride Price & 2 & 0.07 & 2 & 0.05 & 6 & 0.29 & 7 & 0.23 \\
\hline Gift Exchange & 3 & 0.10 & 4 & 0.09 & 0 & 0.00 & 0 & 0.00 \\
\hline Female Relative Exchange & 4 & 0.14 & 4 & 0.09 & 0 & 0.00 & 0 & 0.00 \\
\hline Absence of Consideration & 4 & 0.14 & 7 & 0.16 & 0 & 0.00 & 0 & 0.00 \\
\hline Dowry & 0 & 0.00 & 0 & 0.00 & 0 & 0.00 & 0 & 0.00 \\
\hline Total & 29 & 1.00 & 44 & 1.00 & 21 & 1.00 & 30 & 1.00 \\
\hline
\end{tabular}

Notes: This table reports the number of ethnicities that practice different traditional marriage customs within Indonesia and Zambia. In columns 1 and 3, the data on traditional marriage practices are from the Ethnographic Atlas (Murdock, 1967). In column 2, the data are from Murdock (1967) and LeBar (1972). In column 4, the data are from Murdock (1967), Willis (1966), Whiteley and Slaski (1950), and Schapera (1953).

The distributions of marriage customs for Indonesia and Zambia are reported in columns 1 and 3 of Table $1 .{ }^{4}$ We also supplement information from the Ethnographic Atlas with additional ethnographic sources. For Indonesia, we use LeBar (1972), which is a publication produced as part of the Human Relations Area Files, and for Zambia, we draw on three volumes of the Ethnographic Survey of Africa (Willis, 1966; Whiteley and Slaski, 1950; Schapera, 1953). These sources provide a finer breakdown of ethnic groups and greater coverage than is possible using only the Ethnographic Atlas. ${ }^{5}$ The distribution of marriage customs using these combined sources is reported in columns 2 and 4 of Table 1. This is the variation that we use in our analysis. ${ }^{6}$

Importantly, Table 1 makes clear that none of the ethnic groups within Indonesia and Zambia practice dowry as their primary marriage practice. Thus, our estimates of differences between bride price cultures and non-bride price cultures do not reflect the effects of whether a group practices dowry or not. Therefore, our study does not speak to the question of whether or not the custom of dowry also influences educational investment. ${ }^{7}$

\footnotetext{
${ }^{4}$ Ethnic groups are reported in the table if they were matched to groups listed in the 1995 Indonesia Intercensal data or the 1996, 2001, 2007, and 2013 Zambia Demographic and Health Surveys (DHS). A list of the ethnic groups in each sample, as well as whether they practice bride price or not, is reported in Appendix Tables A1 and A2 .

${ }^{5}$ The additional sources also allow us to check the validity of the Ethnographic Atlas. We find that in the vast majority of cases the sources report the same marriage practices. There are a very small number of cases where the sources disagree. In these instances, we use the coding from the Ethnographic Atlas.

${ }^{6}$ All of the results that we report are robust to using the Ethnographic Atlas information only.

${ }^{7}$ We caution against mistakenly viewing dowry as a "reverse" (or negative) bride price. While bride price is a transfer of resources from the groom or groom's parents to the parents of the bride, dowry is a transfer of resources from the bride's parents to the bride and her husband at the time of marriage (Goody and Tambiah, 1973; Anderson, 2007a). This has led scholars to view the dowry as having important pre-mortem bequest motives (e.g., Goody and Tambiah, 1973; Botticini and Siow, 2003; Anderson and Bidner, 2016). The practice that is the "reverse" of bride price is called
} 
Figure 1: Geographic distribution of the practice of bride price in Indonesia and Zambia
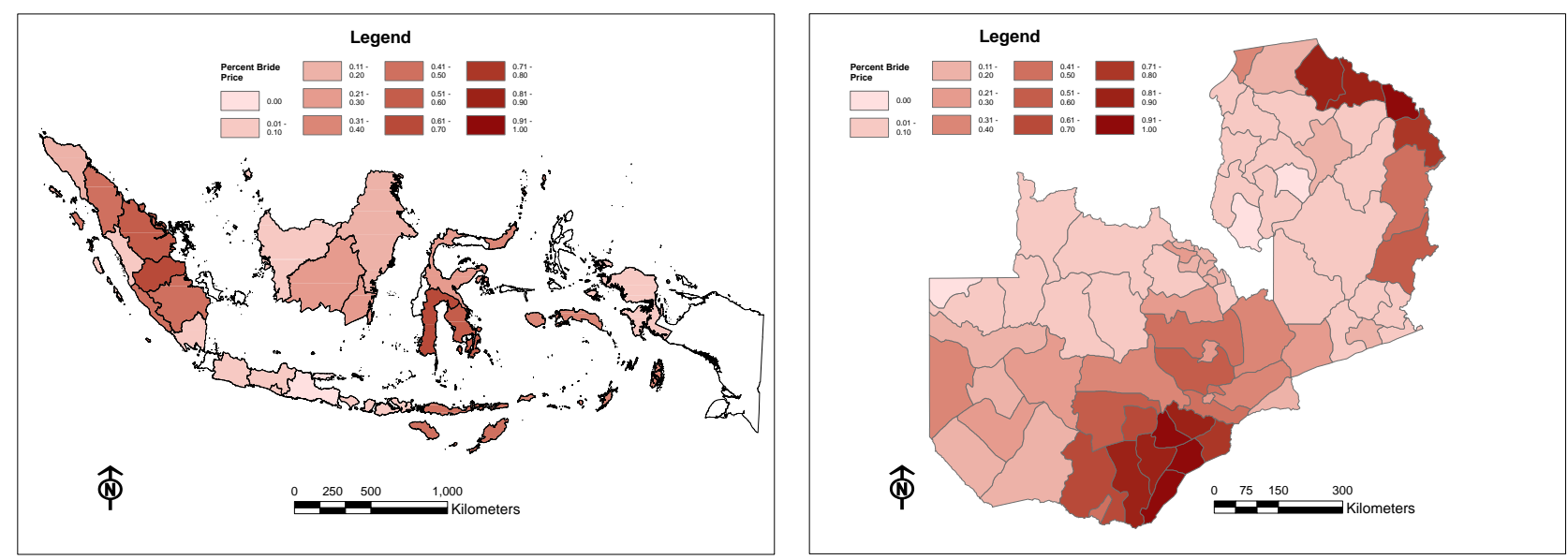

Notes: The maps show the spatial distribution of the practice of bride price. The figures are calculated using the 1995 Indonesia Intercensal Survey (left) and the 1996, 2001, 2007, and 2013 Zambia Demographic and Health Surveys (right). We link individuals to traditional bride price practice using their self-reported mother tongue in Indonesia and using their self-reported ethnicity in Zambia.

Figure 1 provides an overview of the geographic distribution of the practice of bride price in Indonesia and Zambia. The figures are constructed by combining survey data that report both respondents' locations and their mother tongue or ethnicity. For Indonesia, the data are from the 1995 Indonesia Intercensal Survey and are matched to information on traditional marriage customs using respondents reported mother tongue. ${ }^{8}$ For Zambia, the data are from the 1996, 2001, 2007, and 2013 rounds of the Demographic and Health Surveys, and we link individuals to traditional marriage customs using their self-reported ethnicity. ${ }^{9}$ Figure 1 reports the proportion of respondents in each province in Indonesia, and each district in Zambia, that are from an ethnic group that traditionally practices bride price as opposed to the other customs. In the actual analysis for Indonesia, we work at a much finer spatial resolution (i.e., districts rather than provinces). However, for clarity of presentation, we display the more aggregate provincial averages here.

a groom-price, which is a payment made from the bride or bride's parents to the groom's parents. It is extremely rare and has only found in a small number of societies (Divale and Harris, 1976).

${ }^{8}$ In total, 174 different languages are recorded as being spoken in the Intercensal Survey, which we match to 44 distinct ethnic groups for which we have bride price information. All but 11 of the 174 language groups in the Indonesia Intercensal Survey could be matched to the ethnographic data. These comprise 0.43 percent of the observations with non-missing language data.

${ }^{9}$ The Zambia DHS reports 65 distinct ethnic groups. Of these, we are able to match 53 of them to 30 more coarselydefined groups for which we have bride price information. The remaining unmatched groups are small and comprise less than 2.5 percent of the DHS sample. 
Table 2: Correlations between bride price and other customs

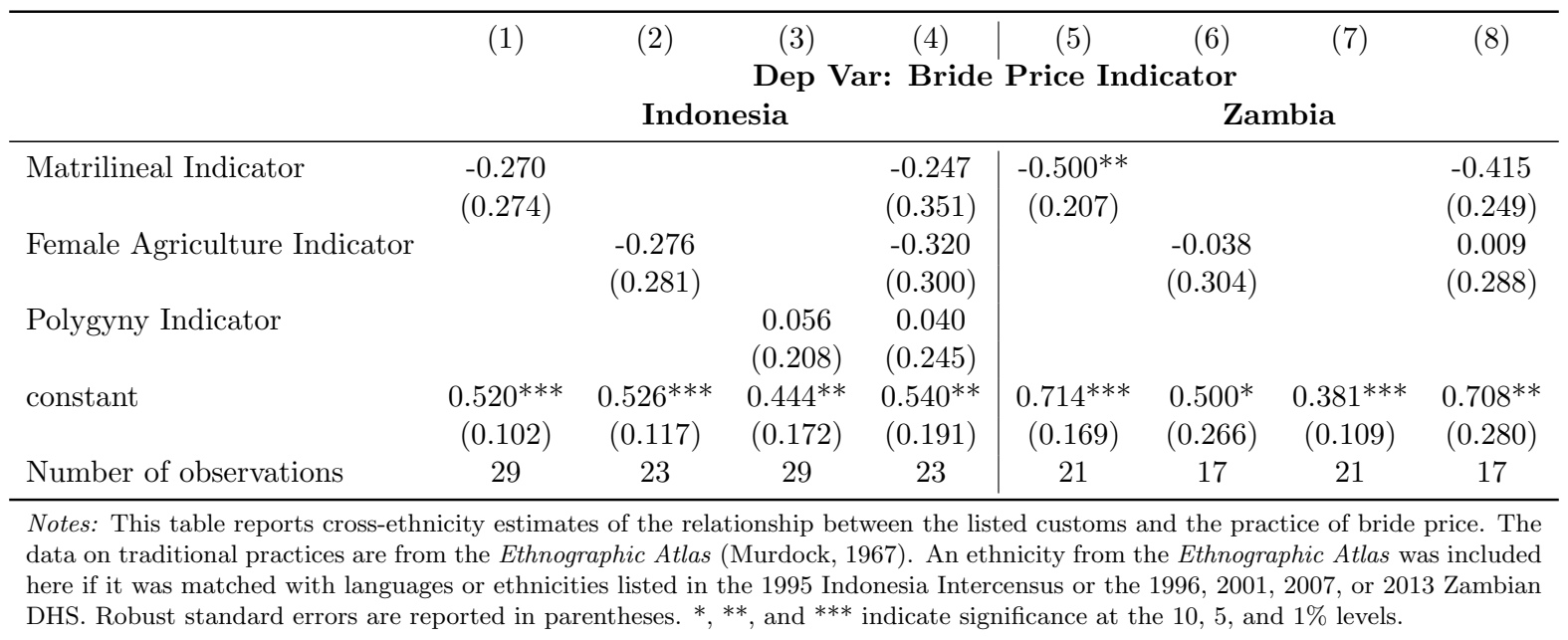

\subsection{The origins and correlates of bride price}

While the historical origins of the bride price practice are not known with complete certainty, there are two dominant theories within the field of anthropology. The first is that the custom historically originated in patrilineal societies, where the wife joins the husband's kinship group following marriage (Vroklage, 1952). Within this system, the bride's lineage loses a member (as well as future offspring) at the time of marriage. Thus, the bride price arose as a way of compensating the bride's lineage for this loss, and as a way of showing appreciation for the investments they made in raising their daughter. According to this hypothesis, although bride price originated in patrilineal societies, it subsequently spread to nearby matrilineal societies.

The practice of bride price has also been linked to the participation of women in agriculture. In societies where women were actively engaged in agriculture, their families would have been more reluctant to part with a daughter unless compensated and therefore, the custom of transferring money to compensate for the loss of a daughter may have evolved (Boserup, 1970). The last, related factor that is potentially relevant for bride price is the practice of polygyny. Work on polygyny by Grossbard (1978), Becker (1981), and Tertilt (2005) indicates that, in societies where polygyny is prevalent, high bride prices are necessary to clear the marriage market. Thus, places with polygyny may be more likely to have also adopted bride price.

Using data from the Murdock (1967), we examine the extent to which cross-ethnicity correlations are consistent with these hypotheses within our countries of interest. The estimates for our two samples of interest are reported in Table 2. Each column of the table reports estimates from a regression where the dependent variable is an indicator variable that equals one if the ethnic group 
traditionally practiced bride price. By and large, we only find weak evidence of the correlations suggested by the literature. In Indonesia, none of the variables are correlated with bride price. In Zambia, all ethnic groups traditionally practice polygyny so, mechanically, there is no relationship between this variable and bride price. In addition, there is also no relationship between traditional female participation in agriculture and bride price. There is, however, a negative relationship between matrilineality and bride price. This can be contrasted with estimates using the global sample (reported in Appendix Table A3), where one does observe the expected relationships between bride price and matrilineal societies, female participation in agriculture, and polygyny. Matrilineal societies are less likely to practice bride price, while groups where women more actively participate in agriculture and groups that practice polygyny are more likely to practice bride price. Thus, while we observe strong patterns globally, they are much weaker when looking within our countries of interest. To be as cautious as possible, our analysis will confirm the robustness of our findings to controlling for these ethnicity-level characteristics. In addition, in some of our Indonesian and Zambian data (the Indonesia Family Life Survey and the Zambian Demographic and Health Surveys), where we have information about the practice of polygyny at the household level, we control for this practice in our most conservative specifications.

\subsection{The modern practice of bride price}

Throughout our analysis, our measure of bride price is an ethnicity-level indicator variable for the traditional presence of the custom (i.e., category 1 in subsection 2.1). Thus, we will not directly use either the prevalence of the practice today or the value of bride price payments to identify the effects of bride price. Relative to traditional practices, these are more likely to be endogenous to contemporary factors, including the policies of interest. However, we now verify that the traditional custom of bride price is strongly correlated with actual bride price payments today.

For Indonesia, information on bride price payments at marriage is taken from rounds 3 and 4 of the Indonesian Family Life Surveys (IFLS). ${ }^{10}$ The survey also collects the self-reported ethnicities of respondents, which we use to assign the presence of a traditional bride price custom (or not) to a married couple. ${ }^{11}$ We find that both bride price and non-bride price groups tend to report positive

\footnotetext{
${ }^{10}$ The IFLS asks about dowry and bride price together and does not distinguish between the two. However, according to the IFLS documentation, the marriage custom is bride price except for marriages among the matrilocal Minangkabau group (RAND, 1999), who we omit from the analysis.

${ }^{11}$ We use the ethnicity of the individual who reports the characteristics of the marriage to the IFLS to determine whether the couple belongs to a bride price ethnic group. In cases where both the husband and the wife were surveyed and both reported on the marriage, we keep the husband's information, including his ethnic group, under the assumption that he is more likely to correctly remember the bride price. However, since intermarriage between ethnic groups with different bride price customs is very low in Indonesia (less than $2 \%$ in the Intercensal data), using the husband or wife's
} 
payments at marriage. ${ }^{12}$ As we discuss in more detail below, this is because groups in Indonesia without a tradition of bride price typically still engage in small payments that take the form of a token bride price, gift exchange, or other forms of symbolic transfer. There are noticeable differences in the sizes of payments between the two groups. For individuals from groups that traditionally practice bride price, the median bride price payment equals $8.7 \%$ of the per capita GDP in the year of marriage; the mean payment is $80 \%$. For non-bride price couples, the median is only $4 \%$, and the mean is $37 \%$ (Appendix Table A4). ${ }^{13}$

We find a similar pattern in Zambia, where we examine information from peri-urban Lusaka that was collected using a module we created and implemented within the Zambia Fertility Preferences Survey (ZFPS) (Ashraf et al., 2017). ${ }^{14}$ Linking couples to traditional bride price customs using the self-reported ethnicity of the wife, we find that both groups tend to have some payment at marriage, but that the size of the payment is much larger for bride price groups. ${ }^{15}$ For bride price couples, the median bride price payment is $57 \%$ of the per capita GDP in the year of marriage, while the mean is $205 \%$. For non-bride price couples, the median is $45 \%$, and the mean is $87 \%$. The fact that non-bride price ethnic groups report paying a sizeable bride price is in part explained by the fact that in both countries, a number of non-bride price groups traditionally had a "token bride price," and in Indonesia, a number of groups practiced gift exchange (see Table 2). These practices still involve a payment or gift at the time of marriage, although one that is much smaller in magnitude than a full bride price. ${ }^{16}$

In addition to showing differences in bride price payments across ethnic groups, the statistics also provide some sense of the magnitude of bride price payments. In both countries, payments are large.

ethnicity is unlikely to affect the results.

${ }^{12} \mathrm{~A}$ non-zero bride price payment is reported for $92 \%$ of couples that belong to groups that practice bride price and for $91 \%$ of the couples that do not practice bride price.

${ }^{13}$ In the data, a small number of observations report extreme bride price values. These are likely due to data entry and reporting errors. In the figures we report here, we omit reported bride price payments that are greater than 100 times per capita GDP. This results in the omission of 43 observations in Indonesia and 4 observations in Zambia.

${ }^{14}$ Further details of the survey are provided in the data appendix.

${ }^{15}$ Among individuals from ethnic groups that traditionally practiced bride price, $86 \%$ of couples report non-zero bride price payments, while this figure is $77 \%$ among non-bride price couples.

${ }^{16}$ Differences between the two groups are also likely masked by heterogeneity in wealth, which tends to affect the value of a bride price, token bride price, and gifts exchanged. If we, for example, examine differences for couples with a similar level of wealth, the differences appear starker. For example, for the 20 percent of the sample with the lowest wealth, which is likely the population that is most relevant for school construction, we find that the average payment at marriage is $420 \%$ higher for bride price groups than non-bride price groups. 


\section{Model}

We now turn to a theoretical framework that helps us understand how parents' decisions about whether to educate their daughters depend on the practice of bride price. To do this, we draw on the seminal models by Chiappori et al. (2009) and Chiappori et al. (2016), where individuals choose their education before matching in a frictionless marriage market with transferable utility. In our setting, parents, who are imperfectly altruistic, choose the education of their children. The bride price payment is modeled as the marriage market transfer to the woman's side that is appropriated by the parents. We make the assumption that daughters cannot otherwise commit to pay their parents back for their educational investments.

\subsection{Setup}

The model has two periods. There are multiple ethnic groups $e$, and there is a unit mass of women (daughters) and a unit mass of men (sons) in each ethnic group. Parents have only one child and enjoy utility from consumption $\left\{c_{t}\right\}_{t=1}^{2}$ and from the well-being of their child. A daughter's utility is denoted as $v$ and altruism as $\gamma \in(0,1)$, which is the weight parents place on their daughter's utility. A son's utility is denoted as $u$ and altruism as $\delta \in(0,1)$.

Let $y$ be the parents' income in each period and $r \geq 0$ be the discount rate. Daughters, indexed by $i$, are endowed with innate ability $a_{i}$, which is distributed according to a unimodal probability density function $g()$ with a strictly monotone cumulative distribution function $G()$. Sons, indexed by $j$, are endowed with innate ability $a_{j}$, which has the same distribution. Ability affects the utility that children derive from schooling in the first period, in a multiplicative way, $a_{i} S_{i}$, and has no direct impact on the children's utility in the second period.

In the first period, parents decide whether or not to educate their children $(S \in\{0,1\}$ for a girl and $P \in\{0,1\}$ for a boy) at the cost $k$ and enjoy consumption $\left(c_{1}\right)$. There is no borrowing nor saving. ${ }^{17}$ In the second period, children marry, transfers are made, and parents enjoy consumption $\left(c_{2}\right)$. At the time of their daughter's marriage, parents receive a bride price payment if they belong to an ethnic group that engages in this practice, which is paid by the groom and is the marriage market transfer the groom would otherwise make to the bride to clear the marriage market. The indicator $I_{e}$ denotes ethnic groups in which the groom pays a bride price to the bride's family at marriage

\footnotetext{
${ }^{17}$ As long as income in the first period is greater than the cost of schooling, the household does not need to borrow to finance the education of the daughter. Hence, the same household could have multiple daughters and sons, and as long as borrowing constraints do not bind, their problems can be separated.
} 
$\left(I_{e}=1\right)$ as opposed to ethnic groups in which he does not $\left(I_{e}=0\right) .{ }^{18}$ There is no intermarriage between ethnic groups. ${ }^{19}$

\subsubsection{Educational investment}

Parents choose whether to educate their child to maximize their utility. Their problem is

$$
\begin{gathered}
\max _{S_{i} \in\{0,1\}, c \geq 0} \quad c_{1}+\frac{c_{2}}{1+r}+\gamma\left[a_{i} S_{i}+\frac{v_{2}\left(I_{e}, S_{i}\right)}{1+r}\right] \\
\text { s.t. } \quad c_{1}+k \cdot S_{i} \leq y \quad \text { and } \quad c_{2} \leq y+I_{e} \cdot B P\left(S_{i}\right)
\end{gathered}
$$

for a daughter and

$$
\begin{gathered}
\max _{P_{j} \in\{0,1\}, c \geq 0} \quad c_{1}+\frac{c_{2}}{1+r}+\delta\left[a_{j} P_{j}+\frac{u_{2}\left(I_{e}, P_{j}\right)}{1+r}\right] \\
\text { s.t. } \quad c_{1}+k \cdot P_{j} \leq y \quad \text { and } \quad c_{2} \leq y
\end{gathered}
$$

for a son. Consistent with the reality of our settings, we assume that the bride price is paid by the groom, which is done in the second period. ${ }^{20}$ Given this, $u_{2}$ depends on the ethnic group $e$.

\subsubsection{Marriage market}

We consider ethnic groups with a bride price tradition $\left(I_{e}=1\right)$, where the bride's parents appropriate the marriage market transfer, and ethnic groups without a bride price tradition $\left(I_{e}=0\right)$, where the bride and the groom share the marriage surplus through the intra-household allocation of resources (Choo and Siow, 2006; Iyigun and Walsh, 2007).

Define $\zeta_{i}^{f}$ and $\zeta_{j}^{m}$ to be the womens' and mens' respective values if they remain single, i.e. their labor market earnings, and let $\zeta_{i j}$ be the total value of a marriage between $i$ and $j$, i.e. the marriage output. These values do not depend on the ethnic group $e$. Marriage surplus is defined as $z_{i j}=$ $\zeta_{i j}-\zeta_{i}^{f}-\zeta_{j}^{m}$. Since one's value when single and the marriage surplus only depend on education, they

\footnotetext{
${ }^{18}$ All the predictions of the model are robust to allowing bride price to vary on the intensive rather than the extensive margin in the model. That is, we could also model belonging to a bride price ethnic group as increasing the share of the daughter's marriage market transfer that is appropriated by the parents.

${ }^{19}$ In the Indonesia 1995 Intercensal Survey, only $1.50 \%$ of married household heads aged $25-45$ are in a marriage in which the bride price practice of the husband and wife differ. That proportion is $16.80 \%$ in the pooled Zambia DHS.

${ }^{20}$ The fact that the groom is generally the one who pays most of the bride price is based on focus groups from Zambia. This fact has also been documented in similar settings in sub-Saharan Africa. For example, Lowes and Nunn (2017) find that for 80 percent of the 317 marriages that they study in the Democratic Republic of Congo, the groom contributed to the bride price payment. A theoretical rationale for assuming that sons pay the bride price is that the bride price is the portion of the marriage surplus that belongs to the women's side of the marriage market. If the marital surplus accrues to the husband's home, then it is natural to assume that he will be the one to make the payment.
} 
can be indexed by $S_{i}$ and $P_{j}$ :

$$
\zeta_{i j}=\zeta_{S_{i} P_{j}}, \quad \zeta_{i}^{f}=\zeta_{S_{i}}^{f}, \quad \zeta_{j}^{m}=\zeta_{P_{j}}^{m}, \quad z_{i j}=z_{S_{i} P_{j}}
$$

It is assumed that the marriage surplus is increasing in each spouse's educational attainment (i.e. if a spouse is educated, then marital output is higher):

$$
z_{11}-z_{10}>0, \quad z_{11}-z_{01}>0, \quad z_{10}-z_{00}>0, \quad z_{01}-z_{00}>0 .
$$

We also make the standard supermodularity assumption in the assignment literature (Becker, 1973), which is that there is complementarity between the education of the two spouses: $z_{00}+z_{11}>z_{10}+z_{01}$. Lastly, we also assume that the surplus from the marriage between two uneducated people is always positive: $z_{00}>0$. This ensures that everyone marries in equilibrium.

\subsection{Predictions}

To generate empirical predictions, we solve the model backwards. We start with the marriage market, which determines children's utilities in the second period $\left(v_{2}\right.$ and $\left.u_{2}\right)$ which, in turn, define the returns to education. Based on such returns, parents decide whether to undertake the educational investment.

\subsubsection{Matching}

A match in the marriage market is an equilibrium outcome if the match is stable. That is, no man and woman can be made better off by leaving their respective spouses and marrying one another. When utility is transferable, a stable equilibrium maximizes aggregate surplus (Shapley and Shubik, 1971; Becker, 1973). Hence, under the conditions we have imposed on the marriage surplus, everyone marries in equilibrium and matches assortatively, as shown in Chiappori et al. (2009). Consistently with the data, we consider the case in which more men than women are educated and provide conditions for that to occur in equilibrium. Chiappori et al. (2009) show that the unique, stable equilibrium in this market is one in which educated women only marry educated men, while some educated men marry uneducated women. ${ }^{21}$ This result leads to our first prediction.

Prediction 1. Matching is assortative by education irrespective of the practice of bride price.

\footnotetext{
${ }^{21}$ For a proof of existence and uniqueness, see Chiappori et al. (2009) Online Appendix, page 2.
} 
Education leads to a labor market return to schooling $(R)$, which varies by gender: $R^{f} \equiv \zeta_{1}^{f}-$ $\zeta_{0}^{f}$ and $R^{m} \equiv \zeta_{1}^{m}-\zeta_{0}^{m}$. Let $V_{i, e}$ be the material surplus that women or their parents (in the form of a bride price) receive in equilibrium in the marriage market, and $U_{j, e}$ be the surplus that men receive. The marriage surplus $z_{S P}$ is then allocated between the women's side and the men's side: $V_{i, e}+U_{j, e}=z_{S_{i} P_{j}}$. Moreover, let $\Delta V_{i, e}=V_{i, e}\left(S_{i}=1\right)-V_{i, e}\left(S_{i}=0\right)$ and $\Delta U_{j, e}=U_{j, e}\left(P_{j}=\right.$ 1) $-U_{i, e}\left(P_{j}=0\right)$ be the marriage markets returns to education (Chiappori et al., 2009). Then, the total returns to schooling enjoyed by the daughter are:

$$
v_{2}\left(S_{i}=1, I_{e}\right)-v_{2}\left(S_{i}=0, I_{e}\right)=R^{f}+\left(1-I_{e}\right) \Delta V_{i, e},
$$

while those enjoyed directly by the parents are the bride price returns:

$$
B P\left(S_{i}=1\right)-B P\left(S_{i}=0\right)=\Delta V_{i, e}
$$

An important result in Chiappori et al. (2009) is that, in equilibrium, men with the same education all obtain the same share of marriage surplus, and the same is true for women (or their parents when there is bride price). Hence, the shares of surplus, in equilibrium, do not depend on $e, i$ or $j$. When men have higher education rates than women, marriage surplus shares, $U_{S}$ and $V_{P}$, satisfy:

$$
V_{0}+U_{0}=z_{00}, \quad V_{1}+U_{1}=z_{11}, \quad V_{0}+U_{1}=z_{01}, \quad V_{1}+U_{0}>z_{10} .
$$

Subtracting these conditions, we obtain the following expressions for the returns to education in the marriage market, which again do not depend on $e, i$, or $j$ :

$$
\left(V_{0}+U_{1}\right)-\left(V_{0}+U_{0}\right)=\Delta U=z_{01}-z_{00}, \quad\left(V_{1}+U_{1}\right)-\left(V_{0}+U_{1}\right)=\Delta V=z_{11}-z_{01} .
$$

Educated women, who are the side in short supply, receive their marginal contribution in a marriage with an educated man, which parents in bride price communities capture. Educated men, the side in excess supply, receive their marginal contribution to a marriage with an uneducated woman, irrespectively of whom they actually marry. ${ }^{22}$

Hence, thanks to transferable utility and homogeneity within educational groups, men are indif-

\footnotetext{
${ }^{22}$ If there were more educated women than educated men, before or after the school construction programs, educated men would only marry educated women, and some educated women would marry uneducated men. Women obtain their contribution to a marriage with an uneducated man, and the returns to education in the marriage market are $\left(V_{1}+U_{0}\right)-\left(V_{0}+U_{0}\right)=\Delta U=z_{11}-z_{10}$ and $\left(V_{1}+U_{0}\right)-\left(V_{1}+U_{1}\right)=\Delta V=z_{10}-z_{00}$, which are still positive.
} 
ferent between marrying an educated woman or an uneducated one. A match will only be stable (and therefore, an equilibrium outcome) if women (or their family) can appropriate the entire additional surplus they provide to a match with an educated man because educated women are scarce. If they did not, another man matched to an uneducated woman would outbid the initial transfer by offering slightly more to the educated woman to convince her to marry him instead, and therefore, the original match would not be stable (Chiappori et al., 2009).

This result has direct implications for the bride price return to education in equation (1). In bride price ethnicities, the bride price return to education is the whole marriage market return to education

$$
B P\left(S_{i}=1\right)-B P\left(S_{i}=0\right)=\Delta V_{i, e}=\Delta V=z_{11}-z_{01}
$$

which is strictly positive and which the parents appropriate as the marriage-market clearing transfer. This finding generates our second prediction.

Prediction 2. Educated women command higher bride price payments.

\subsubsection{The investment stage}

Having established what the returns to education are, we now examine their implications for educational attainment. Substituting the budget constraints into the objective function, we find that parents choose to educate the daughter $\left(S_{i}=1\right)$ whenever

$$
a_{i} \geq a^{*}\left(I_{e}, k\right) \equiv \frac{k}{\gamma}-\frac{R^{f}}{1+r}-\frac{\Delta V_{i, e}}{1+r}\left(1+I_{e} \frac{1-\gamma}{\gamma}\right)
$$

We denote the daughter's ability for the household on the margin of making the education investment by $a_{I_{e}}^{*}(k)$, which depends on $I_{e}$ and $k$. Parents will educate their daughter $i$ as long as her ability $a_{i} \geq a_{I_{e}}^{*}(k){ }^{23}$ Therefore, the probability that daughter $i$ is educated is given by

$$
\operatorname{Pr}\left(S_{i}=1 \mid k, I_{e}\right)=\operatorname{Pr}\left(a_{i} \geq a_{I_{e}}^{*}(k)\right)=1-G\left(a_{I_{e}}^{*}(k)\right)
$$

To derive the condition under which more men than women will be educated in equilibrium, we follow the same procedure that we used for daughters, and we obtain the probability that a son is educated

\footnotetext{
${ }^{23}$ Efficient investment in schooling implies that every girl with $a_{i} \geq\left[k-\frac{\Delta v\left(I_{e}, k\right)}{1+r}\right]$ gets educated. However, because altruism is imperfect $(\gamma<1)$, education rates will be lower than the efficient benchmark. The bride price custom can help overcome under-investments in daughters' schooling due to imperfect commitment across generations. When $\gamma=1$, all three thresholds are the same.
} 


$$
\operatorname{Pr}\left(P_{j}=1 \mid I_{e}, k\right)=\operatorname{Pr}\left(a_{j} \geq \frac{k}{\delta}-\frac{R^{m}}{1+r}-\frac{\Delta U_{j, e}}{1+r}\right)=1-G\left(\frac{k}{\delta}-\frac{R^{m}}{1+r}-\frac{\Delta U_{j, e}}{1+r}\right) .
$$

Hence, given these conditions and the equilibrium marriage market returns to education, we expect that more boys than girls will be educated in equilibrium if and only if

$$
\left(\frac{1}{\gamma}-\frac{1}{\delta}\right) k+\frac{R^{m}-R^{f}}{1+r}+\frac{z_{01}-z_{00}}{1+r}-\frac{z_{11}-z_{01}}{1+r}\left(1+I_{e} \frac{1-\gamma}{\gamma}\right)>0
$$

As long as (3) is satisfied before and after the school construction, the marriage market equilibrium is as described above. ${ }^{24}$ Therefore, the ability threshold for girls becomes

$$
a_{I_{e}}^{*}(k)=\frac{k}{\gamma}-\frac{R^{f}}{1+r}-\frac{z_{11}-z_{01}}{1+r}\left(1+I_{e} \frac{1-\gamma}{\gamma}\right) .
$$

Let $a_{B P}^{*}=a^{*}\left(I_{e}=1, k\right)$ be the ability threshold for girls from bride price groups and let $a_{N o B P}^{*}=$ $a^{*}\left(I_{e}=0, k\right)$ be the ability threshold for girls from non-bride price groups. For $\gamma<1$, the comparison below leads to our main set of predictions

$$
a_{B P}^{*}=\frac{k}{\gamma}-\frac{R^{f}}{1+r}-\frac{z_{11}-z_{01}}{1+r}\left(1+\frac{1-\gamma}{\gamma}\right)<a_{N o B P}^{*}=\frac{k}{\gamma}-\frac{R^{f}}{1+r}-\frac{z_{11}-z_{01}}{1+r},
$$

and hence $G\left(a_{B P}^{*}\right)<G\left(a_{N o B P}^{*}\right)$. This is summarized in the following prediction.

Prediction 3. The probability that a girl is educated, $\operatorname{Pr}\left(S_{i}=1\right)$, is higher among ethnicities that engage in bride price payments: $\operatorname{Pr}\left(S_{i}=1 \mid I_{e}=1, k\right)>\operatorname{Pr}\left(S_{i}=1 \mid I_{e}=0, k\right)$.

We next turn to the average ability of girls who are educated for bride price and non-bride price

${ }^{24}$ The first term $\left(\frac{1}{\gamma}-\frac{1}{\delta}\right) k$ is driven by the gender preferences of parents: if they prefer sons to daughters, they are more willing to educate their sons. The second terms captures differential labor market returns, and it is likely to be positive in this context in which men have higher employment rates and better opportunities in the labor market. The third and fourth term capture differential returns in the marriage markets, and the difference between them depends on the relative contribution of an educated woman compared to an educated man to the marriage surplus. In groups that don't engage in bride price, the sign of this term $\left(\frac{\Delta U_{j, e}}{1+r}-\frac{\Delta V_{i, e}}{1+r}=\frac{2 z_{01}-z_{11}-z_{00}}{1+r}\right)$ depends on how $z_{01}$ and $z_{10}$ compare, i.e. if a household with an educated man and an uneducated woman is more productive than the opposite. Finally, the last term, $\frac{1-\gamma}{\gamma} \frac{z_{11}-z_{01}}{1+r}$, captures the impact of the bride price education premium on the parents' budget constraint, which alone should increase female schooling relative to male schooling. We can also rule out that an equilibrium exists in which more women than men get educated because (3) implies that $\left(\frac{1}{\gamma}-\frac{1}{\delta}\right) k+\frac{R^{m}-R^{f}}{1+r}+\frac{z_{11}-z_{10}}{1+r}-\frac{z_{10}-z_{00}}{1+r}\left(1+I_{e} \frac{1-\gamma}{\gamma}\right)>0$ under the assumptions we have imposed on marital surplus. 
groups. The average ability of educated girls is equal to

$$
E\left[a_{i} \mid S=1, I_{e}, k\right]=E\left[a_{i} \mid a_{i}>a_{I_{e}}^{*}(k)\right]=\int_{a_{I_{e}}^{*}(k)}^{\infty} a_{i} g\left(a_{i} \mid a_{i}>a_{I_{e}}^{*}(k)\right) d a_{i}
$$

By the Leibniz integral rule, $\frac{\partial E\left[a_{i} \mid a_{i}>a^{*}\right]}{\partial a^{*}}=\frac{g\left(a^{*}\right)}{1-G\left(a^{*}\right)}\left\{E\left[a_{i} \mid a_{i}>a^{*}\right]-a^{*}\right\}>0$. This gives the following prediction.

Prediction 4. The average ability of educated girls is lower among ethnicities that engage in bride price payments relative to ethnicities that do not.

Predictions 3-4 stem from the fact that the bride price provides an additional incentive for parents to educate their daughter, as long as parents are not perfectly altruistic. Thus, we will observe higher rates of enrollment among ethnicities that practice bride price. In addition, higher enrollment rates among bride price ethnicities imply that girls with relatively lower ability will get educated in bride price ethnicities because the bride price premium justifies the parents' education investment.

\subsubsection{Bride price and the response of female education to education policies}

We now turn to our primary comparative static of interest: how the increase in education due to a reduction in the cost of education $k$ depends on the presence of a bride price custom. Consistent with our setting of interest, we consider the case in which education levels are low, namely the case in which a girl with modal ability does not get educated. ${ }^{25}$ When the distribution of ability is unimodal and female schooling is low, $g\left(a_{B P}^{*}\right)-g\left(a_{N o B P}^{*}\right)>0$.

Our main empirical results then follow directly from a comparison of the two partial derivatives:

$$
\frac{\partial \operatorname{Pr}\left(S_{i}=1 \mid k, I_{e}=1\right)}{\partial k}=-\frac{g\left(a_{B P}^{*}(k)\right)}{\gamma} \quad \text { versus } \quad \frac{\partial \operatorname{Pr}\left(S_{i}=1 \mid k, I_{e}=0\right)}{\partial k}=-\frac{g\left(a_{\text {NoBP }}^{*}(k)\right)}{\gamma} .
$$

Prediction 5. When female education rates are low, a decline in the cost of schooling increases education more for girls from bride price ethnic groups than for girls from non-bride price ethnic groups.

Figure 2 illustrates the intuition behind prediction 5. The figure shows a hypothetical unimodal distribution of ability $a_{i}$, as well as the threshold ability $a^{*}$ for both bride price and non-bride price

\footnotetext{
${ }^{25}$ This assumption does not necessarily imply that the median-ability girl is uneducated. If the distribution of daughters' schooling abilities has positive skewness (i.e., is right skewed), as with the commonly-observed lognormal or Pareto distributions, then a girl with modal ability can have an ability that is well below the median ability. Thus, in this case, the median-ability girl will be educated while the modal-ability girl will not.
} 
Figure 2: Distribution of girls' abilities, schooling decisions, and declines in the cost of education

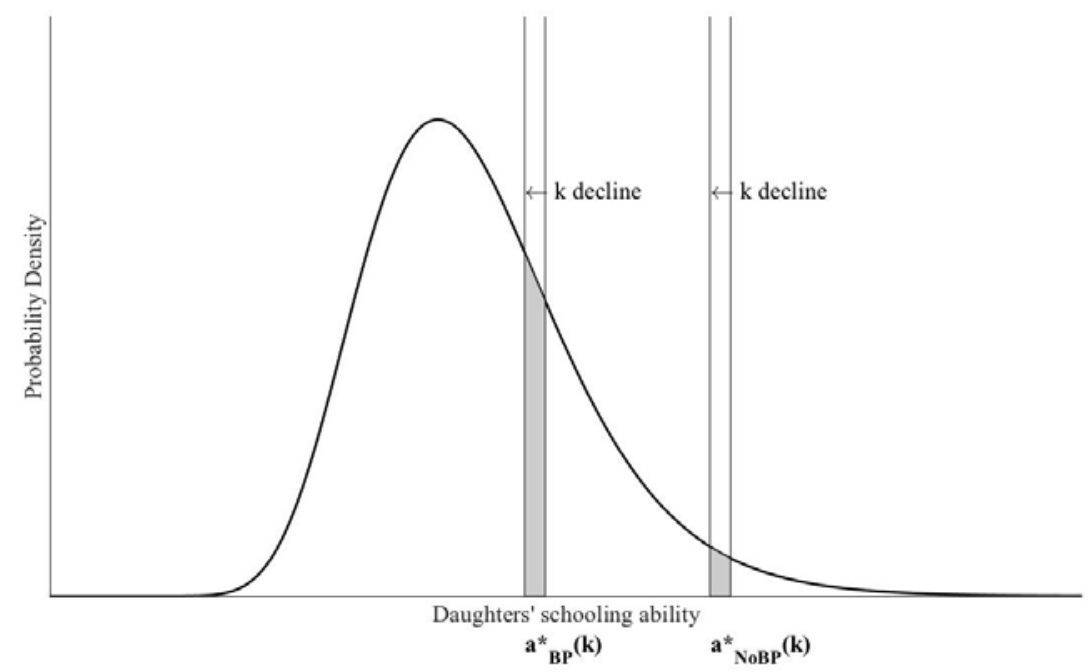

girls. Girls with ability above this threshold become educated and those below do not. The unimodal assumption of $a_{i}$ guarantees that at the ability threshold for girls from bride price groups, there is more density than there is for the threshold for girls from non-bride price groups. ${ }^{26}$ The decline in the costs of schooling is shown in Figure 2 by a decline in the thresholds for the two groups. As illustrated, there will be more girls on the margin who respond to the policy change from bride price ethnicities relative to non-bride price ethnicities. In other words, the effects of the school construction policy on girls' education will be greater among bride price groups than among non-bride price groups.

\subsubsection{Bride price and male education}

We next turn to the model's predictions for boys. First, note that the boys' education probability in equation (2) does not depend on $I_{e}$ once we substitute for $\Delta U_{j, e}$ with the equilibrium marriage market return to education for men:

$$
\operatorname{Pr}\left(P_{j}=1 \mid k\right)=1-G\left(\frac{k}{\delta}-\frac{R^{m}}{1+r}-\frac{z_{01}-z_{00}}{1+r}\right)
$$

In the boys' case, transferable utility and the homogeneity within education groups ensure that returns to education in the marriage market are the same across ethnic groups as long as boys are always more likely to be educated than girls. Then, the bride price does not affect educational invest-

\footnotetext{
${ }^{26}$ The unimodality argument is related to one put forth by Fabinger and Weyl (2013), who show that a unimodal distribution of consumer valuations leads to S-shaped demand functions. Then, the elasticity of demand with respect to a price change depends on whether such a change occurs in a part of the demand curve that is concave or convex. Becker et al. (2010) use a related argument to explain why women's education rates have overtaken those of men in developed countries.
} 
ments. Because the levels of education do not vary by ethnic group at baseline, ability distributions are similar among educated boys across ethnic groups. Moreover, for boys, an expansion in the supply of schools does not affect ethnic groups differently, as long as education rates remain larger among

boys than among girls in all groups. Indeed, the expression $\frac{\partial \operatorname{Pr}\left(P_{j}=1 \mid k\right)}{\partial k}=-\frac{1}{\delta} \cdot g\left(\frac{k}{\delta}-\frac{R^{m}}{1+r}-\frac{z_{01}-z_{00}}{1+r}\right)$ does not depend on $I_{e}$. This result leads to our final prediction.

Prediction 6. The probability that a boy is educated, the average ability of educated boys and the responsiveness of male educational attainment to a reduction in the cost of schooling do not differ among ethnicities that engage in bride price payments relative to other ethnicities.

\section{Testing the Predictions of the Model: Bride Price, Marriage Mar- kets and Female Education}

We now test the predictions of our model using data from two countries, Indonesia and Zambia. We have chosen these two because of our ultimate interest in examining how the effectiveness of school construction projects depends on the practice of bride price. Indonesia's large-scale school construction initiative during the 1970s was the largest of its kind and has been well studied (e.g., Duflo, 2001). Zambia had a similar large-scale project in the late 1990s and early 2000s. Additionally, both countries have rich within-country variation in the extent to which different ethnic groups practice bride price. Throughout the analysis, we measure traditional bride price practice using the ethnographic sources discussed in Section 2, which are linked to respondents using their self-reported ethnicity or mother tongue.

\subsection{Prediction 1. Is matching assortative by education?}

Prediction 1 of the model suggests that there should be a positive relationship between the education of the wife and that of the husband, and that this relationship should be the same for bride price and non-bride price groups. We test for this by examining married couples and estimating the correlation between the education of the wife and that of the husband. We use the following estimating equation:

$$
I_{i e d t}^{\text {Husband Primary }}=\alpha_{e}+\alpha_{d}+\alpha_{t}+\beta_{1} I_{\text {iedt }}^{\text {Wife Primary }}+\beta_{2} I_{i e d t}^{\text {Wife Primary }} \times I_{e}^{\text {BridePrice }}+\mathbf{X}_{i t} \boldsymbol{\Gamma}+\varepsilon_{i e d t}
$$

where $i$ indexes a marriage, $e$ indexes the ethnicity of the bride, $d$ districts, and $t$ indexes the survey year. The indicator variable $I_{e}^{\text {BridePrice }}$ is equal to one if a wife belongs to an ethnic group that 
traditionally practices bride price and zero otherwise. $I_{i e d t}^{\text {Wife Primary }}$ and $I_{i e d t}^{\text {Husband Primary }}$ are indicator variables equal to one if the wife and husband have completed primary school respectively. $\alpha_{e}$ denotes ethnicity fixed effects, $\alpha_{d}$ district fixed-effects, and $\alpha_{t}$ survey-year fixed effects (where applicable). To be conservative, we cluster the standard errors at the district level, which is the level at which the supply of schools and the marriage market are likely to vary.

We estimate equation (4) using three different samples: the 1995 Indonesia Intercensal Data, the 2000 and 2007 Indonesia Family Life Surveys (IFLS), and the 1996, 2001, 2007, and 2013 Zambia Demographic and Health Surveys (DHS). Each data source measures educational attainment slightly differently. The Intercensus directly reports information for whether individuals have completed primary school. In the IFLS, we infer primary school completion if reported educational attainment is "some junior secondary school" or more. In the DHS, we infer primary school completion from respondents' reporting that they have attended secondary school (or higher).

The vector $\mathbf{X}_{i t}$ includes a quadratic in the year of marriage, a quadratic in the wife's age of marriage, an indicator variable that equals one if the wife reports being Muslim and its interaction with whether she completed primary school, and indicator variables for an individual belonging to an ethnic group that is matrilineal and that has female dominated agriculture interacted with the wife's education. In the IFLS and DHS regressions, $\mathbf{X}_{i t}$ also includes an indicator variable for the marriage being polygynous and its interaction with the wife's education. These controls do not appear in the Intercensus regressions because, although asked, no respondents report belonging to a polygynous marriage.

Estimates of equation (4) are reported in Table 3. Estimates using the Intercensus sample are reported in columns 1 and 2, those using the IFLS are reported in columns 3 and 4, and those using the DHS are reported in columns 5 and 6 . The odd numbered columns report estimates using a more parsimonious set of controls, while the even numbered columns use the full set of covariates. The estimates show that matching on education is positively assortative in all three samples, and that the strength of this relationship is not statistically different between bride price and non-bride price ethnic groups. Thus, as predicted by the model, the practice of the bride price does not affect the nature of sorting in the marriage market. ${ }^{27}$

\footnotetext{
${ }^{27}$ The same results also hold if we cluster at the ethnicity-level and generate p-values using the wild bootstrap procedure.
} 
Table 3: Degree of assortative matching in Indonesia and Zambia

\begin{tabular}{|c|c|c|c|c|c|c|}
\hline & (1) & $(2)$ & $(3)$ & (4) & $(5)$ & (6) \\
\hline & \multicolumn{6}{|c|}{ Dep Var: Indicator variable for husband completed primary } \\
\hline & \multicolumn{2}{|c|}{ Indonesia } & \multirow{2}{*}{\multicolumn{2}{|c|}{ IFLS }} & \multicolumn{2}{|c|}{ Zambia } \\
\hline & \multicolumn{2}{|c|}{ Intercensus } & & & \multicolumn{2}{|c|}{ Pooled DHS } \\
\hline$I_{i}^{\text {Wife Primary }}$ & $0.466^{* * *}$ & $0.460^{* * *}$ & $0.445^{* * *}$ & $0.440^{* * *}$ & $0.534^{* * *}$ & $0.510^{* * *}$ \\
\hline & $(0.005)$ & $(0.015)$ & $(0.025)$ & $(0.025)$ & $(0.022)$ & $(0.041)$ \\
\hline \multirow[t]{2}{*}{$I_{i}^{\text {Wife Primary }} \times I_{e}^{\text {BridePrice }}$} & 0.022 & 0.021 & -0.041 & -0.042 & -0.006 & 0.004 \\
\hline & $(0.014)$ & $(0.014)$ & $(0.038)$ & $(0.037)$ & $(0.020)$ & $(0.023)$ \\
\hline Ethnicity FE & $\mathrm{Y}$ & $\mathrm{Y}$ & $\mathrm{Y}$ & $\mathrm{Y}$ & $\mathrm{Y}$ & $\mathrm{Y}$ \\
\hline District FE & $\mathrm{Y}$ & $\mathrm{Y}$ & $\mathrm{Y}$ & $\mathrm{Y}$ & $\mathrm{Y}$ & $\mathrm{Y}$ \\
\hline Marriage Year Controls & $\mathrm{Y}$ & $\mathrm{Y}$ & $\mathrm{Y}$ & $\mathrm{Y}$ & $\mathrm{Y}$ & $\mathrm{Y}$ \\
\hline Marriage Age Controls & $\mathrm{Y}$ & $\mathrm{Y}$ & $\mathrm{Y}$ & $\mathrm{Y}$ & $\mathrm{Y}$ & $\mathrm{Y}$ \\
\hline Wife Muslim Controls & $\mathrm{N}$ & $\mathrm{Y}$ & $\mathrm{N}$ & $\mathrm{Y}$ & $\mathrm{N}$ & $\mathrm{Y}$ \\
\hline Ethnicity Controls Interactions & $\mathrm{N}$ & $\mathrm{Y}$ & $\mathrm{N}$ & $\mathrm{Y}$ & $\mathrm{N}$ & $\mathrm{Y}$ \\
\hline Polygynous Marriage Controls & $\mathrm{N} / \mathrm{A}$ & $\mathrm{N} / \mathrm{A}$ & $\mathrm{N}$ & $\mathrm{Y}$ & $\mathrm{N}$ & $\mathrm{Y}$ \\
\hline Mean of dependent variable & 0.653 & 0.653 & 0.655 & 0.659 & 0.565 & 0.571 \\
\hline SD of dependent variable & 0.476 & 0.476 & 0.475 & 0.474 & 0.496 & 0.495 \\
\hline Number of observations & 107,338 & 107,338 & 4,847 & 4,785 & 22,793 & 18,574 \\
\hline Clusters & 221 & 221 & 35 & 35 & 78 & 78 \\
\hline Adjusted $\mathrm{R}^{2}$ & 0.367 & 0.367 & 0.338 & 0.336 & 0.348 & 0.336 \\
\hline
\end{tabular}

Notes: This table reports evidence on assortative matching using the Indonesian 1995 Intercensal data, rounds 3 and 4 of the IFLS, and the pooled 1996, 2001, 2007, and 2013 rounds of the Zambia DHS. The unit of observation is a married couple (i.e., a husband and wife). For all three samples, the husband and wife's education levels are measured as indicator variables for completing primary schooling. The mean (and standard deviation) of the indicator for the wife completing primary school, $I_{i}^{\text {Wife Primary }}$ is $0.465(0.499)$ for the Indonesia Intercensus, 0.599 (0.490) for the IFLS, and 0.204 (0.403) for Zambia. 'Marriage Year Controls' consist of the year married and its square. 'Marriage Age Controls' consist of the wife's age at marriage and its square. The 'Wife Muslim Controls' consist of an indicator variable that equals one if the wife is Muslim and its interaction with whether she completed primary school. 'Ethnicity Control Interactions' consist of indicator variables for an individual belonging to an ethnic group that is matrilineal and that has female dominated agriculture respectively interacted with the wife's education. 'Polygynous Marriage Controls' consist of an indicator variable that equals one if the marriage is polygynous and its interaction with the wife's education. Standard errors clustered at the district-level appear in parentheses. ${ }^{*}, * *$, and $* * *$ indicate significance at the 10,5 , and $1 \%$ levels.

\subsection{Prediction 2. Do the bride price amounts increase with the bride's education?}

We now turn to prediction 2 of the model and test whether the value of the bride price is increasing in the educational attainment of the bride. Our empirical strategy is to estimate hedonic regressions where bride price payments are a function of the wife's educational attainment. Therefore, we estimate the following equation:

$$
\ln (\text { BPAmount })_{\text {iet }}=\alpha_{e}+\alpha_{t}+\beta_{1} I_{\text {iet }}^{\text {Primary }}+\beta_{2} I_{\text {iet }}^{\text {JuniorSec }}+\beta_{3} I_{\text {iet }}^{\text {SeniorSec }}+\mathbf{X}_{i t} \boldsymbol{\Gamma}+\varepsilon_{i e t},
$$

where $i$ indexes a marriage, $e$ indexes the ethnicity of the wife, and $t$ indexes the survey year. $B P$ Amount is the value of the bride price that was paid at marriage. ${ }^{28}$ The variables $I_{i}^{\text {Primary }}$, $I_{i}^{J u n i o r S e c}$, and $I_{i}^{\text {SeniorSec }}$ are indicator variables that equal one if the wife in marriage $i$ completed primary school, junior secondary, and senior secondary, respectively. The vector $\mathbf{X}_{i t}$ includes a quadratic in the year of marriage. In addition, depending on the specification, it also includes a

\footnotetext{
${ }^{28}$ In cases where both the husband and wife report the bride price amount, we use the amount reported by the husband under the logic that, as the individual who pays the price, he is most likely to remember it accurately. When the husband's report is missing, we use the wife's reported value. Using the wife's value instead delivers similar results.
} 
quadratic in the wife's age of marriage, fixed effects for the husband's education, a quadratic in the husband's age at marriage, a measure of the wife's premarital wealth, an indicator variable for the wife being Muslim, and an indicator for the marriage being polygynous. We use two different samples, one from the 2000 and 2007 Indonesia Family Life Survey and the other from the Zambia Fertility Preferences Survey, which includes information on 715 monogamous couples from a poor suburb of Lusaka (Ashraf et al., 2017).

Estimates of equation (5) are reported in Table 4. Columns 1-5 report estimates for the hedonic regressions in Indonesia, while columns 7-11 report estimates for Zambia. For each country, we report five different specifications, with additional covariates added incrementally. The estimates show that the amount of bride price paid at marriage is positively associated with the bride's educational attainment. In addition, as shown in columns 3-5 and 9-11, the relationship remains robust to the inclusion of controls for the husband's characteristics, which are potentially endogenous. It is also robust to accounting for the wife's premarital socio-economic status, as measured by her self-reported $\log$ pre-marital wealth as measured in the IFLS (column 5) and by whether her family owned any property or land as measured in the ZFPS (column 11). This is despite the fact that due to missing data, ${ }^{29}$ the sample size in the IFLS is reduced from 4,548 observations to $1,597 .{ }^{30}$

The estimated effects of education on bride price are large in magnitude. For example, according to the estimates for Indonesia, reported in column 2, completion of primary school is associated with a $58 \%$ increase in the value of the bride price (relative to no schooling), completion of junior secondary school is associated with an additional $67 \%$ increase in the bride price, and completion of senior secondary schooling is associated with an additional $86 \%$ increase. $^{31}$ According to the estimates, parents of women who completed secondary school, on average, receive bride price payments that are $211 \%$ higher than parents of women who did not complete primary education. The estimates for the smaller Zambian sample are also large and replicate the pattern of findings in Indonesia. According to the point estimates from column 8 , completing primary school is associated with a $2 \%$ increase in the bride price payment, completing junior secondary school is associated with another $26 \%$ increase, and completing secondary school with another $39 \%$ increase. Hence, bride price payments for secondary

\footnotetext{
${ }^{29}$ Missing data arises if (1) a wife was not included in the sample, and therefore, she wasn't asked about her pre-marital assets, (2) the wife did not know her pre-marital assets, and (3) the wife reported 0 pre-marital assets.

${ }^{30}$ Interestingly, we observe a positive and significant relationship between the bride price payment and a man's education in Indonesia (although not in Zambia). In our model, where people only sort on education, strictly speaking, the bride price should not vary with a man's education. However, the model also predicts that some uneducated women match with educated men since there are fewer educated women than men. If these women are more desirable in other dimensions than the uneducated women who match with uneducated men (e.g., attractiveness, health, etc.) and if these characteristics are reflected in the bride price paid, then, due to assortative matching, we will observe a positive relationship between the husband's education and bride price, even after we control for the wife's education.

${ }^{31}$ For Indonesia, the indicator measures having completed secondary school and attended some college.
} 
school graduates are $67 \%$ higher than payments for women who did not complete primary education. ${ }^{32}$

It is important to emphasize that, if more desirable women, who command larger bride prices, are also independently more likely to be educated, the estimates of Table 4 do not have a causal interpretation, just as Mincerian wage regressions cannot typically identify the labor market returns to education (Griliches, 1977; Card, 1994; Heckman et al., 2006). Given this, we pursue a number of alternative strategies to better understand the extent to which the correlations we observe are potentially driven by third factors, like the wife's unobserved quality.

First, we follow Duflo (2001) and use primary school construction as an instrument for a wife's completion of primary school. In doing this, we restrict our sample to ethnic groups that practice bride price. As we will show (when testing prediction 5), school construction had no effect on the education of girls from non-bride price ethnic groups. Following Duflo (2001), we also restrict the sample to individuals born between 1950 and 1972, and allow the effect of school construction to vary by a child's age in 1974, restricting the effect to 0 if a child was older than 12 in $1974 .{ }^{33}$ In the end, the restrictions result in a sample of only 264 women.

The 2SLS estimates of the effect of primary school completion on the value of the bride price at marriage are reported in column 6 of Table $4 .^{34}$ Although the estimated effect is less precisely estimated than the OLS estimates, it is larger in magnitude. However, the estimates should be interpreted with caution given that the school construction instruments are fairly weak (the first-stage $F$-statistic is 3.04). This is not surprising given the very small size of our sample (264 observations). ${ }^{35}$

As a second strategy, we provide additional evidence on the extent to which the bride's education has a causal effect on bride price payments by using additional information from the ZFPS. In the survey, each spouse of the 715 couples was asked a series of questions on the practice of bride price or lobola as it is called locally. Respondents were unprompted and asked to indicate the factors that affect the value of the bride price in their community today (starting with the most important). The answers are summarized in Table 5 . The plurality of respondents (39\%) listed education as the single most important determinant of the value of the bride price at marriage. The next most commonly listed factors as the first determinant were family values (16\%) and good morals (15\%). Overall, $69 \%$ of respondents listed education as one of the three most important factors affecting the value of the

\footnotetext{
${ }^{32}$ Since the Zambian sample is drawn from the capital city of Zambia, which has levels of educational attainment that are higher than the rest of the country, secondary schooling may be a more important determinant of bride price (and primary schooling less important) in this sample than for the rest of Zambia.

${ }^{33}$ Full details of the estimating equations for the instrumental variables strategy are reported in Appendix B.

${ }^{34}$ The first-stage estimates are reported in Appendix Table A5.

${ }^{35}$ To partially address the weak-instruments problem, we also check the robustness of our estimates to using a limited information maximium likelihood regression. Doing so yields a similarly positive estimate of 3.78 (and standard error of 2.05).
} 


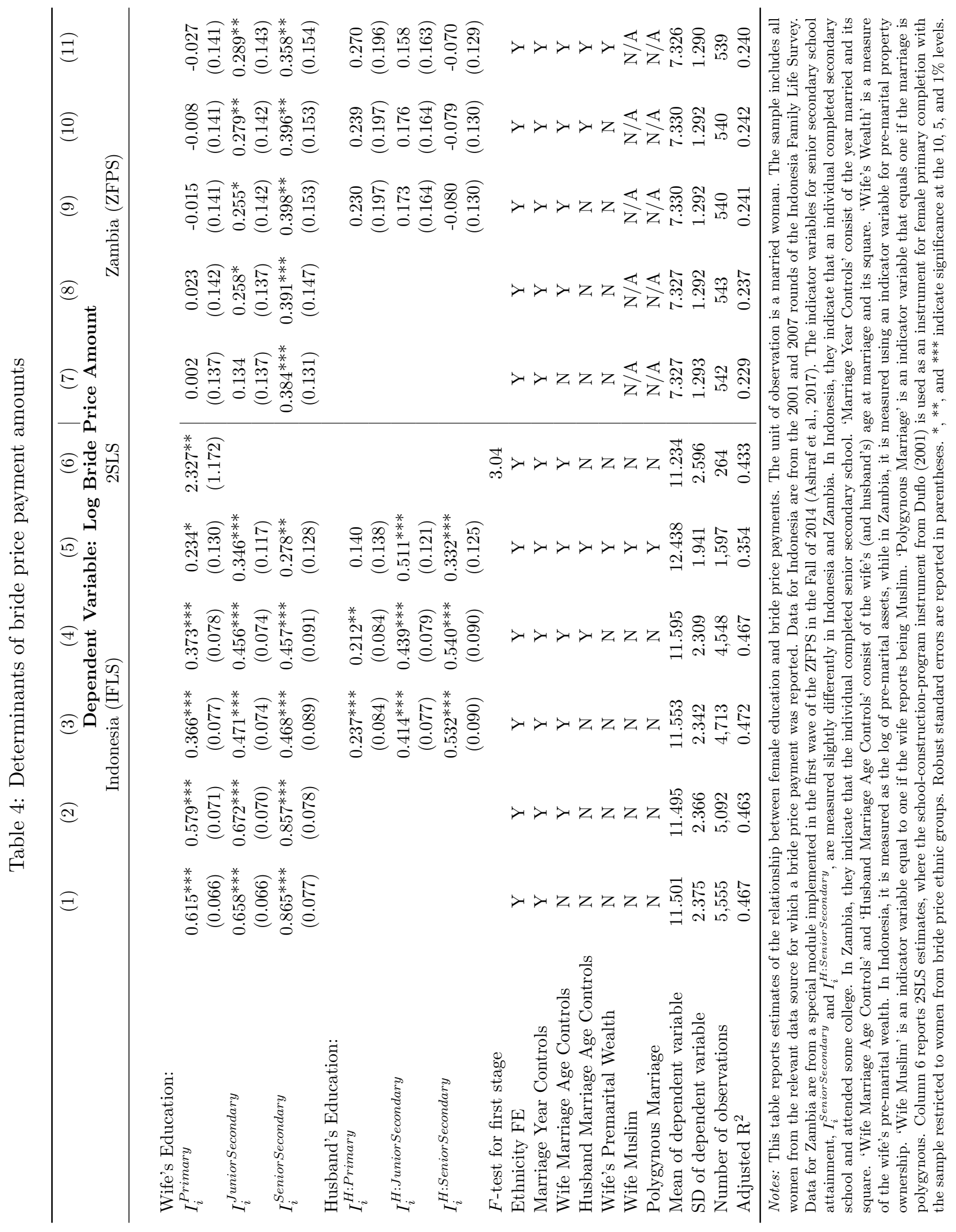


Table 5: Perceived determinants of bride price values in Zambia

\begin{tabular}{|c|c|c|c|c|c|}
\hline \multicolumn{6}{|c|}{$\begin{array}{c}\text { Think about the factors that affect bride price today: } \\
\text { what is the .. most important factor? }\end{array}$} \\
\hline & & First & Second & Third & Not listed \\
\hline \multirow[t]{2}{*}{ Education } & obs. & 531 & 216 & 150 & 454 \\
\hline & & $39.3 \%$ & $17.0 \%$ & $13.0 \%$ & $30.7 \%$ \\
\hline \multirow[t]{2}{*}{ Family values } & obs. & 222 & 268 & 206 & 655 \\
\hline & & $16.4 \%$ & $21.1 \%$ & $17.9 \%$ & $44.6 \%$ \\
\hline \multirow[t]{2}{*}{ Good morals } & obs. & 197 & 278 & 210 & 666 \\
\hline & & $14.6 \%$ & $21.9 \%$ & $18.2 \%$ & $45.3 \%$ \\
\hline \multirow[t]{2}{*}{ Virginity } & obs. & 131 & 179 & 177 & 864 \\
\hline & & $9.7 \%$ & $14.1 \%$ & $15.4 \%$ & $60.9 \%$ \\
\hline \multirow[t]{2}{*}{ Tribe } & obs. & 96 & 115 & 185 & 955 \\
\hline & & $7.11 \%$ & $9.1 \%$ & $16.1 \%$ & $67.8 \%$ \\
\hline \multirow[t]{2}{*}{ Age } & obs. & 39 & 93 & 139 & 1080 \\
\hline & & $2.9 \%$ & $7.3 \%$ & $12.1 \%$ & $77.7 \%$ \\
\hline \multirow[t]{2}{*}{ Other } & obs. & 135 & 121 & 86 & 1009 \\
\hline & & $10.0 \%$ & $9.5 \%$ & $7.5 \%$ & $73.0 \%$ \\
\hline
\end{tabular}

Notes: This table reports respondents' answers when asked "Think about the factors that affect bride price today. What is the [first, second, or third] most important factor?" An observation is a person, either male or female, who is a member of 715 couples from peri-urban Lusaka. The data were collected as a special module implemented in the first wave of the ZFPS in the Fall of 2014 (Ashraf et al., 2017).

bride price.

As a further check of whether the relationship between bride price and education is spurious, respondents were also asked to indicate why, in their opinion, bride price payments are higher for more educated brides. Respondents indicated several reasons that were categorized and are reported in Appendix Table A6. ${ }^{36}$ The most common answer for why they thought that the bride price is increasing in education was that parents should be compensated for the educational investments made in their daughter. This is consistent with the common anthropological interpretation of the bride price as compensation for the parents' investments made in the bride (e.g., Vroklage, 1952). Other common explanations attributed the higher bride price to the increased productivity of the bride, either in relation to earnings in the labor market, improved skills within the household, or increased ability to promote the health and education of children (Lavy, 1996; Behrman et al., 1999). This interpretation is in line with the model's assumption that the wife's education positively affects marital output in addition to labor market productivity.

Few respondents agree with the interpretation that the estimated relationship could be driven by omitted factors, such as more educated brides having richer parents who demand a higher bride

\footnotetext{
${ }^{36}$ Respondents were first asked unprompted and then were asked about specific reasons and could either agree or disagree. The unprompted responses are reported in column 1 and the prompted responses in columns 2 and 3 .
} 
price. When asked unprompted, only $7.5 \%$ of the sample said the association between bride price and education is because education "is associated with her parents being rich," making it the least popular answer. Taken together, the survey responses from Table 5 and Appendix Table A6 show that, at least in the minds of individuals, the relationship appears to be causal. ${ }^{37}$

\subsection{Prediction 3. Do bride price ethnic groups have higher levels of female edu- cational attainment?}

We now turn to prediction 3, which states that girls from bride price ethnic groups are more likely to become educated. We test this prediction by estimating the relationship between the traditional practice of bride price and school enrollment in Indonesia and Zambia.

Our estimating equation is:

$$
I_{\text {iedt }}^{\text {Enrolled }}=\alpha_{d}+\alpha_{t}+\beta_{1} I_{e}^{\text {BridePrice }}+\mathbf{X}_{i} \boldsymbol{\Gamma}+\mathbf{X}_{e} \boldsymbol{\Pi}+\varepsilon_{\text {iedt }},
$$

where $i$ indexes girls aged 5-22, e ethnic groups, $d$ districts, and $t$ the year of the survey. As before, for Indonesia, we use the 1995 Intercensal Survey, and for Zambia, we use either the pooled DHS or the ZFPS. When we use the Indonesia Intercensal Survey and the Zambian DHS, the dependent variable $I_{i e d t}^{\text {Enrolled }}$ is an indicator variable that equals one if girl $i$ is enrolled in school. For the ZFPS sample, because the sample comprises married women who are older than school age, the dependent variable is an indicator that equals one if the woman completed primary school. As before, $I_{e}^{\text {BridePrice }}$ is an indicator variable that equals one if ethnicity $e$ traditionally engages in the practice of bride price payments at marriage. $\alpha_{d}$ denotes district fixed effects and $\alpha_{t}$ denotes survey-year fixed effects (which are relevant for the Zambia sample only). The vector $\mathbf{X}_{i}$ includes the age of the girl at the time of the survey, as well as her age squared, and in all samples but the ZFPS sample, it also includes an indicator that equals one if woman $i$ reports being Muslim, and an indicator for if she reports being in a polygynous marriage. The vector $\mathbf{X}_{e}$ includes our baseline set of ethnicity-level covariates: an indicator for traditional matrilineal inheritance and an indicator for traditional female participation in agriculture. We cluster our standard errors at the ethnicity-level and report $p$-values from a wild cluster bootstrap procedure. Estimates of equation (6) are reported in Table 6. Columns 1 and 2 report estimates for Indonesia, while columns 5-9 report estimates for Zambia using either the DHS (columns 5-7) or the ZFPS (columns 8 and 9). The first column for each sample (columns 1, 5 and

\footnotetext{
${ }^{37}$ The survey findings are also consistent with information garnered from focus groups conducted by our research team in Lusaka. For example, one respondent told us that when a parent negotiates lobola, he or she calculates how much was spent on education.
} 
8) report estimates of equation (6) without the muslim, polygynous marriage, matrilineal, or female participation in agriculture controls. The next column of each sample (columns 2, 6, and 9) include these controls. For the Zambian DHS sample, we also report a third specification (column 7) that replaces district fixed effects with much finer census cluster fixed effects. Since census clusters are not harmonized in the DHS over time, these amount to census cluster by survey year fixed effects.

In all specifications, we estimate a positive relationship between belonging to an ethnic group that practices bride price and female education. The estimates for the larger Indonesian sample indicate that girls from age 5-22 in bride price ethnic groups are 4.1-4.9 percentage points more likely to be enrolled in school than girls from ethnic groups that do not practice bride price. In Zambia, in the nationally-representative DHS sample, the coefficients are smaller (1.2-2.1 percentage points), while in the smaller Lusaka-based ZFPS sample they are slightly larger in magnitude (4.5-7.7 percentage points), although imprecisely estimated.

\subsection{Prediction 4: Do girls from bride price ethnic groups have lower test scores?}

The fourth prediction to emerge from the model states that girls from bride price ethnic groups should have lower academic ability on average, conditional on attending school. We use self-reported, retrospective test score data, taken from rounds 3 and 4 of the IFLS, to test whether this is the case for primary school students in Indonesia. Unfortunately, no similar data are available for Zambia, and so we only have estimates for Indonesia.

Our sample includes all female students in the IFLS who took the Ebtanas state exam, which was the national exam between 1980 and $2001 .^{38}$ Our estimating equation is:

$$
\text { TestScore }_{\text {iepst }}=\alpha_{t}+\delta_{p s}+\beta_{1} I_{e}^{\text {BridePrice }}+\mathbf{X}_{i} \boldsymbol{\Gamma}+\mathbf{X}_{e} \boldsymbol{\Pi}+\varepsilon_{\text {iepst }},
$$

where $i$ indexes a female primary school student, $e$ indexes her ethnicity, $p$ indexes a province, $s$ indexes the year the test was taken, and $t$ indexes the IFLS survey year. The dependent variable is the student's test score, normalized to have mean of zero and a standard deviation of one in our sample. $\alpha_{t}$ denotes survey-year fixed effects and $\delta_{p s}$ denotes province by test-year fixed effects, which are included because the Ebtanas exam system was standardized at the province-level each year. The vector $\mathbf{X}_{i}$ includes our age controls, age and age squared, and a control for whether the individual reports being muslim. ${ }^{39}$ The vector $\mathbf{X}_{e}$ includes our set of ethnicity-level controls: indicators for

\footnotetext{
${ }^{38}$ In 2001 , the Ebtanas exam was replaced by the UNAS exam.

${ }^{39}$ Since test takers are asked about their scores retrospectively as adults, we typically do not observe test-takers in the same household as their parents. Therefore, we cannot include controls for other household characteristics such as
} 


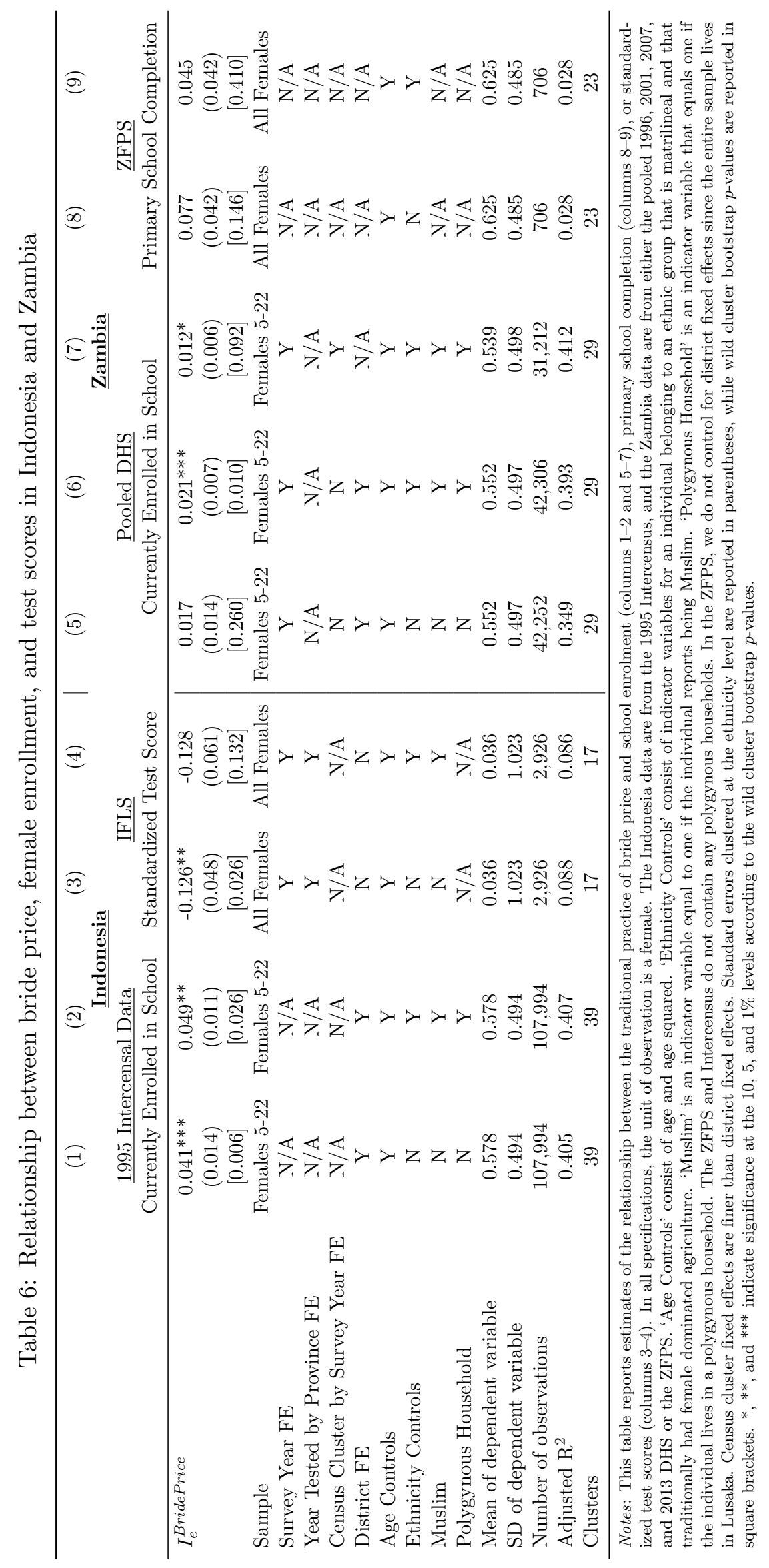


belonging to a traditionally matrilineal ethnic group or an ethnic group with female participation in agriculture. We report standard errors clustered at the ethnicity level, as well as $p$-values from a wild cluster bootstrap procedure.

Estimates of equation (7) are reported in columns 3 and 4 of Table 6 . Column 3 reports estimates without the muslim and ethnicity controls, while column 4 reports estimates with the controls. Consistent with proposition 4, the test scores of girls from bride price groups are estimated to be 0.126 standard deviations lower than girls from non-bride groups.

\section{Prediction 5. Differential Effects of Education Policies}

We now turn to the main prediction of our model, which describes how the presence of a bride price custom generates heterogeneity in the effects of a decline in the cost of schooling on female enrollment. To test the prediction, we first exploit the same quasi-experimental variation as in Duflo (2001) and estimate the effects of Indonesia's INPRES school construction program on female education. We then explore a large expansion in the supply of schools in Zambia in the late 1990s and early 2000s.

\subsection{Evidence from Indonesia}

The INPRES program was initiated in 1973, and over the following five years, 61,800 primary schools were constructed, which is equivalent to two schools for every thousand children enrolled in 1971. Between 1973 and 1978, the average aggregate enrollment rate for boys aged 7-12 increased from 69 to 83 percent. In her study, Duflo (2001) estimates the causal effect of the program on boys' education. She finds that in the average district, the program increased years of schooling completed by male students by 0.27 years. Since Duflo (2001) mainly used the program to estimate the returns to education in terms of wages, her sample only included males. We now turn to an examination of the effects of the program on females.

We start with the baseline estimating equation from her analysis:

$$
y_{i d k}=\alpha_{k}+\alpha_{d}+\beta_{1} I_{k}^{\text {Post }} \times \text { Intensity }_{d}+\sum_{j} \mathbf{X}_{d}^{\prime} \mathbf{I}_{k}^{j} \boldsymbol{\Gamma}_{j}+\varepsilon_{i d k}
$$

where $i$ indexes individuals, $d$ indexes the district of birth, and $k$ indexes the year of birth. The dependent variable, $y_{i d k}$, is an indicator that equals one if individual $i$ completed primary school. ${ }^{40}$

socioeconomic status or whether parents practiced polygyny.

${ }^{40}$ Because the school construction program built primary schools, we focus our analysis on primary school completion rates. Examining years of schooling, we find estimates that are similar but slightly less precise. 
$\alpha_{k}$ denotes birth-year fixed effects and $\alpha_{d}$ denotes district fixed effects. $I_{k}^{\text {Post }}$ is an indicator variable equal to one if an individual belongs to the younger cohort that was born between 1968 and 1972 (and would have fully experienced the intervention). $I_{k}^{\text {Post }}$ equals zero for the older cohort that was born between 1950 and 1962 (and would not have experienced the intervention since they would have been too old for primary school by time it was implemented). As in the baseline specification of Duflo (2001), partial treatment cohorts born between 1963 and 1967 are not included in the sample. Intensity $_{d}$ is the number of schools (per 1,000 school-age children) built in birth district $d$ during the school construction program. $I_{k}^{j}$ is an indicator variable that equals one if individual $i$ 's year of birth is equal to $j$ and zero otherwise, and $\sum_{j} \mathbf{X}_{d}^{\prime} \mathbf{I}_{k}^{j} \boldsymbol{\Gamma}_{j}$ denotes birth-year fixed effects interacted with the following district-level covariates: the number of school-aged children in the district in 1971 before the school building program took place, the enrollment rate of the district in 1971, and the exposure of the district to the second largest INPRES program, a water and sanitation program. Following Duflo (2001), we cluster standard errors at the level of an individual's district of birth. However, for robustness, we also report Conley standard errors that account for spatial correlation.

Estimates of equation (8) are reported in column 1 of Table 7 . We see that in contrast to Duflo's findings for males, for females, the estimated effect of school construction on primary school enrollment is small in magnitude and not statistically different from zero. This is a fact that has been previously documented in Hertz and Jayasundera (2007).

We next show that this average effect masks significant heterogeneity. To do this, we estimate an extension of equation (8) that allows for a differential effect of the school construction program depending on whether a girl's ethnic group traditionally practices bride price:

$$
\begin{aligned}
y_{i e d k}= & \beta_{1} I_{k}^{\text {Post }} \times \text { Intensity }_{d} \times I_{e}^{\text {NoBridePrice }}+\beta_{2} I_{k}^{\text {Post }} \times \text { Intensity }_{d} \times I_{e}^{\text {BridePrice }} \\
& +\alpha_{k} I_{e}^{\text {NoBridePrice }}+\alpha_{k} I_{e}^{\text {BridePrice }}+\alpha_{e}+\alpha_{e} I_{k}^{\text {Post }}+\alpha_{e} \text { Intensity }_{d}+\alpha_{d} I_{e}^{\text {NoBridePrice }} \\
& +\alpha_{d} I_{e}^{\text {BridePrice }}+I_{e}^{\text {NoBridePrice }} \sum_{j} \mathbf{X}_{d}^{\prime} \mathbf{I}_{k}^{j} \boldsymbol{\Gamma}_{j}+I_{e}^{\text {BridePrice }} \sum_{j} \mathbf{X}_{d}^{\prime} \mathbf{I}_{k}^{j} \mathbf{\Upsilon}_{j}+\varepsilon_{i e d k},
\end{aligned}
$$

where all indices and variables are defined as in equation (8). As in our previous analyses, $e$ indexes

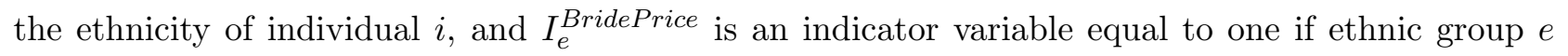
traditionally practices bride price. Additionally, $I_{e}^{\text {NoBridePrice }}$ is an indicator that equals one if the group does not traditionally practice bride price. The inclusion of $I_{k}^{\text {Post }} \times$ Intensity $_{d} \times I_{e}^{\text {NoBridePrice }}$ and $I_{k}^{\text {Post }} \times$ Intensity $_{d} \times I_{e}^{\text {BridePrice }}$ allow us to estimate the impact of school construction separately for ethnic groups that make bride price payments at marriage and those that do not. Thus, $\beta_{1}$ and 
$\beta_{2}$ are our primary coefficients of interest.

Equation (9) allows the district fixed effects to vary depending on the bride price customs of

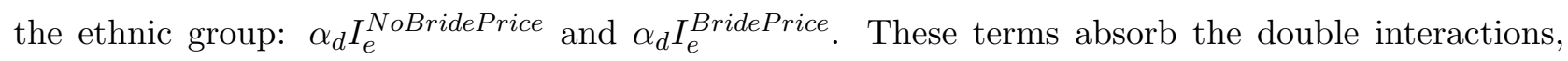
Intensity $_{d} \times I_{e}^{\text {NoBridePrice }}$ and Intensity I $\times I_{e}^{\text {BridePrice }}$, of the triple interactions of interest. We also interact the ethnicity fixed effects with the post-treatment indicator variable, $\alpha_{e} I_{k}^{P o s t}$. These fixed effects absorb the double interaction terms $I_{k}^{\text {Post }} \times I_{e}^{\text {NoBridePrice }}$ and $I_{k}^{\text {Post }} \times I_{e}^{\text {BridePrice }}$. Lastly, we allow the effects of our baseline set of district-level covariates interacted with cohort fixed effects to vary depending on whether ethnicity e practices bride price: $I_{e}^{\text {NoBridePrice }} \sum_{j} \mathbf{X}_{d}^{\prime} \mathbf{I}_{k}^{j} \boldsymbol{\Gamma}_{j}$ and $I_{e}^{\text {BridePrice }} \sum_{j} \mathbf{X}_{d}^{\prime} \mathbf{I}_{k}^{j} \boldsymbol{\Gamma}_{j} .{ }^{41}$

The estimates of equation (9) are reported in column 2 of Table 7 . We find a positive and statistically significant effect of the school construction program on primary school completion rates for bride price females but not for non-bride price females. The point estimates suggest that an increase of one school per 1,000 school-aged children in a district increases the likelihood that a female from a bride price ethnicity will complete primary school by 2.6 percentage points. The Wald test of the equality of the effects of school construction for bride price and non-bride price ethnic groups gives an $F$-statistic of $2.84(p=0.09)$. Thus, the equality of the estimated effects for the two groups can be rejected at a $10 \%$ significance level.

We confirm this finding by estimating equation (9) separately for girls belonging to ethnic groups with bride price (column 3) and for those belonging to ethnic groups without bride price (column 4). The separate estimates also help to illustrate the importance of bride price for policy evaluation. If an evaluator estimated the effects looking within bride price ethnic groups (column 3), she would conclude that the program was highly successful. However, if she estimated the effects looking within non-bride price groups (column 4), she would conclude the program was a failure. ${ }^{42}$

The remaining columns of Table 7 test the robustness of the estimates. First, we focus on the possible relationship between bride price and religion in Indonesia. Although the dominant religion in Indonesia is Islam, the custom of the bride price does not have its roots in Islam, but in traditional indigenous customs, referred to as adat, that pre-date conversion to Islam (Vroklage, 1952). ${ }^{43}$ As a

\footnotetext{
${ }^{41}$ For the interested reader, balance statistics for the difference between bride price and non-bride price groups are reported in Appendix Table A7.

${ }^{42}$ One important caveat to keep in mind when interpreting the estimates is the possibility of classical measurement error, which would bias the estimated effect downwards for both bride price and non-bride price groups. Thus, although it would not affect the differential response between the two groups, it would affect the level for each group. Therefore, it is possible that the effect for bride price girls is higher than estimated, and the effect for the non-bride girls is not exactly zero, but a small or even modest positive effect.

${ }^{43}$ The fact that Indonesian bride price customs do not originate from Islamic customs is important given the common Muslim custom/law that a payment, or mehr, be paid by the husband to the wife at the time of marriage. Upon divorce, the mehr is kept by the woman, thereby serving as a form of divorce insurance (Ambrus et al., 2010; Quale, 1988). It
} 
Table 7: Bride price status and the INPRES school expansion in the 1995 Indonesia Intercensal Data

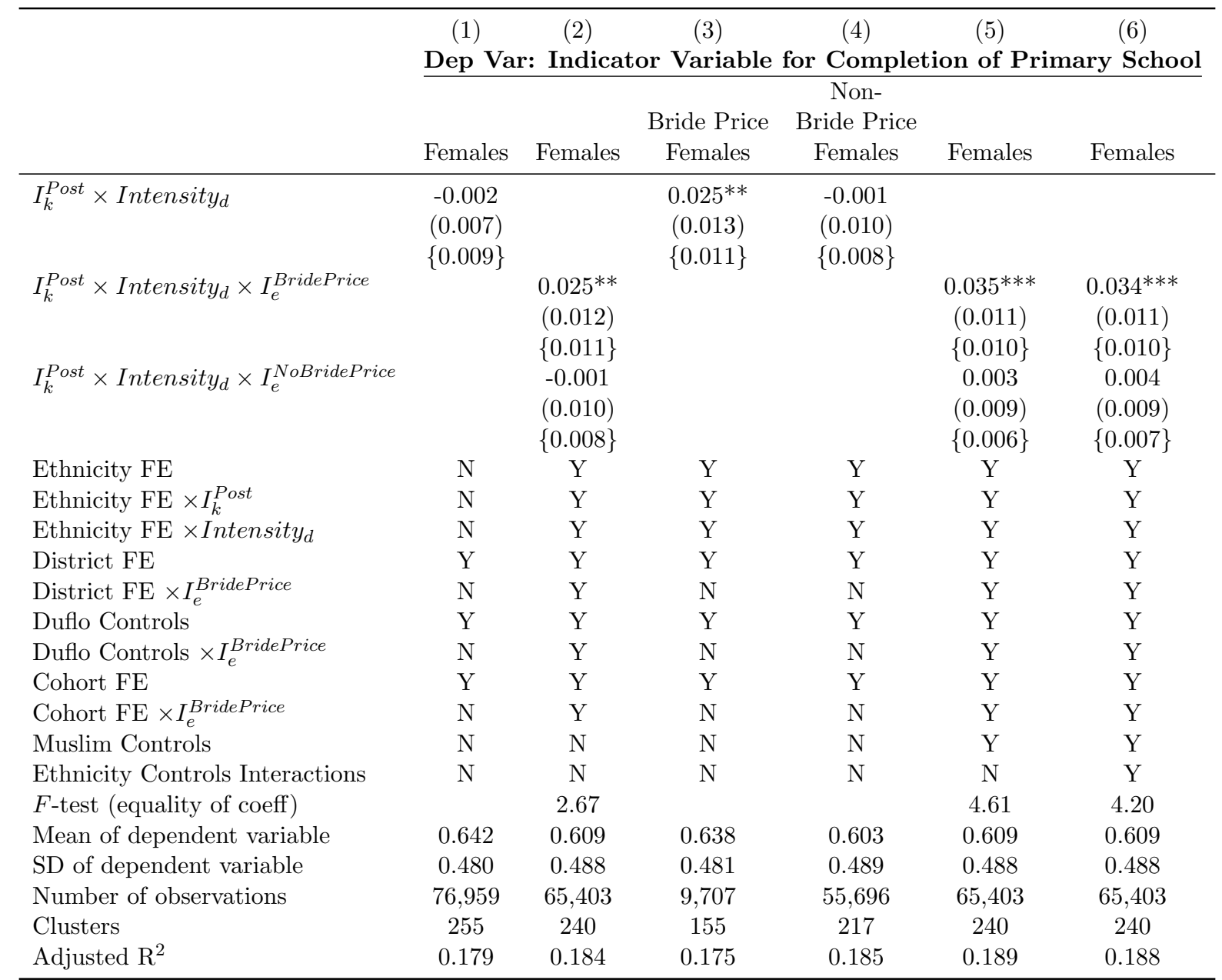

Notes: This table reports estimates of the effect of school building on educational attainment for females from ethnicities with and without bride price traditions. Following the empirical strategy of Duflo (2001), the sample consists of individuals born between either 1968 and 1972 or 1950 and 1962. $I_{k}^{\text {Post }}$ refers to the treated cohort, born between 1968 and 1972, while the untreated cohort was born between 1950 and 1962. Educational attainment data are taken from the 1995 Indonesia Intercensal Survey. Intensityd is the number of schools built in a district per 1,000 people in the school-aged population. 'Duflo Controls' consist of the interaction of cohort fixed effects with the number of school-aged children in the district in 1971, with the enrollment rate in 1971 and with the district level implementation of a water and sanitation program under INPRES. 'Muslim Controls' consist of an indicator variable for being muslim, its interactions with birth year and birth district fixed effects, and the triple interaction of the muslim indicator, belonging to a treated cohort, and treatment intensity. 'Ethnicity Controls' consist of the interactions between ethnicitylevel indicator variables for female dominated agriculture and matrilineality, being a treated cohort, and treatment intensity. The subscript $d$ indexes birth districts, $k$ indexes cohorts, and $e$ indexes ethnic groups. Standard errors clustered at the level of the district of birth are reported in parentheses. Conley standard errors that allow for correlation in errors of observations within $400 \mathrm{~km}$ appear in curly brackets. ${ }^{*}, *$, and $* * *$ indicate significance at the 10,5 , and $1 \%$ levels according to the clustered standard errors. 
robustness check, we allow the estimated effects of the school construction program to differ for those that report being muslim in the Intercensal survey. In practice, this means including the individuallevel muslim indicator variable interacted with: birth-cohort fixed effects $\alpha_{k}$, district-of-birth fixed effects $\alpha_{d}$, and the post treatment indicator times the district-level treatment intensity measure, $I_{k}^{\text {Post }} \times$ Intensity $_{d}$. The estimates, which are reported in column 5 of Table 7 , show that our finding of interest remains robust, with the effect of the school construction program becoming slightly larger and more precisely estimated for bride price females. ${ }^{44}$

Our last robustness check accounts for the possibility that bride price might be correlated with other ethnicity-level characteristics that could lead to differential effects of the schooling program. Thus, we allow the effect of the school-construction program to differ depending on whether an ethnic group traditionally has matrilineal inheritance or significant female participation in agriculture. This is done by re-estimating equation (9) with the inclusion of the ethnicity-level characteristics, each interacted with $I_{k}^{\text {Post }} \times$ Intensity $_{d}$. The double interaction terms associated with this triple interaction are captured by ethnicity fixed effects interacted with the post treatment indicator $I_{k}^{\text {Post }}$ and ethnicity fixed effects interacted with the district-level treatment intensity measure Intensity $_{d}$, which are already included in the specification. The estimates, which are reported in column 6 , show that the inclusion of these variables leave the bride price and non-bride price interactions virtually unchanged.

An alternative estimation strategy to equation (8), which rigidly defines a pre-treatment and post-treatment cohort, is to allow the effects of school construction to vary flexibly and across a fuller range of cohorts. Specifically, in the more flexible specification, in equation (8), the term $\beta_{1} I_{k}^{\text {Post }} \times$ Intensity $_{d}$ is replaced by $\sum_{l} \beta_{l} I_{k}^{l} \times$ Intensity $_{d}$, where $l$ indexes 3 -year birth cohorts (e.g. those born from 1950-1952, those born from 1953-1955, and so on). This gives the following equation:

$$
y_{i d k}=\alpha_{k}+\alpha_{d}+\sum_{l} \beta_{l} I_{k}^{l} \times \text { Intensity }_{d}+\sum_{j} \mathbf{X}_{d}^{\prime} \mathbf{I}_{k}^{j} \boldsymbol{\Gamma}_{j}+\varepsilon_{i d k}
$$

To examine the differential effects of the program, we estimate equation (10) separately for females from bride price and non-bride price ethnic groups. The estimated relationships between school

is important to point out that the bride price, which is common in our context, is different from mehr.

${ }^{44}$ As another robustness check, we re-estimate equation (9) also allowing the differential effect of schooling between bride price and non-bride price groups to differ depending on whether an individual reports being Muslim or not. The estimates, which are reported in Appendix Table A8, show that the differential effect by bride price is similar for Muslims and non-Muslim girls. If anything, the differential effect of bride price is larger and more significant among non-Muslims, suggesting that the presence of Islam is not driving our results. This is also consistent with the fact that, as we show in the following subsection, we obtain very similar estimates in Zambia, which is a predominantly Christian country. 
Figure 3: Estimates of the effect of school-construction in Indonesia on female education by cohort of birth

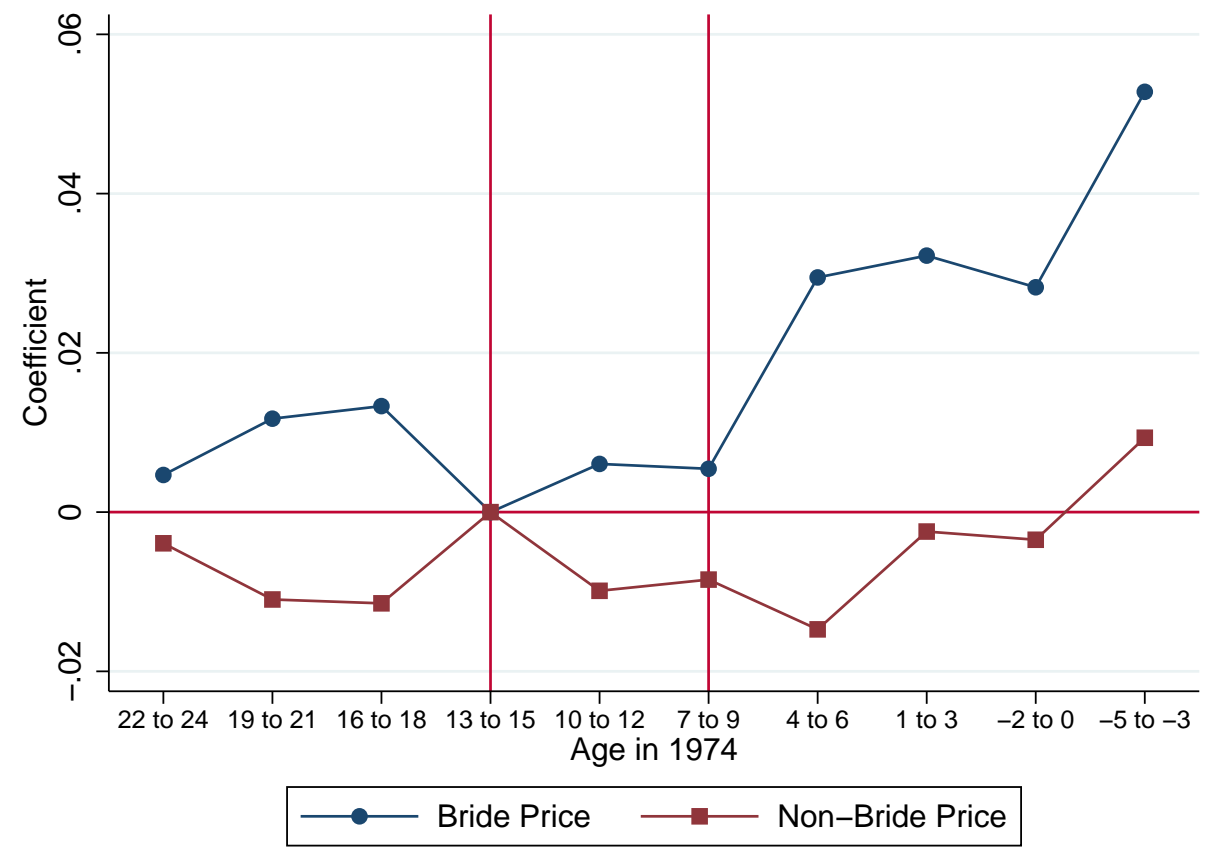

Notes: The figure reports estimates of the effect of school construction on primary school completion for 3-year cohorts separately for females from ethnicities with and without bride price traditions. The $x$-axis reports the age range (in 1974) for each cohort and the $y$-axis reports the estimated coefficient. The sample consists of individuals born between 1950 and 1979. The left vertical line indicates the youngest cohort that did not receive any treatment from school construction. The right vertical line indicates the youngest cohort that could not have received full treatment from school construction. Thus, the "10 to 12" and "7 to 9" cohorts are ones that received partial treatment. The corresponding coefficients and standard errors are reported Appendix Table A9.

construction and primary school completion for the different cohorts - i.e., the $\beta_{l}$ 's - are reported in Appendix Table A9 and shown visually in Figure 3. The $x$-axis denotes each cohort's age as of 1974, the year in which the first schools were completed, and the $y$-axis is the estimated coefficient. The vertical lines in the figure indicate the cohorts that were partially treated. The vertical left line indicates the youngest cohort that would have been too old to have been affected by the school construction program. This cohort was older than primary school age when the construction began in 1974. The right line indicates the youngest cohort that would not have received full treatment. The next youngest cohort, which would have been 4-6 years old in 1974, had the potential to receive virtually full treatment if their location received new schools early in the project period.

The estimates show that for all cohorts that were 13-15 years old or older in 1974, there is no detectable effect of the program on elementary school completion. This is expected since girls belonging to these cohorts would have already finished primary school by the time the program 
was completed in 1978. The program had the potential to fully affect the cohorts who were $4-6$ or younger in 1974. Figure 3 shows that for these cohorts there is a positive effect for girls from bride price groups, but not for girls from non-bride price groups. More generally, we see a very different pattern for the two groups. For bride price girls, the program appears to have had effects exactly on the expected cohorts, while for non-bride price groups, there is little effect of the program across cohorts.

We next turn to an examination of the sensitivity of our estimates of a differential effect of school construction. We begin by checking the sensitivity of our findings to the use of an alternative dataset, the 2010 Indonesia Census, which is a more recent data source than the 1995 Indonesia Intercensal Survey. A benefit of the 2010 data over the 1995 data is its much larger sample size due to its being a Census rather than an Intercensus. However, the data also have a number of important drawbacks, which is why we follow Duflo (2001) and use the 1995 Intercensal Survey as our baseline source. First, in 2010, the oldest members of the sample are 60 (compared to 45 in the 1995 data), which raises concerns about selective attrition due to mortality. Second, due to the creation of many new districts in Indonesia between 1995 and 2010, the school construction data are less precisely matched to individual birth districts in the 2010 data. ${ }^{45}$ Despite these shortcomings of the 2010 data, we check the robustness of our findings by re-estimating equations (8) and (9) using this alternative sample. The estimates, which are reported in columns 1-2 of Appendix Table A10, show that we obtain similar results using the 2010 Census data. As with the 1995 Intercensus data, the estimated effect of school construction is positive and significant for bride price ethnic groups but is not statistically different from zero for non-bride price groups.

The second check that we perform is to test the robustness of our results to the inclusion of linear time trends that are allowed to vary at the district level (and differentially for bride price and non-bride price ethnic groups). Estimates of equation (9) with the new district-specific time trends are reported in columns 3-4 of Appendix Table A10. Although including the controls reduces the precision of the estimates, it does not change the qualitative pattern that the school construction had larger effects for bride price groups in Indonesia. The estimated effect of school construction remains positive for bride price girls and very close to zero for non-bride price girls.

Lastly, we also report the results of a placebo test from Duflo (2001) where we re-estimate equations (8) and (9), but assign children aged 12-17 at the time of the school construction to be the placebo treated cohort and children aged 18-24 at the time to be the placebo untreated cohort. The estimates, which are reported in columns 5-6 of Appendix Table A10, show that the placebo

\footnotetext{
${ }^{45}$ IPUMS is currently in the process of attempting to harmonize district definitions over time in Indonesia.
} 
treatment had no statistically significant effects on either bride price or non-bride price females.

\subsection{Evidence from Zambia}

Like Indonesia, Zambia also implemented a large school construction program that built a total of 5,649 schools between 1994 and 2007. Although this construction program occurred over a longer timespan and the process of choosing the location and timing of school construction was more opaque than in Indonesia, the episode provides large-scale variation in school construction that can be used to test Prediction 5 of the model in a different setting. ${ }^{46}$ We do this using data from the Zambian Ministry of Education on the stock of primary schools by year and district. These data are then combined with four rounds of the Zambia DHS: 1996, which is at the beginning of the school construction episode; 2001, during the middle of the episode; 2007, near the end of the episode; and 2013, after the episode. To better illustrate the relationship between the DHS surveys and the school construction episode, in Appendix Figure A1 we show the number of schools built by year in Zambia between 1940 and 2013, and mark the timing of the four rounds of the DHS. We also report this same information, but separately for each province in Appendix Figure A2. These graphs show that there is significant heterogeneity across space in the timing of the school construction project. As will become clear below, this fact is important given our estimating equation.

In contrast to Indonesia, school construction in Zambia occurred over a longer period of time and the strategy for when and where schools were built is unclear. Therefore, rather than examining variation arising from the interaction of a pre-treatment versus post-treatment cohort indicator variable with the spatial variation in treatment intensity across districts, we instead estimate the relationship between the stock of schools in a district during a given survey year and the probability of enrollment of children aged 5-12 living in that district during at that time. Thus, our baseline estimating equation, which estimates an average effect of school construction across all ethnic group, irrespective of bride price practice, is given by:

$$
y_{i e d k t}=\beta_{1} \text { Schools }_{d t} / \text { Area }_{d}+\alpha_{k t}+\alpha_{e t}+\alpha_{e d}+\varepsilon_{i e d k t} .
$$

\footnotetext{
${ }^{46}$ Within Africa, there are other school expansion episodes that one could potentially use to examine the impacts of interest: Zimbabwe (Agüero and Bharadwaj, 2014), Sierra Leone (Mocan and Cannonier, 2012), and Nigeria (Osili and Long, 2008). However, for Sierra Leone and Nigeria, there is insufficient variation in the practice of bride price. In both countries, nearly all people belong to ethnic groups that practice bride price. In Zimbabwe, sufficiently fine-grained data on ethnic affiliation are not available from the data sources that report education.
} 
Our estimating equation which allows for a differential effect depending on bride price practice is:

$$
\begin{aligned}
y_{i e d k t}= & \beta_{1} \text { Schools }_{d t} / \text { Area }_{d} \times I_{e}^{\text {NoBridePrice }}+\beta_{2} \text { Schools }_{d t} / \text { Area }_{d} \times I_{e}^{\text {BridePrice }} \\
& +\alpha_{k t} I_{e}^{\text {NoBridePrice }}+\alpha_{k t} I_{e}^{\text {BridePrice }}+\alpha_{e t}+\alpha_{e d}+\varepsilon_{i e d k t} .
\end{aligned}
$$

In both equations, $i$ indexes girls who are 5-12 years old, $e$ indexes ethnic groups, $d$ indexes districts, $k$ indexes their birth year, and $t$ indexes the year of the survey (either 1996, 2001, 2007, or 2013). Our outcome of interest, $y_{i e d k t}$, is an indicator variable that equals one if girl $i$ is enrolled in school in year $t$. Our measure of school construction, $S_{\text {chools }} d t / A_{r e a}$, is the stock of schools in district $d$

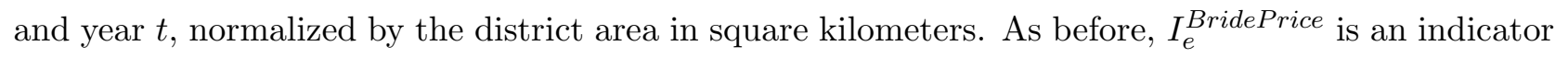
variable that equals one if ethnic group $e$ traditionally practices bride price, while $I_{e}^{\text {NoBridePrice is an }}$ indicator variable that equals one if the ethnic group does not.

The specification also includes cohort-by-survey year fixed effects interacted with the bride price indicator variables, $\alpha_{k t} I_{e}^{\text {NoBridePrice }}$ and $\alpha_{k t} I_{e}^{\text {BridePrice }}$. These are the equivalent of the cohort fixed effects interacted with the bride price indicator variables in equation (9). We also include ethnicitytime period fixed effects, $\alpha_{e t}$, and ethnicity-district fixed effects, $\alpha_{e d}$, which are the equivalent of the ethnicity fixed effects interacted with the post-treatment indicator variable, and the district fixed effects interacted with the bride price indicator variables in equation (9). We cluster our standard errors at the district level and also report Conley standard errors that account for spatial correlation. ${ }^{47}$

Estimates are reported in Table 8. Column 1 reports estimates of equation (11). We see that in Zambia, we find a similar pattern as in Indonesia: the estimates are small and close to zero. Column 2 reports estimates of equation (12), which allows for a differential effect depending on bride price practice. As in Indonesia, positive effects of school construction are concentrated among girls from ethnic groups that traditionally practice bride price. For girls from ethnic groups that do not engage in this practice, the estimated effect is very close to zero. The estimated difference between the two groups is statistically significant. Results from a Wald test indicate that the hypothesis of the equality of the effects for the two groups can be rejected at a 5 percent significance level. The $F$-statistic is 5.22 and the $p$-value is 0.03 .

Columns 3 and 4 report estimates of equation (11) separately for bride price and non-bride price girls. For girls from bride price ethnic groups, we estimate a positive and significant relationship between school construction and enrollment. For girls from non-bride price ethnic groups, we estimate

\footnotetext{
${ }^{47}$ Balance statistics for the difference between bride price and non-bride price groups for are reported in Appendix Table A11.
} 
a relationship that is not statistically different from zero.

The last two columns of Table 8 provide evidence that the results are robust to controlling for potential sources of omitted variable bias. In column 5, we report estimates of equation (12) that include controls for whether the girl lives in a polygynous household and whether the household head is Muslim, and their interactions with the school construction program measure. Including these controls appears to strengthens the results. The estimated effect of the school construction program for bride price girls increases noticeably, while the effect for non-bride price girls continues to be very close to zero. In column 6 , we also include our set of ethnicity-level covariates (i.e., traditional matrlineality and traditional female participation in agriculture), as well as their interactions with the school construction program measure. We find that including these controls increases the estimated treatment effects for both bride price and non-bride price girls. However, we continue to find that the school construction program had substantially larger effects on education for bride price girls.

In terms of magnitudes, we find similar effects in Zambia as in Indonesia. In Indonesia, for girls from bride price ethnic groups, a one standard deviation increase in school construction (0.85) is associated with an increase in primary school completion by 2.1 percentage points $(0.85 \times 0.025)$, and the mean of female primary school completion is $61 \%$. In Zambia, for girls from bride price ethnic groups, a one-standard-deviation increase in the stock of elementary schools (0.271) is associated with an increase in primary school attendance by 1.1 percentage points $(0.271 \times 0.042)$, and the mean of female primary school enrollment is $51 \%$.

As we did for the Indonesian sample, we test whether our Zambian estimates are robust to the inclusion of district-specific linear time trends that are allowed to vary depending on whether an ethnic group practices bride price. The estimates are reported in columns 1 and 2 of Appendix Table A12. We find that the inclusion of the time trends leads to estimates that are larger in magnitude. However, it does not change the qualitative pattern that the school construction had larger effects for bride price groups. The estimated effect of school construction remains positive for bride price girls and not statistically different from zero for non-bride price girls.

As a final sensitivity check, we also test whether our findings are potentially explained by pretrends in districts that received more schools. We estimate a version of equation (12) that includes a one survey-round forward lag of the treatment, Schools $_{d, t+1} /$ Area $_{d}$, and its interactions with $I_{e}^{\text {BridePrice }}$ and $I_{e}^{\text {NoBridePrice }}$. The estimates are reported in columns 3 and 4 of Appendix Table A12. None of the forward-lag interactions positively predict enrollment. In fact, we estimate negative coefficients for the forward lags, which suggests that, as in Indonesia, new schools may have been 
Table 8: School construction and primary school enrollment in the pooled Zambia DHS (1996, 2001, 2007, and 2013)

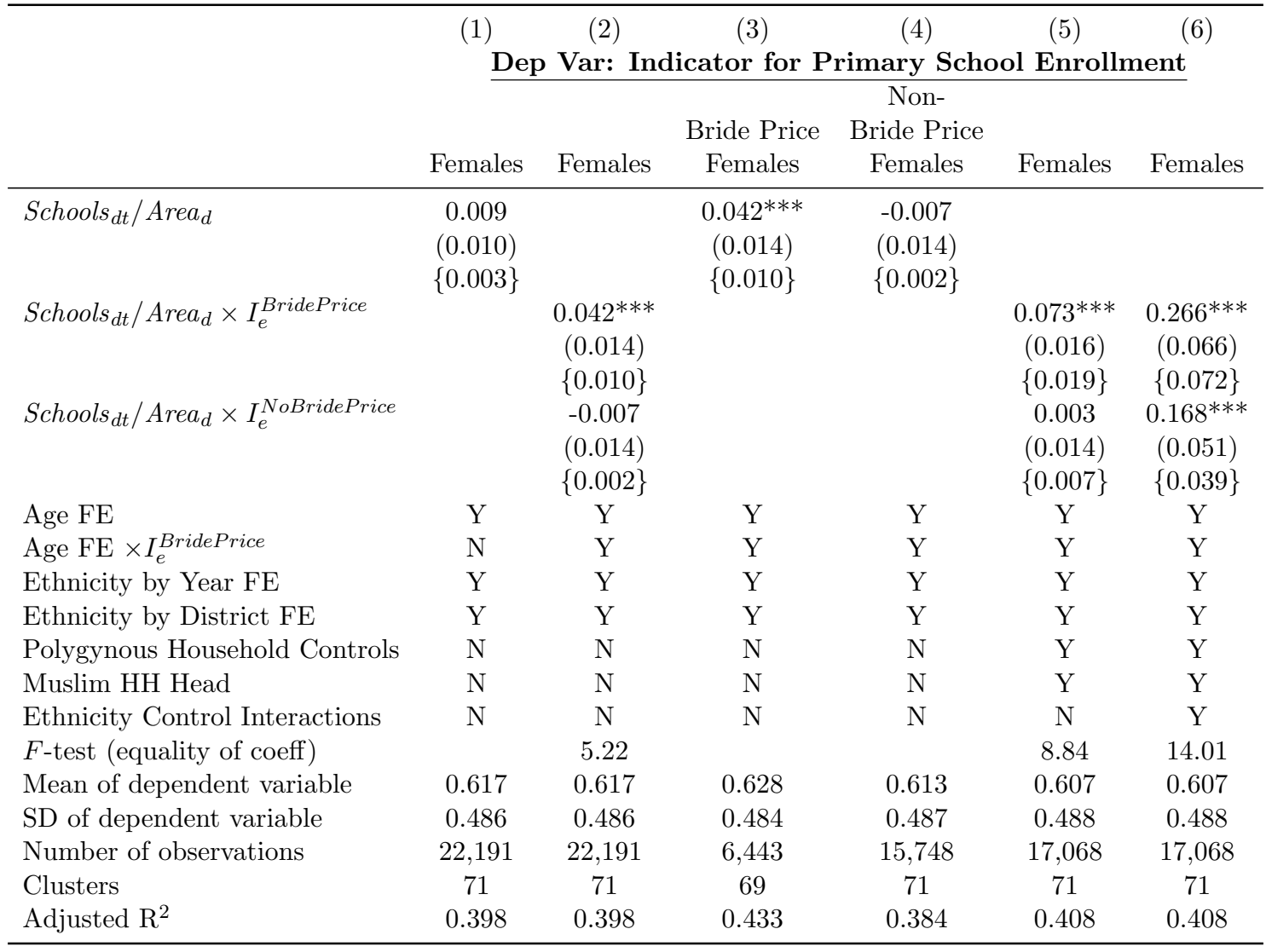

Notes: This table reports estimates of the differential impact of school building in Zambia on bride price and non-bride price females. The sample consists of girls aged 5-12 at the time of the survey. Educational attainment data are taken from the 1996, 2001, 2007, and 2013 rounds of the Demographic and Health Survey. The treatment variable, Schools $d t$ is the number of schools built in a district $d$ by survey year $t$. This is normalized by the area of the district, Area . The subscript $d$ indexes districts, $t$ survey years, and $e$ ethnic groups. 'Ethnicity Control Interactions' consist of the interactions between ethnicity-level indicators for traditional female dominated agriculture and matrilineal kinship with the treatment variable, Schools $d t /$ Area $_{d}$. 'Polygynous Household Controls' consist of an indicator variable that equals one if the individual lives in a household that is polygynous and its interaction with the treatment variable, Schools ${ }_{d t} /$ Area $_{d}$. 'Muslim $\mathrm{HH}$ Head' is an indicator variable that equals to one if the head of the household is Muslim (children do not report their religion in the Zambian DHS). Standard errors clustered at the district level are reported in parentheses. Conley standard errors that allow for correlation in errors of observations within $400 \mathrm{~km}$ are reported in curly brackets. ${ }^{*},{ }^{* *}$, and ${ }^{* * *}$ indicate significance at the 10,5 , and $1 \%$ levels according to the clustered standard errors.

disproportionately allocated to districts with low school enrollment.

\subsection{Testing alternative explanations for the differential behavior of bride price ethnic groups}

We now turn to the possibility that the differential effects that we find are due to other factors that are correlated with the bride price practice and also affect female schooling decisions. For example, it is possible that ethnic groups that engage in bride price payments may be systematically wealthier and therefore, are in a better position to send their daughters to school and respond more strongly to school construction. We check for this possibility by examining whether households that belong 
Table 9: Bride price practice, wealth, sex ratio, and attitudes in Indonesia and Zambia

\begin{tabular}{|c|c|c|c|c|c|}
\hline & $\begin{array}{c}(1) \\
\text { Wealth } \\
\text { Index, 0-1 }\end{array}$ & $\begin{array}{c}(2) \\
\text { Number } \\
\text { of Children } \\
\text { Born }\end{array}$ & $\begin{array}{c}(3) \\
\text { Fraction of } \\
\text { Surviving Children } \\
\text { that are Girls }\end{array}$ & $\begin{array}{c}(4) \\
\text { Fract Reasons } \\
\text { Beating Wife } \\
\text { Not Justified }\end{array}$ & $\begin{array}{c}\quad(5) \\
\text { Fract Reasons } \\
\text { Wife's Refusing } \\
\text { Sex Justified }\end{array}$ \\
\hline & & Panel A & I. Indonesian Inter & census Sample & \\
\hline \multirow[t]{3}{*}{$I_{e}^{\text {BridePrice }}$} & -0.014 & $0.292^{*}$ & -0.002 & & \\
\hline & $(0.016)$ & $(0.078)$ & $(0.005)$ & & \\
\hline & {$[0.488]$} & {$[0.054]$} & {$[0.650]$} & & \\
\hline District FE & $\mathrm{Y}$ & $\mathrm{Y}$ & $\mathrm{Y}$ & & \\
\hline Age Controls & $\mathrm{Y}$ & $\mathrm{Y}$ & $\mathrm{Y}$ & & \\
\hline Muslim & Y & $\mathrm{Y}$ & $\mathrm{Y}$ & & \\
\hline Unit of observation & $\mathrm{HH}$ & Wife & Wife & & \\
\hline Mean of dependent variable & 0.391 & 3.020 & 0.489 & & \\
\hline SD of dependent variable & 0.252 & 1.930 & 0.338 & & \\
\hline Number of observations & 137,503 & 82,399 & 77,519 & & \\
\hline Clusters & 41 & 40 & 40 & & \\
\hline \multirow[t]{2}{*}{ Adjusted $\mathrm{R}^{2}$} & 0.289 & 0.279 & 0.001 & & \\
\hline & \multicolumn{5}{|c|}{ Panel B. Zambian DHS Sample } \\
\hline \multirow[t]{3}{*}{$I_{e}^{\text {BridePrice }}$} & 0.005 & -0.014 & 0.008 & 0.012 & -0.006 \\
\hline & $(0.023)$ & $(0.092)$ & $(0.007)$ & $(0.008)$ & $(0.006)$ \\
\hline & {$[0.848]$} & {$[0.894]$} & {$[0.268]$} & {$[0.126]$} & {$[0.296]$} \\
\hline District FE & $\mathrm{Y}$ & $\mathrm{Y}$ & $\mathrm{Y}$ & $\mathrm{Y}$ & $\mathrm{Y}$ \\
\hline Survey Year FE & $\mathrm{Y}$ & $\mathrm{Y}$ & $\mathrm{Y}$ & $\mathrm{Y}$ & $\mathrm{Y}$ \\
\hline Age Controls & $\mathrm{Y}$ & $\mathrm{Y}$ & $\mathrm{Y}$ & $\mathrm{Y}$ & $\mathrm{Y}$ \\
\hline Polygynous Household & $\mathrm{Y}$ & $\mathrm{Y}$ & $\mathrm{Y}$ & $\mathrm{Y}$ & $\mathrm{Y}$ \\
\hline Unit of observation & $\mathrm{HH}$ & Wife & Wife & All & All \\
\hline Mean of dependent variable & 0.482 & 4.712 & 0.497 & 0.676 & 0.757 \\
\hline SD of dependent variable & 0.341 & 2.530 & 0.286 & 0.379 & 0.313 \\
\hline Number of observations & 17,403 & 15,893 & 15,216 & 21,607 & 21,600 \\
\hline Clusters & 29 & 29 & 29 & 29 & 29 \\
\hline Adjusted $\mathrm{R}^{2}$ & 0.354 & 0.377 & -0.001 & 0.195 & 0.056 \\
\hline \multicolumn{6}{|c|}{$\begin{array}{l}\text { Notes: This table reports estimates of the relationship between various individual- or household-level characteristics and bride price status within In } \\
\text { donesia and Zambia. In column } 1 \text {, the unit of observation is a household, in columns } 2 \text { and } 3 \text { it is women aged } 25-45 \text {, and in columns } 4-6 \text {, it is men } \\
\text { and women aged } 25-45 \text {. The dependent variable in column } 1 \text { is a wealth index. For Indonesia, the index is constructed using the first principle com- } \\
\text { ponent using indicator variables for household assets. In Zambia, the DHS reports an assets variable. We normalize both variables to lie between zero } \\
\text { and one. In column } 2 \text {, the dependent variable is the total number of children born. In column } 3 \text {, it is the number of surviving female children over } \\
\text { the total number of surviving children born. In column } 4 \text {, it is the fraction of reasons for which it was reported that a husband beating his wife is not } \\
\text { justified. In column } 5 \text {, it is the fraction of reasons for which it was reported that a wife's refusing to have sex was justified. For Indonesia, individual- } \\
\text { and household-level data are from the } 1995 \text { Intercensal data. For Zambia, individual- and household-level data are from the } 1996,2001,2007 \text {, and } 2013 \\
\text { DHS. 'Age Controls' consist of the respondent's age and age squared (and the household head's age and age squared in the case of column } 1 \text { ). 'Muslim } \\
\text { is an indicator variable equal to one if the household head (column } 1 \text { ) or respondent (columns } 2 \text { and } 3 \text { ) reports being Muslim. 'Polygynous Household } \\
\text { is an indicator variable equal to one if the household is polygynous. Standard errors, clustered at the ethnicity level, are reported in parentheses. } p \\
\text { values obtained using the wild cluster bootstrap procedure appear in square brackets. *, } * * \text {, and *** indicate significance at the } 10,5 \text {, and } 1 \% \text { levels } \\
\text { according to the wild cluster bootstrap } p \text {-values. }\end{array}$} \\
\hline
\end{tabular}

to bride price ethnic groups have greater wealth. In practice, we estimate a variant of equation (6), but at the household-level and with household wealth as the dependent variable. We identify the household's ethnicity using the ethnicity of the household head. The estimates are reported in column 1 of Table 9. Panel A reports estimates from the Indonesian sample, which uses the Intercensal data, and panel B reports estimates for the Zambian sample, which uses the DHS data. We find no evidence of differences in the wealth of bride price and non-bride price households in either country.

Even if household wealth is the same in both groups, it is still possible that bride price ethnic groups have fewer children and therefore have more wealth per child. ${ }^{48}$ To test for this hypothesis, we estimate equation (6) using a sample of women aged 25-45 and with the number of children born

\footnotetext{
${ }^{48}$ Boomgaard (2003) argues that in Indonesia bride price has led to delayed marriage and lower rates of fertility.
} 
at the time of the survey as the dependent variable. The estimates, which are reported in column 2 of Table 9, show no evidence that women from bride price ethnic groups have fewer children. In Zambia, the coefficient is very close to zero and insignificant, while in Indonesia is actually positive, although only marginally significant.

Another alternative explanation for our findings is that bride price households are more altruistic toward daughters, leading them to educate their daughters more (and to respond more to the schoolconstruction program). Therefore, we test for the possibility that bride price families have different attitudes towards girls relative to boys by estimating the relationship between bride price and the fraction of surviving children that are girls. This reflects differential preferences for boys relative to girls that result in differential mortality rates due to differential access to family resources, such as healthcare or nutrition, or even sex selective abortion or infanticide. The estimates are reported in column 3 of table 9 . In both Indonesia and Zambia, we find no evidence of differences in daughter preference as measured by the fraction of surviving children who are female.

We are able to further explore the evidence for a relationship between bride price and gender attitudes in Zambia using the DHS, which collects information on respondents' attitudes about the rights of women in marriage. ${ }^{49}$ The first measure that we use is based on a question that asks respondents whether a husband beating his wife in justified in five different scenarios. The measure is the proportion of the five scenarios for which the respondent reports a beating is not justified. The second measure is similar, but is based on the proportion of reasons for which the respondent feels it is justified for women to refuse to have sex with her husband. ${ }^{50}$ Thus, both measures are increasing in gender equality and female empowerment. The estimates are reported in columns $4-5$ of the panel B of Table 9. For both measures, we find no evidence of a relationship between bride price and gender attitudes. Both coefficients are small in magnitude and statistically insignificant. ${ }^{51}$

A final alternative explanation for the differential response of bride price ethnic groups to school construction is that the returns to education are higher for this group. We test for this by checking whether the relationship between a women's level of education and either her employment status or her income is stronger for women from bride price ethnic groups. Using our sample of women from Indonesia and Zambia, we estimate the relationship between our three levels of schooling and employment, wages, wealth, and (in Zambia) child health, allowing the effect of education to differ depending on whether a woman's ethnic group practices bride price. The finer details of the estimation

\footnotetext{
${ }^{49}$ The analysis does not include the 1996 DHS, which did not ask these questions.

${ }^{50}$ In 2001, four reasons are asked about, and in 2007 and 2013, three reasons are asked about. The details of the questions asked are reported in Appendix A.

${ }^{51}$ Estimates are very similar if we restrict the sample to be only men, only women, or include a gender fixed effect.
} 
are summarized in Appendix B and the estimates are reported in Appendix Table A13. The estimates provide no evidence of a differential return to education for women belonging to bride price ethnic groups.

\subsection{Prediction 6. Evidence on bride price and male education}

We next turn to prediction 6 of the model, which summarizes the predicted effects of bride price for males. We test the prediction by replicating the tests of predictions $3-5$ using a sample of men rather than women. The model predicts that we should not see the same relationships in the data for men as we do for women.

We begin by studying whether men from bride price ethnic groups tend to have higher education rates than men from non-bride price ethnic groups (prediction 3 for women). To do this, we reestimate equation (6) using the samples of men in the IFLS, the DHS and the ZFPS, thus replicating the analysis reported in Table 6. As reported in columns 1-2 and 5-9 of Table 10, we do not find the same patterns among men. Specifically, across the seven regressions, there is only a significant positive association between bride price and male education in Indonesia (column 1), and this association is no longer significant when we control for Islam (column 2). The point estimates for the coefficient on the bride price indicator are small in magnitude and fluctuate between being positive and negative, depending on the sample. Turning to the second part of prediction 6 , we check for differences in test scores among men from bride price ethnic groups (prediction 4 for females). The estimates, which are reported in columns 3 and 4 of Table 10, show no significant difference between the two groups.

We test the final part of prediction 6 (prediction 5 for females) by estimating equation (9) for Indonesia and equation (12) for Zambia. The estimates are reported in Table 11. Again, we do not observe the same consistent patterns for males as we do for females. The estimated effects of the program are not systematically different for bride price and non-bride price boys.

\section{Discussion}

Our analysis of two developing countries, Indonesia and Zambia, has shown that the traditional practice of bride price is associated with substantially larger investments in female primary education and greater responsiveness to education policies. For both large-scale school-construction projects that we examine, we find a positive and significant effect of school construction on female education

only among groups that practice bride price. For those that do not, we find no evidence that female education increased in response to the programs. 


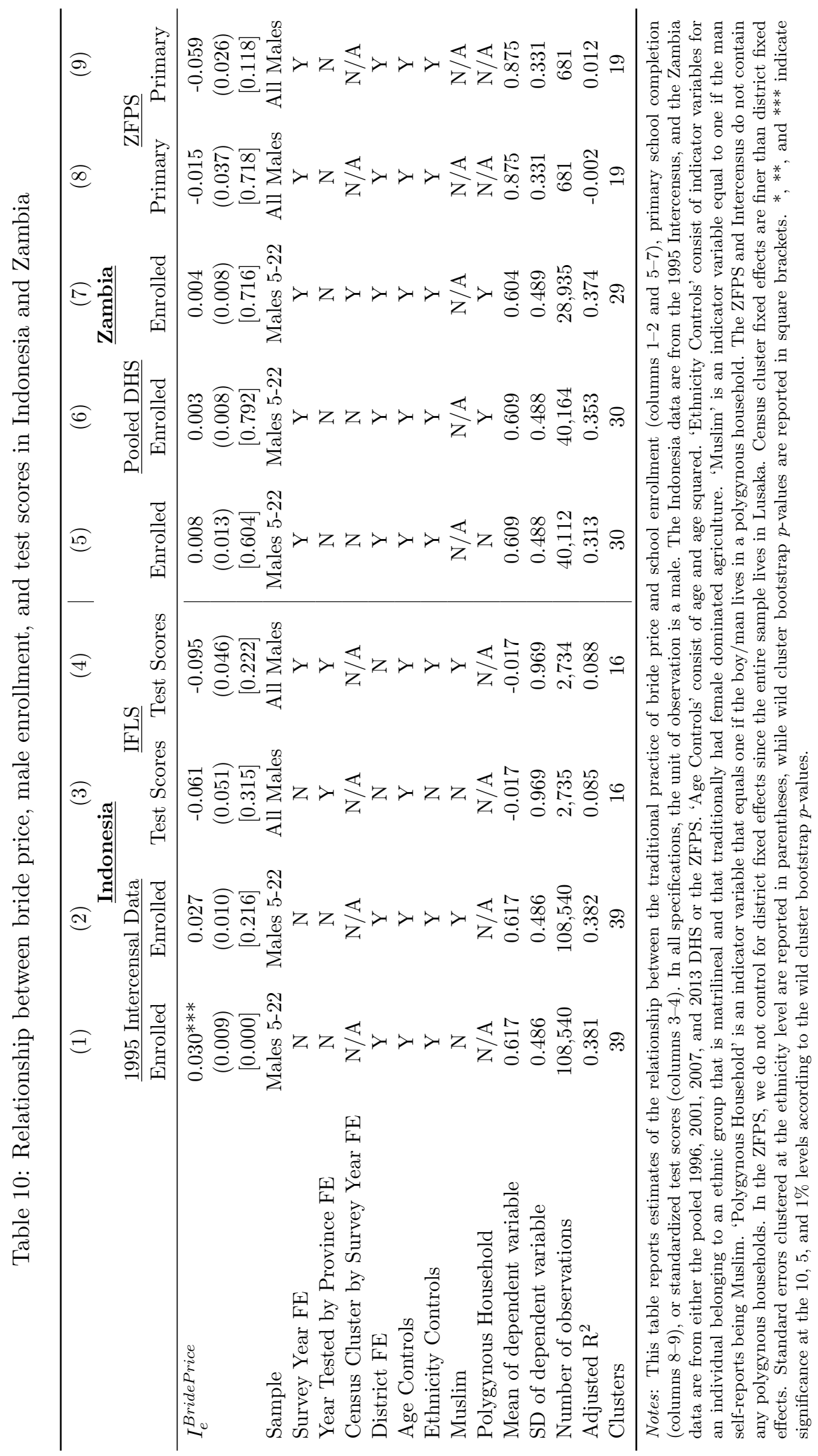


Table 11: Effects of school construction on male schooling

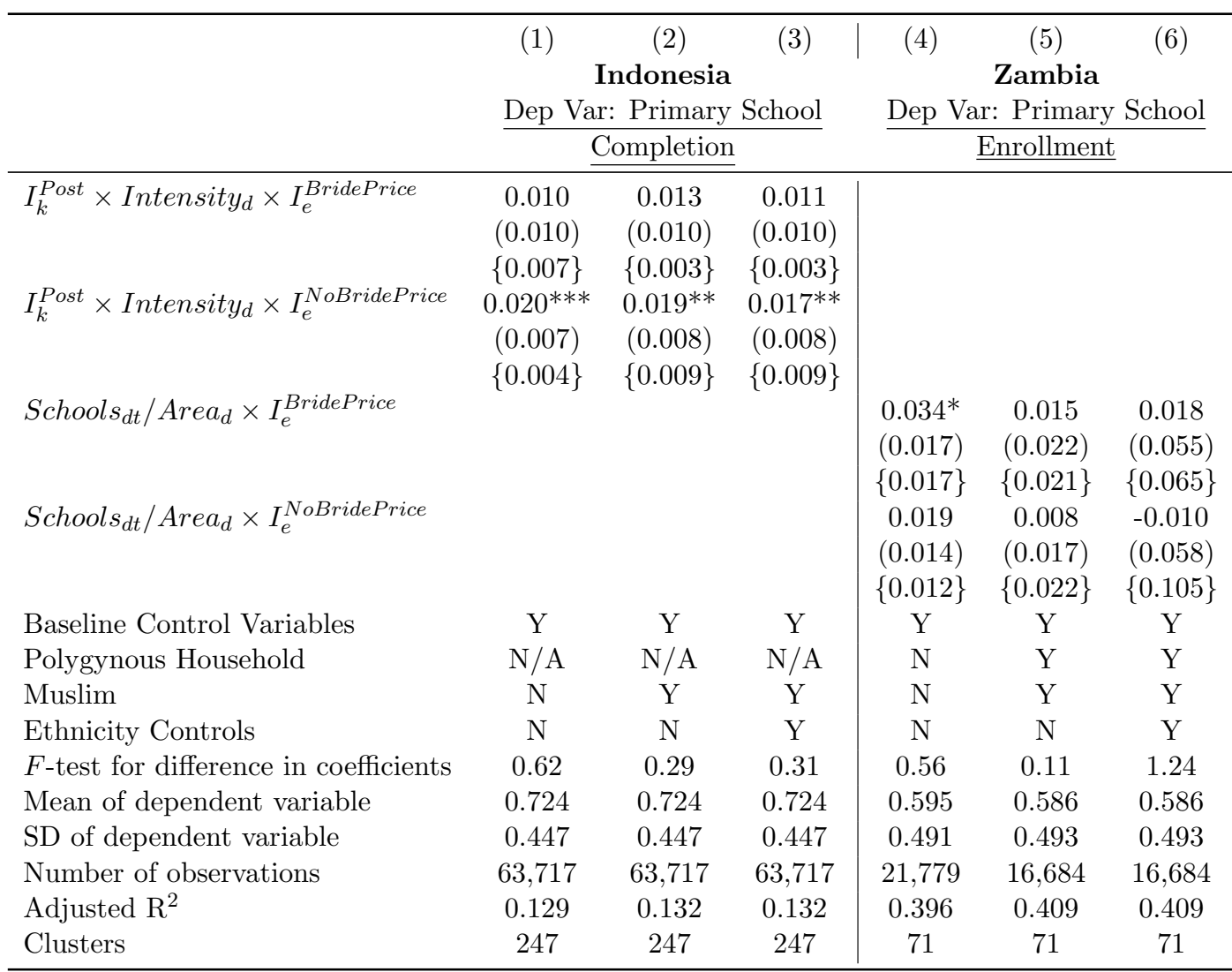

Notes: This table estimates the specifications of columns 2, 5, and 6 of Tables 7 and 8 using a sample of males. The data for Indonesia are from the 1995 Intercensus. The data for Zambia are from the pooled 1996, 2001, 2007, and 2013 DHS. 'Baseline Control Variables' consist of the control variables that are included in all specifications in the regressions of Tables 7 and 8 . These are slightly different for the two samples and are described in detail in the notes of the two tables. 'Polygynous Household' is an indicator variable that equals one if the boy/man lives in a polygynous household. Since the Intercensus does not contain any households that report being polygynous, this control drops out of the Indonesia regressions. 'Muslim' is an indicator variable equal to one if the man selfreports being Muslim. 'Ethnicity Controls' consist of indicator variables for an individual belonging to an ethnic group that is matrilineal and that traditionally had female dominated agriculture. Standard errors clustered at the ethnicity level are reported in parentheses, while Conley standard errors with a distance cut-off of $400 \mathrm{~km}$ are reported in curly brackets. ${ }^{*}, * *$, and ${ }^{* *}$ indicate significance at the 10,5 , and $1 \%$ levels according to the clustered standard errors.

Our findings are particularly important given that greater female education is widely believed to be the development outcome with one of the highest, if not the highest, economic and social returns. For example, Sperling and Winthorp (2016, p. 4) write that "girls' education is the world's best investment with the widest-ranging returns." They cite returns to education for both incomes and economic growth, as well as for infant mortality, maternal mortality, child marriage, health, and agricultural productivity. Despite these benefits, in sub-Saharan Africa, only $66 \%$ of females complete primary school, and completion rates are below $50 \%$ in many countries. ${ }^{52}$ In addition, these enrollment rates, and their growth over recent decades, mask low school attendance and low quality instruction (Pritchett, 2013). Therefore, better understanding what policies and mechanisms

\footnotetext{
${ }^{52}$ The figures refer to 2014 and are from the World Bank's World Development Indicators.
} 
can contribute to raising female education in developing countries is important for economists and policymakers alike.

Our theoretical model suggests a compelling economic interpretation of our findings. The custom of bride price allows parents to enjoy (part of) the returns to education that their daughters accrue in the marriage market, and thus it encourages parents to educate them. Indeed, we provide the first empirical evidence that bride price payments are substantially larger for more educated women and that parents are aware of this relationship and perceive it as causal.

To measure the magnitude of the association between female education and bride price in Indonesia, we use the IFLS data from Indonesia, which is our most comprehensive source of data on bride price payment amounts, to normalize the bride price returns to female education. Combining the IFLS data with data on per-capita consumption and Indonesia's CPI from the World Bank, we find that the bride price premium - that is, the extra payment parents receive if they educate their daughter - for a daughter completing primary school is equal to $24 \%$ of per capita annual consumption. ${ }^{53}$ Assuming an $8 \%$ discount rate and an 8-year delay between the completion of primary school and marriage, the net present value of the bride price premium at the time of educational investment corresponds to $\frac{1}{(1+0.08)^{8}} \cdot 0.24=12.5 \%$ of annual per capita consumption. In the same IFLS sample, bride price females are 2 percentage points more likely to complete primary school than non-bride females. Thus, this premium is associated with 2 percentage points higher rate of primary school completion for bride price ethnic groups compared to other groups.

Our findings suggest that customs and institutions that allow parents to partake in the returns to their children's education can promote investments in human capital by helping to complete the intergenerational contract between parents and children. Gary Becker proposed just such a role for the practice of bride price, writing, "Bride price then not only compensates parents for the transfer of their property, but also induces them to invest optimally in daughters if girls with appropriate accumulations of human capital command sufficiently high prices" (Becker, 1981, p. 129). Individual and public educational investments in developing countries may, therefore, be hampered when parents cannot capture the returns to these investments. This may be a particularly important obstacle for female education. In many developing countries, including India and China, sons remain in their parents' lineage group and care for them later in life, giving parents an incentive to educate sons (e.g., Bau, 2016; Jayachandran and Pande, 2017). By contrast, daughters typically leave their parents' household and join their husband's lineage group, which exacerbates the incomplete contracting

\footnotetext{
${ }^{53}$ This is based on the difference in mean bride price amounts for those with and without primary schooling in the IFLS data, after the data have normalized to be in terms of percent of consumption.
} 
problem in intergenerational investment.

Our study also add new insights to the lively public debate that has ensued over the past decades about the potentially negative consequences of the bride price custom. Critics of bride price traditions suggest that they are equivalent to the buying and selling of women and lead wives to be poorly treated. They argue that parents may have an incentive to "sell" their daughters early for bride price, and women may feel that they cannot leave a marriage because their parents would have to return the payment. ${ }^{54}$ In Indonesia, concerns have been raised about women continually needing to "earn" their bride price through obedience to their husbands (Sitompul, 2009). Citing pervasive anecdotes of domestic violence associated with the practice, activist groups around the world have called for the abolishment of bride price (Eryenyu, 2014; IRIN News, 2006). In addition to these potential negative consequences of bride price, our results indicate that bride price payments may also provide significant incentives to invest in daughters' human capital, working to raise aggregate welfare.

In considering the effects of bride price for women, it is important to understand that the net effects of the bride price on women's welfare are ambiguous. As our model indicates, from a static, ex post perspective, the practice grants property rights over the marital transfers to the bride's family rather than to the bride herself. However, from a dynamic perspective, bride price can also raise women's welfare if girls receive more education and accrue the benefits in the labor market for themselves. These considerations may indeed become more important as women's labor market and marriage market returns to education increase. Hence, in the absence of offsetting policies promoting female education, proposed changes to this practice, such as an attempt to ban bride price in Kenya in 2012 and in Uganda in 2015, may have unintended negative consequences for women and society.

Beyond improving our understanding of the relationship between female education, intergenerational transfers, and marriage markets, the findings in the paper also make a broader point. They provide one concrete example of how the cultural context of a society can influence the efficacy of development policies. Indeed, if policy makers in Indonesia or Zambia were evaluating the effects of their school construction programs on girls' education, they would get dramatically different answers depending on which groups they were examining. If they studied ethnic groups that do not have bride price, they would conclude that the program was unsuccessful at improving female education. If they studied bride price groups, they would conclude that it was instead effective.

\footnotetext{
${ }^{54}$ Corno and Voena (2016) document that, in the Kagera region of Tanzania, where bride price payments are customary, idiosyncratic negative rainfall shocks lead to increases in female child marriages. Corno et al. (2017) find large positive effects of (aggregate) droughts on female child marriages throughout Sub-Saharan Africa, and especially in bride price countries. In India instead, where dowry is prevalent, droughts lead to a decline in female child marriages.
} 
From an evaluation perspective, the exact nature of this relationship (including whether it is truly a causal effect of bride price) is not necessarily relevant. Even if the bride price is just a correlate or a proxy for other more fundamental cultural traits, it provides an observable characteristic that can be used when designing and evaluating the effects of education policies. In developing countries that also have variation in marriage customs, policy makers should be aware of the possibility that bride price and non-bride price groups will likely respond very differently to school construction. For non-bride price groups, simply building schools may not be enough to educate girls. Instead, school construction may have to be combined with conditional cash transfers or additional subsidies, such as free school uniforms or scholarships, in order to have a discernible effect on the educational attainment of girls (Baird et al., 2011; Duflo et al., 2015, 2017).

\section{Concluding remarks}

Our analysis has documented a (perhaps surprising) economic consequence of bride price, which is a payment made by the husband and/or his family to the wife's parents at marriage. We began our analysis by developing a model of educational choice with and without the practice of bride price. The model developed a number of testable predictions that we tested using data for two countries, Indonesia and Zambia, that were chosen because they had large-scale school construction projects and because they have within-country variation in whether bride price is practiced.

Consistent with the predictions of our model, we found that more educated daughters command a higher bride price. As a consequence of this added monetary benefit to education, girls belonging to bride price ethnic groups are also more likely to be educated. We also find that, consistent with the model, bride price ethnic groups are more responsive than non-bride price ethnic groups to policies that are aimed at increasing female education. In Indonesia, we revisited the Sekolah Dasar INPRES school construction program and found that, for bride price ethnic groups, the increased supply of schools resulted in a significant increase in female education. However, for those without the bride price custom, the program had no effect on female education. We examined a similar schoolconstruction project in Zambia and found the same effects. The project increased the educational attainment of girls from bride price ethnic groups, but had no effect on girls from non-bride price ethnicities.

In addition to improving our understanding of the relationship between marriage customs, marriage markets, and education, our findings illustrate the importance of the cultural context of developing countries for the efficacy of development projects. They also show that the cultural factors 
that are important for policy purposes are not always ex ante intuitive. In the context of educational policies, it is not immediately obvious that marriage customs would play a role. Thus, our findings highlight the importance of adopting a holistic approach when governments, policymakers, and NGOs consider new interventions. In other words, it is important to consider all aspects of the culture of a society when designing and evaluating policies, even those that are not obviously related to the outcomes of interest.

\section{References}

Agüero, Jorge M. and Prashant Bharadwaj, "Do the More Educated Know More about Health? Evidence from Schooling and HIV Knowledge in Zimbabwe," Economic Development and Cultural Change, 2014, 62 (3), 489-517.

Algan, Yann and Pierre Cahuc, "Inherited Trust and Growth," American Economic Review, 2010, 100 (5), 2060-2092.

Ambrus, Attila, Erica Field, and Maximo Torero, "Muslim Family Law, Prenuptial Agreements, and the Emergence of Dowry in Bangladesh," Quarterly Journal of Economics, 2010, 125 (3), 1349-1397.

Anderson, Siwan, "Why Dowry Payments Declined with Modernization in Europe but are Rising in India," Journal of Political Economy, 2003, 111 (2), 269-310.

_ , "The Economics of Dowry and Brideprice," Journal of Economic Perspectives, 2007, 21 (4), 151-174.

_ , "Why the Marriage Squeeze Cannot Cause Dowry Inflation," Journal of Economic Theory, 2007, 137, $140-152$.

- and Chris Bidner, "Property Rights over Marital Transfers," 2016. Quarterly Journal of Economcis, forthcoming.

Arunachalam, Raj and Suresh Naidu, "The Price of Fertility: Marriage Markets and Family Planning in Bangladesh," 2015.

Ashraf, Nava, Erica Field, Giuditta Rusconi, Alessandra Voena, and Roberta Ziparo, "Traditional beliefs and learning about maternal risk in Zambia," American Economic Review, 2017, 107 (5), 511-515.

Atkin, David, "The Caloric Cost of Culture: Evidence from Indian Migrants," American Economic Review, 2016, 106 (4), 1144-1181.

Baird, Sarah, Craig McIntosh, and Berk Özler, "Cash or condition? Evidence from a cash transfer experiment," The Quarterly Journal of Economics, 2011, 126 (4), 1709-1753.

Bau, Natalie, "Can Policy Crowd Out Culture?," 2016. Mimeo, Harvard University.

Becker, Gary S., "A Theory of Marriage: Part I," Journal of Political Economy, 1973, pp. 813-846.

_, A Treatise on the Family, Cambridge, M.A.: Harvard University Press, 1981.

_ , "Nobel Lecture: The Economic Way of Looking at Behavior," Journal of Political Economy, 1993, 101 (3), $385-409$.

_, William H.J. Hubbard, and Kevin M. Murphy, "Explaining the Worldwide Boom in Higher Education of Women," Journal of Human Capital, 2010, 4 (3), 203-241. 
Behrman, Jere R, Andrew D Foster, Mark R Rosenweig, and Prem Vashishtha, "Women's schooling, home teaching, and economic growth," Journal of political Economy, 1999, 107 (4), 682-714.

Bishai, David and Shoshana Grossbard, "Far above Rubies: Bride Price and Extramarital Sexual Relations in Uganda," Journal of Population Economics, 2010, 23 (4), 1177-1187.

Boomgaard, Peter, "Bridewealth and Birth Control: Low Fertility in the Indonesian Archipelago, 15001900," Population and Development Review, 2003, 29 (2), 197-214.

Boserup, Ester, Woman's Role in Economic Development, London: George Allen and Unwin Ltd., 1970.

Botticini, Maristella and Aloysius Siow, "Why Dowries?," American Economic Review, 2003, 93 (4), $1385-1398$.

Breierova, Lucia and Esther Duflo, "The Impact of Education on Fertility and Child Mortality: Do Fathers Really Matter Less than Mothers?," 2002. Mimeo, M.I.T.

Card, David, "Earnings, Schooling, and Ability Revisited," 1994. NBER Working Paper 4832.

Chiappori, Pierre-André, Bernard Salanié, and Yoram Weiss, "Partner Choice, Investment in Children, and the Marital College Premium," American Economic Review, August 2017, 107 (9), 2109-67.

_ , Monica Costa Dias, and Costas Meghir, "The marriage market, labor supply and education choice," Technical Report, National Bureau of Economic Research 2016.

_ , Murat Iyigun, and Yoram Weiss, "Investment in Schooling and the Marriage Market," American Economic Review, 2009, 99 (5), 1689-1713.

Choo, Eugene and Aloysius Siow, "Who Marries Whom and Why," Journal of Political Economy, 2006, $114(1), 175-201$.

Collier, Paul, "Culture, Politics, and Economic Development," Annual Review of Economics, 2017, 20, 111125.

Corno, Lucia and Alessandra Voena, "Selling Daughters: Age of Marriage, Income Shocks and Bride Price Tradition," Unpublished Manuscript 2016.

_, Nicole Hildebrandt, and Alessandra Voena, "Age of Marriage, Weather Shocks, and the Direction of Marriage Payments," Technical Report, National Bureau of Economic Research 2017.

Dalton, George, "“Bridewealth" vs."Brideprice” 1," American Anthropologist, 1966, 68 (3), 732-738.

Divale, William Tulio and Marvin Harris, "Population, Warfare, and the Male Supremacist Complex," American Anthropologist, 1976, 78 (3), 521-538.

Duflo, Esther, "Schooling and Labor Market Consequences of School Construction in Indonesia: Evidence from an Unusual Policy Experiment," American Economic Review, 2001, 91 (4), 795-813.

_, Pascaline Dupas, and Michael Kremer, "Education, HIV, and early fertility: Experimental Evidence from Kenya," American Economic Review, 2015, 105 (9), 2757-2797.

_ , _, and _ , "The Impact of Free Secondary Education: Experimental Evidence from Ghana," Technical Report, Working Paper 2017.

Eryenyu, Jeff, "Payment of Bride Price Turns Women into Commodities," September 2014. Uganda Daily Monitor. [Online; posted 10-September-2014].

Fabinger, Michal and E. Glen Weyl, "Pass-Through and Demand Forms," Working Paper 2013.

Fernandez, Raquel, "Women, Work and Culture," Journal of the European Economic Association, 2007, 5 (2-3), 305-332. 
_ , "Does Culture Matter?," in Jess Benhabib, Matthew O. Jackson, and Alberto Bisin, eds., Handbook of Social Economics, Vol. 1A, Amsterdam: North-Holland, 2011, pp. 481-510.

- and Alessandra Fogli, "Culture: An Empirical Investigation of Beliefs, Work, and Fertility," American Economic Journal: Macroeconomics, 2009, 1 (1), 146-177.

Gale, William G. and John Karl Scholz, "Intergenerational Transfers and the Accumulation of Wealth," Journal of Economic Perspectives, 1994, 8 (4), 145-160.

Gaspart, Frederic and Jean-Philippe Platteau, "Strategic Behavior and Marriage Payments: Theory and Evidence from Senegal," Economic Development and Cultural Change, 2010, 59 (1), 149-185.

Goldin, Claudia, "The Quiet Revolution That Transformed Women's Employment, Education, and Family," The American Economic Review, 2006, 96 (2), 1-21.

Goody, Jack and S.J. Tambiah, Bridewealth and Dowry, Cambridge: Cambridge University Press, 1973.

Griliches, Zvi, "Estimating the Returns to Schooling: Some Econometric Problems," Econometrica, 1977, $45(1), 1-22$.

Grossbard, Amyra, "Towards a Marriage between Economics and Anthropology and a General Theory of Marriage," American Economic Review, 1978, 68 (2), 33-37.

Heckman, James J., Lance J. Lochner, and Petra E. Todd, "Earnings Functions, Rates of Return and Treatment Effects: The Mincer Equation and Beyond," Handbook of the Economics of Education, 2006, 1, $307-458$.

Hertz, Tom and Tamara Jayasundera, "School Construction and Intergenerational Mobility in Indonesia," Working Paper, American University 2007.

IRIN News, "Study Links Payment of Bride Price to Abuse of Women," May 2006. [Online; posted 16-May2006].

Iyigun, Murat and P. Randall Walsh, "Building the Family Nest: Premarital Investments, Marriage Markets, and Spousal Allocations," Review of Economic Studies, 2007, 74 (2), 507-535.

Jacoby, Hanan G., "The Economics of Polygyny in Sub-Saharan Africa: Female Productivity and the Demand for Wives in Côte d'Ivoire," Journal of Political Economy, 1995, 103 (5), 938-971.

Jayachandran, Seema and Rohini Pande, "Why are Indian Children So Short? The Role of Birth Order and Son Preference," American Economic Review, 2017, 107, 2600-2629.

La Ferrara, Eliana and Annamaria Milazzo, "Customary Norms, Inheritance and Human Capital: Evidence from a Reform of the Matrilineal System in Ghana," 2011. Working paper.

Lavy, Victor, "School Supply Constraints and Children's Educational Outcomes in Rural Ghana," Journal of Development Economics, 1996, 51 (2), 291-314.

LeBar, Frank M., Ethnic Groups of Insular Southeast Asia. Volume 1: Indonesia, Adaman Islands, and Madagascar, New Haven: Human Relations Area Files Press, 1972.

Levine, David and Michael Kevane, "Are Investments in Daughters Lower when Daughters Move Away? Evidence from Indonesia," World Development, 2003, 31 (6), 1065-1084.

Lowes, Sara, "Matrilineal Kinship and Spousal Cooperation: Evidence from the Matrilineal Belt," 2017. Working paper.

- and Nathan Nunn, "Bride Price and the Wellbeing of Women," 2017. UN WIDER Working Paper $2017 / 131$. 
Mocan, Naci H. and Colin Cannonier, "Empowering Women Through Education: Evidence from Sierra Leone," 2012. NBER Working Paper 18016.

Moore, Erin, "Translating Girls' Empowerment: Gender, Adolescence and Transnational NGOs in Urban Uganda," PhD Dissertation, University of Chicago 2016.

Mujuzi, Jamil Ddamulira, "Bride Wealth (Price) and Women's Marriage - Related Rights in Uganda: A Historical Constitutional Perspective and Current Developments," International Journal of Law, Policy and the Family, August 2010, 24 (3), 414-430.

Murdock, George Peter, Ethnographic Atlas, Pittsburgh: University of Pittsburgh Press, 1967.

_, Atlas of World Cultures, Pittsburgh: University of Pittsburgh Press, 1981.

Osili, Una Okonkwo and Bridget Terry Long, "Does Female Schooling Reduce Fertility? Evidence from Nigeria," Journal of Development Economics, 2008, 87 (1), 57-75.

Pritchett, Lant, The Rebirth of Education: Schooling Ain't Learning, Washington, D.C.: CGD Books, 2013.

Quale, G. Robina, A History of Marriage Systems, New York: Greenwood Press, 1988.

RAND, "Family Life Surveys Newsletter," August 1999.

Rao, Vijayendra and Michael Walton, Culture and Public Action: A Cross-Disciplinary Dialogue on Development Policy, Palo Alto: Stanford University Press, 2004.

Schapera, Isaac, The Tswana, London: International African Institute, 1953.

Shapley, Lloyd S. and Martin Shubik, "The Assignment Game I: The Core," International Journal of Game Theory, 1971, 1 (1), 111-130.

Sitompul, Lola Utama, "Tata Cara Penetapan Mahar Bagi Perempuan Nias (Studi Kasus Pada Perempuan Nias Yang Bekerja di Sektor Informal di Padang Bulan)," 2009. Working paper.

Sperling, Gene B. and Rebecca Winthorp, What Works in Girls' Education, Brookings Institution Press, 2016.

Tertilt, Michele, "Polygyny, Fertility, and Savings," Journal of Political Economy, 2005, 113 (6), 1341-1371.

_ , "Polygyny, Women's Rights, and Development," Journal of the European Economic Association, 2006, 4 (2-3), 523-530.

Vroklage, Bernh, "Bride Price or Dower," Anthropos, 1952, Bd. 47, H. 1./2., 133-146.

Wendo, Charles, "African Women Denounce Bride Price," The Lancet, February 2004, 363 (9410), 716.

Whiteley, Wilfred and J. Slaski, Bemba and Related Peoples of Northern Rhodesia, London: International African Institute, 1950.

Willis, Roy, The Fipa and Related Peoples of South-West Tanzania and North-East Zambia, London: International African Institute, 1966.

World Bank, World Development Report 2015: Mind, Society, and Behavior, Washington, D.C.: World Bank Publications, 2015. 
Appendix for

\title{
Bride Price And Female Education
}

\author{
NAVA ASHRAF \\ London School of Economics and BREAD \\ NATALie BAU \\ University of Toronto \\ NATHAN NUNN \\ Harvard University, NBER, and BREAD \\ Alessandra Voena \\ University of Chicago, NBER, and BREAD
}

February 26, 2018 


\section{Appendix A: Data description}

\section{Indonesian Data Sources}

\section{Intercensal Survey}

The Indonesia Intercensal Survey is a large-scale, nationally representative population survey of Indonesia carried out between the 1990 and 2000 censuses. It is housed by the Minnesota Population Center (1995). Importantly, it includes data on primary language spoken, which can be linked to ethnicity and matched to an ethnic group's bride price custom in the Ethnographic Atlas. It also contains information on educational attainment, birth year, and birth district, which following Duflo (2001), can be combined with data on the number of schools built in 1974 as part of the large-scale school construction program.

\section{Indonesian Family Life Survey (IFLS)}

The Indonesian Family Life Survey (IFLS) is an ongoing longitudinal study of households in Indonesia covering over 30,000 individuals. Data is gathered from 13 of Indonesia's 27 provinces, and the study is considered representative of 83 percent of the Indonesian population. This paper uses data from rounds 3 and 4 of the IFLS (Strauss et al., 2004, 2009), which unlike previous rounds of the IFLS, includes questions about individuals' ethnicities.

\section{Census}

We use a 10 percent random extract of the 2010 Indonesia Census to replicate the results on the effects of the school construction program in a second, larger data set. This extract is also housed by the Minnesota Population Center (1995). We use a concordance between the ethnic groups in the census and the Ethnographic Atlas, to determine an individual's ethnicity level customs. Our sample of interest consists of the same cohorts analyzed in the Intercensal data (a treated group of individuals who were 2-6 in 1974, at the time of school construction, and an un-treated group of individuals who were $12-24$ at the time of school construction). 


\section{Zambian Data Sources}

\section{Data from the Zambia Fertility Preferences Study (ZFPS)}

Data on bride price amounts and beliefs about bride price and education are drawn from unique survey data collected in Lusaka in Fall 2014 as part of an experimental study on family planning. The study involves 715 couples (1,430 individuals) living in the catchment area of Chipata clinic, a poor peri-urban segment of Lusaka. Each spouse was interviewed in private and was asked a series of questions on the practice of lobola, leading to a total of 1,430 observations.

\section{Demographic and Health Survey (DHS)}

Our analysis pools the 1996, 2001, 2007, and 2013 rounds of the Zambia Demographic and Health Survey. When we analyze how school construction impacts school enrollment, we limit the sample to primary-school aged children (5-12) since most new schools are primary schools. The Appendix Table A11 reports summary statistics by brice price status. Once we control for district and cohort fixed effects (column 7), there are no significant differences in characteristics except for the likelihood of being in a polygynous household.

Additionally, data from the pooled DHS surveys allow us to test whether bride price is correlated with gender attitudes. ${ }^{1}$ To do so, we form two indices, pooling male and female respondents. The first index is the portion of times a respondent replied that a husband was not justified in beating his wife, and the second index is the portion of times a respondent said that a wife was justified in refusing a husband sex. ${ }^{2}$

\section{Ethnographic Data Sources}

Information on bride price practices is taken from the Ethnographic Atlas (Murdock, 1967) and LeBar (1972) for Indonesia and the Ethnographic Atlas (Murdock, 1967) and the Ethnographic Survey of Africa (Willis, 1966; Whiteley and Slaski, 1950; Schapera, 1938) for Zambia.

\footnotetext{
${ }^{1}$ The gender attitude questions were not asked in the 1996 DHS.

${ }^{2}$ The questions for the first index take the form, "Wife beating justified if..." The options were "if she goes out without telling him," "if she neglects the children," "if she argues with him," "if she refuses to have sex with him," and "if she burns the food." The questions in the second index take the form, "reason for not having sex:", and the possible answers are "husband has STD," "husband has other women," "recent birth" (only asked in 2001) and "tired, mood."
} 
Our primary analysis for Indonesia uses the 1995 Indonesia Intercensal Survey, which records 174 different spoken languages. These are matched to 44 ethnic groups from the Ethnographic Atlas and LeBar (1972). To undertake the matching, we exploited the previous matching of ethnic groups to languages undertaken by Alesina et al. (2013), where the 1,265 ethnic groups of the Ethnographic Atlas were matched to one of 7,612 language groups in the Ethnologue: Languages of the World (Gordon, 2005). All but 11 of the 172 language groups in the Indonesia Intercensal Survey could be matched to an ethnicity from our sources. These comprise 0.43 percent of the observations with non-missing language data.

Our baseline analysis for Zambia uses the four rounds of the Zambia Demographic and Health Surveys (1996, 2001, 2007, and 2013). The Zambia DHS reports 65 distinct ethnic groups. Of these, we are able to match 53 of them to 30 more-coarsely defined ethnic groups from the Ethnographic Atlas and the Ethnographic Survey of Africa (Willis, 1966; Whiteley and Slaski, 1950; Schapera, 1938). The remaining unmatched groups are small and comprise less than 2.5 percent of the DHS sample. The matching was done by hand, relying heavily on Murdock (1959).

The ethnicity-level control variables used in the analysis (female participation in agriculture and matrilineal descent) are taken from the Ethnographic Atlas. We create a measure of female participation in agriculture using variable $v 54$ ("sex differences: agriculture") from the Ethnographic Atlas. The original variable records ethnic groups as belonging to one of the following categories: (1) males only, (2) males appreciably more, (3) differentiated but equal participation, (4) equal participation, (5) female appreciably more, (6) females only, and (7) absent or unimportant activity. Using this information, we create a measure of female participation in agriculture that takes on the value of one for categories 5 and 6 and zero for all other categories. We also create a second indicator variable that equals one if either agriculture was not present or was unimportant - i.e., category (7) - or if information was missing for the ethnicity. In both cases, we are not able to observe female participation in agriculture.

A second control variable is a measure of the presence of matrilineal inheritance. This was based on variable $v 43$ ("descent: major type"). The original variable groups ethnicities into one of the following categories: (1) patrilineal, (2) duolateral, (3) matrilineal, (4) quasi-lineages, (5) ambilineal, (6) bilateral, and (7) mixed. We construct a matrilineal indicator variable that takes on the value of one if variable $v 43$ identifies an ethnic group as belonging to category 3 , and zero 
otherwise. Information on inheritance is never missing if bride price information is available.

\section{Appendix B: Additional Analyses}

\section{Instrumental variables regression for the bride price education premium}

This sections reports details of the specifications behind the estimates of the impact of education on bride price amounts, using the same procedure as in Duflo (2001), where school construction is used as an instrument for the educational attainment of women from bride price ethnic groups. We restrict our sample to ethnic groups that practice bride price. As we have shown, for non-bride price ethnic groups, there was no impact on female education and therefore no first-stage predictive power. In line with Duflo (2001), we allow the effect of school construction to vary by a child's age in 1974, restricting the effect to be 0 if a child was older than 12 in 1974. Following Duflo (2001), we also restrict the sample to those born between 1950 and 1972. Unfortunately, the resulting sample of couples from bride price ethnicities who were asked questions about bride price is only 264 .

The first-stage estimating equation is:

$$
\begin{array}{r}
I(\text { Completed Primary })_{i d k t}=\alpha_{d}+\alpha_{k}+\alpha_{t}+\sum_{a=2}^{12} \beta_{a} \text { Intensity }_{d} \times I\left(\text { age }_{1974}=a\right)_{k} \\
+\sum_{j} \mathbf{X}_{d}^{\prime} \mathbf{I}_{k}^{j} \boldsymbol{\Gamma}_{j}+\epsilon_{i d k t},
\end{array}
$$

where $d$ denotes the district, $i$ denotes the individual, $t$ denotes the survey year, and $k$ denotes the cohort. $\alpha_{d}$ denotes district fixed effects, $\alpha_{k}$ cohort fixed effects, and $\alpha_{t}$ survey-round fixed effects. $\sum_{j} \mathbf{X}_{d}^{\prime} \mathbf{I}_{k}^{j} \boldsymbol{\Gamma}_{j}$ are the cohort-specific controls for the INPRES sanitation program, the enrollment rate in 1971, and the total number of school-aged children in 1971. In addition, we include a quadratic in age of marriage to account for the fact that bride prices are reported in nominal terms.

The second-stage equation is:

$$
y_{i d k t}=\alpha_{d}+\alpha_{k}+\alpha_{t}+\gamma I(\text { CompletedPrimary })_{i}+\sum_{j} \mathbf{X}_{d}^{\prime} \mathbf{I}_{k}^{j} \boldsymbol{\Gamma}_{j}+\mu_{i d k t},
$$

where the outcome variable $y_{i d k t}$ is the natural log of the bride price.

Appendix Table A5 reports the first stage for the 2SLS estimates. The instruments are jointly 
significant, but are weak ( $F$-statistic of 3.04). In the main text, Table 4 reports the second stage estimate of the effect of primary schooling on log bride price. The point estimate is imprecise, but it corroborates the results from the OLS regressions. Completing elementary school increases bride price payments by a statistically significant 233 percent.

\section{Differential returns to education}

An alternative explanation for the differential response of bride price ethnic groups to school construction is that the returns to education are higher. We test for this by checking whether the relationship between a women's level of education and either her employment status or her income is stronger for women from bride price cultures, relative to women from non-bride price cultures.

We estimate the following equation:

$$
\begin{aligned}
y_{i k e d}= & \alpha_{d}+\alpha_{k}+\beta_{1} I_{i}^{\text {Primary }}+\beta_{2} I_{i}^{\text {Primary }} \times I_{e}^{\text {BridePrice }} \\
& +\beta_{3} I_{i}^{\text {JuniorSecondary }}+\beta_{4} I_{i}^{\text {JuniorSecondary }} \times I_{e}^{\text {BridePrice }} \\
& +\beta_{5} I_{i}^{\text {SeniorSecondary }}+\beta_{6} I_{i}^{\text {SeniorSecondary }} \times I_{e}^{\text {BridePrice }}+\varepsilon_{\text {kied }}
\end{aligned}
$$

where $i$ indexes a woman between the ages of 25 and 45, e her ethnicity, $d$ her district, and $k$ her year-of-birth. $y_{i k e d}$ is a proxy for income. We describe these in further detail below. $I_{i}^{\text {Primary }}$ is an indicator variable that equals one if individual $i$ has completed primary school and attended junior secondary school, $I_{i}^{\text {JuniorSecondary }}$ is an indicator variable equal to 1 if an individual has

completed junior secondary school and attended upper secondary school, and $I_{i}^{\text {SeniorSecondary }}$ is an indicator for having attended college. $\alpha_{d}$ denotes district fixed effects, which are intended to capture district-level differences in the labor market, and $\alpha_{k}$ denotes year-of-birth fixed effects. We cluster our standard errors at the ethnicity-level and report wild cluster bootstrapped $p$-values in the square brackets.

The estimates are reported in Appendix Table A13. For the Indonesian sample (columns 1-3), our outcomes are an indicator variable that equals one if the individual is employed, the natural $\log$ of the wage among those employed in the formal sector, ${ }^{3}$ and the wealth index of a woman's household. ${ }^{4}$ For the Zambian sample (columns 4-6), we also examine an employment indicator,

\footnotetext{
${ }^{3}$ The Indonesia Intercensal data only report wages for formal sector employees.

${ }^{4}$ The wealth index is constructed by a principal components analysis including indicator variables for owning an
} 
as well as the wealth index that is calculated and reported directly in the Zambian DHS (now normalized to lie between 0 and 1), and an indicator variable if a woman's child (aged $0-5)^{5}$ is categorized as being severely stunted. ${ }^{6}$ Unfortunately, the Zambian DHS does not report wages.

Overall, we find no evidence of a differential return to education for women belonging to bride price ethnic groups. Unsurprisingly, we find that more education is associated with a higher likelihood of employment, higher wages, and greater household wealth. However, we find no strong evidence that these relationships are systematically different for women from bride price ethnicities. $^{7}$ In Appendix Table A13, we also report the estimate of the predicted effect of the bride price indicator on the outcome of interest for a woman with the average value of education for the sample, which is a $63 \%$ chance of graduating primary school in Indonesia and a $32 \%$ chance of attending junior secondary school in Zambia. In all but one case (employment in Zambia), we cannot reject a zero effect of bride price for a woman with average education. In the case of employment in Zambia, the point estimate is negative, which is consistent with the fact that our model suggests that more educated bride price girls are negatively selected relative to more educated non-bride price girls.

automobile, television, radio, stove, buffet, bicycle boat, and motorboat. The wealth index is the first principal component of the factor analysis, and has then been normalized to lie between 0 and 1 .

${ }^{5}$ Thus, the sample in column 6 is children aged $0-5$.

${ }^{6}$ Severe stunting indicates that a child has a height more than three standard deviations below the mean of the growth distribution for healthy children based on a study of six baseline countries chosen by the WHO - Brazil, India, Oman, Ghana, Norway and the USA.

${ }^{7}$ Although the coefficients of the interactions between educational attainment and bride price custom are not statistically significant, the point estimates suggest that returns to education may in fact be lower for girls in bride price groups. This pattern can be explained within our theoretical framework, where more lower-ability girls are educated in bride price groups than in non-bride price groups. While, in our model, ability only affects girls in the first period of their life, allowing lower ability girls to have lower returns to education later in life would account for these relationships in the data. 


\section{Appendix C: Appendix tables}

Table A1: Ethnic groups in our Indonesian sample and whether bride price is practiced

\begin{tabular}{llll}
\hline Ethnicity & $I_{e}^{\text {BridePrice }}$ & Ethnicity & $I_{e}^{\text {BridePrice }}$ \\
\hline BALINESE & 0 & ALORESE & 1 \\
CHAM & 0 & AMBONESE & 1 \\
DANI & 0 & BANGGAI & 1 \\
ENGGANO & 0 & BATAK & 1 \\
IBAN & 0 & BELU & 1 \\
JAVANESE & 0 & BUNGKU & 1 \\
KENYAH-KAYAN-KAJANG & 0 & DAWAN & 1 \\
KERAKI & 0 & GORONTALO & 1 \\
KUBU & 0 & ILI-MANDI & 1 \\
MARINDANI & KEI & 1 \\
MENTAWEIA & 0 & MACASSARE & 1 \\
MIMIKA & 0 & MALAYS & 1 \\
MINANGKAB & 0 & MANOBO & 1 \\
REJANG & 0 & MINAHASANS & 1 \\
SASAK & 0 & MUJU & 1 \\
SOROMADJA & 0 & MUNA & 1 \\
SUMBANESE & 0 & NIASANS & 1 \\
SUMBAWANE & 0 & PANTAR & 1 \\
SUNDANESE & 0 & ROTINESE & 1 \\
SUVANESE & 0 & SUGBUHANO & 1 \\
WAROPEN & 0 & TOBELORES & 1 \\
& 0 & TOMINI & 1 \\
& & TORADJA & 1 \\
\hline
\end{tabular}

Notes: The table reports the ethnic groups in our Indonesian sample (1995 Indonesia Intercensal data), as well as the value of the bride price indicator variable for that ethnic group, whereby the indicator equals 1 if they practice bride price and 0 if they do not. 
Table A2: Ethnic groups in our Zambian sample and whether bride price is practiced

\begin{tabular}{llll}
\hline Ethnicity & $I_{e}^{\text {BridePrice }}$ & Ethnicity & $I_{e}^{\text {BridePrice }}$ \\
\hline BEMBA & 0 & BWILE & 1 \\
BISA & 0 & ILA & 1 \\
CHEWA & 0 & IWA & 1 \\
CHOKWE & 0 & LUNGU & 1 \\
KAONDE & 0 & MAMBWE & 1 \\
KUNDA & 0 & MBUNDA & 1 \\
LALA & 0 & PL.TONGA & 1 \\
LAMBA & 0 & SALA & 1 \\
LOZI & 0 & SHONA & 1 \\
LUANO & 0 & SOLI & 1 \\
LUCHAZI & 0 & TUMBUKA & 1 \\
LUNDA (LUA) & 0 & & \\
LUNDA (LW) & 0 & & \\
LUVALE & 0 & & \\
NYANJA & 0 & & \\
SHILA & 0 & & \\
SWAKA & 0 & & \\
TABWA & 0 & & \\
USHI & 0 & & \\
\hline
\end{tabular}

Notes: The table reports the ethnic groups in our Zambian sample (1996, 2001, 2007, and 2013 Zambia Demographic and Health Surveys (DHS)), as well as the value of the bride price indicator variable for that ethnic group, whereby the indicator equals 1 if they practice bride price and 0 if they do not. 
Table A3: Correlations between bride price and other customs using a global sample

\begin{tabular}{lcccc}
\hline & $(1)$ & $(2)$ & $(3)$ & $(4)$ \\
& \multicolumn{3}{c}{ Dep Var: Bride } & Price Indicator \\
\hline Matrilineal & $-0.118^{* * *}$ & & & $-0.153^{* * *}$ \\
& $(0.042)$ & & & $(0.051)$ \\
Female Agriculture & & $0.109^{* * *}$ & & 0.062 \\
& & $(0.039)$ & & $(0.038)$ \\
Polygyny & & & $0.335^{* * *}$ & $0.397^{* * *}$ \\
& & & $(0.034)$ & $(0.041)$ \\
constant & $0.534^{* * *}$ & $0.489^{* * *}$ & $0.233^{* * *}$ & $0.199^{* * *}$ \\
& $(0.015)$ & $(0.023)$ & $(0.031)$ & $(0.036)$ \\
Number of observations & 1,246 & 716 & 1,219 & 708 \\
\hline
\end{tabular}

Notes: This table reports cross-ethnicity estimates of the relationship between the listed customs and the practice of bride price. The global data on traditional practices are from the Ethnographic Atlas (Murdock, 1967). Each column reports estimates from one regression where the dependent variable is an indicator variable that equals one if the ethnic group traditionally practices bride price. Robust standard errors are reported in parentheses. ${ }^{*}, * *$, and ${ }^{* * *}$ indicate significance at the 10,5 , and $1 \%$ levels. 
Table A4: Contemporary bride price payments and traditional customs in Indonesia and Zambia

\begin{tabular}{l|c|c}
\hline \multicolumn{2}{c}{ Panel A. Indonesian Sample } \\
\hline IFLS $(2000,2007)$ & $I_{e}^{\text {BridePrice }}=0$ & $I_{e}^{\text {BridePrice }}=1$ \\
\hline Number of observations & 4,643 & 1,877 \\
$\%(B P>0)$ & $91 \%$ & $92 \%$ \\
Mean (payment / per capita GDP) & $37 \%$ & $80 \%$ \\
Median (payment / per capita GDP) & $4 \%$ & $8.7 \%$ \\
\hline
\end{tabular}

Panel B. Zambian Sample

\begin{tabular}{l|c|c}
\hline ZFPS (2014) & $I_{e}^{\text {BridePrice }}=0$ & $I_{e}^{\text {BridePrice }}=1$ \\
\hline Number of observations & 524 & 179 \\
$\%(B P>0)$ & $77 \%$ & $86 \%$ \\
Mean (payment / per capita GDP) & $87 \%$ & $205 \%$ \\
Median (payment / per capita GDP) & $45 \%$ & $57 \%$ \\
\hline
\end{tabular}

Notes: This table reports summary statistics on the prevalence of bride price practices and the size of bride prices paid in Indonesia and Zambia. The table draws on data from the 2001 and 2007 rounds of the Indonesia Family Life Survey and from the ZFPS (Fall 2014). Bride price payments greater than 100 times GDP per capita (4 observations in Zambia and 43 observations in Indonesia) are dropped as these extreme values are likely due to data entry error. Bride price data are from the Ethnographic Atlas (Murdock, 1967) and LeBar (1972) for Indonesia and from the Ethnographic Atlas (Murdock, 1967) and the Ethnographic Survey of Africa (Willis, 1966; Whiteley and Slaski, 1950; Schapera, 1938) for Zambia. 
Table A5: First stage regression for instrumented effect of primary school completion on bride price values

\begin{tabular}{|c|c|}
\hline & $\begin{array}{c}\text { Dep Var: Indicator Variable for } \\
\text { Completion of Primary School } \\
\end{array}$ \\
\hline Intensity $_{d} \times I\left(\text { Age }_{1974}=2\right)_{i}$ & $\begin{array}{c}0.091 \\
(0.246)\end{array}$ \\
\hline Intensity $_{d} \times I\left(\text { Age }_{1974}=3\right)_{i}$ & $\begin{array}{c}0.028 \\
(0.183)\end{array}$ \\
\hline Intensity $_{d} \times I\left(\text { Age }_{1974}=4\right)_{i}$ & $\begin{array}{l}-0.392 \\
(0.266)\end{array}$ \\
\hline Intensity $_{d} \times I\left(\text { Age }_{1974}=5\right)_{i}$ & $\begin{array}{c}0.262 \\
(0.335)\end{array}$ \\
\hline Intensity $_{d} \times I\left(\text { Age }_{1974}=6\right)_{i}$ & $\begin{array}{c}0.183 \\
(0.648)\end{array}$ \\
\hline Intensity $_{d} \times I\left(\text { Age }_{1974}=7\right)_{i}$ & $\begin{array}{c}-0.256^{* *} \\
(0.120)\end{array}$ \\
\hline Intensity $_{d} \times I\left(A g e_{1974}=8\right)_{i}$ & $\begin{array}{l}-0.578 \\
(0.588)\end{array}$ \\
\hline Intensity $_{d} \times I\left(\text { Age }_{1974}=9\right)_{i}$ & $\begin{array}{l}-0.025 \\
(0.307)\end{array}$ \\
\hline Intensity $_{d} \times I\left(\text { Age }_{1974}=10\right)_{i}$ & $\begin{array}{l}-0.024 \\
(0.366)\end{array}$ \\
\hline Intensity $_{d} \times I\left(\text { Age }_{1974}=11\right)_{i}$ & $\begin{array}{c}0.206 \\
(0.231)\end{array}$ \\
\hline Intensity $_{d} \times I\left(\text { Age }_{1974}=12\right)_{i}$ & $\begin{array}{l}-0.376 \\
(0.427)\end{array}$ \\
\hline Survey-Year FE & $\mathrm{Y}$ \\
\hline District FE & $\mathrm{Y}$ \\
\hline Cohort FE & $\mathrm{Y}$ \\
\hline Duflo Controls & $\mathrm{Y}$ \\
\hline Marriage Age Controls & $\mathrm{Y}$ \\
\hline Ethnicity FE & $\mathrm{Y}$ \\
\hline Marriage-Year Controls & $\mathrm{Y}$ \\
\hline$F$-stat & 3.04 \\
\hline Number of observations & 264 \\
\hline Clusters & 93 \\
\hline Adjusted $\mathrm{R}^{2}$ & 0.259 \\
\hline
\end{tabular}

Notes: This table reports the first stage estimates for the effect of primary school completion on the bride price payment received at marriage; the second stage estimate is reported in table 4 of the main text. Following the specification used in Duflo (2001), we instrument for primary school completion with the interactions of treatment intensity and age in 1974 fixed effects. The sample is restricted to ethnic groups that practice bride price. Following Duflo (2001), we also restrict the sample to individuals born between 1950 and 1972, and allow the effect of school construction to vary by a child's age in 1974, restricting the effect to 0 if a child was older than 12 in 1974. $d$ denotes a birth district. The Duflo controls consist of cohort fixed effects interacted with the number of school-aged children in the district in 1971, cohort fixed effects interacted with the enrollment rate in 1971, and cohort fixed effects interacted with the regency-level implementation of a water and sanitation program under INPRES. These are the same controls as used in Duflo (2001). Standard errors are clustered at the district level. $*{ }^{* *}$, and ${ }^{* *}$ indicate significance at the 10,5 , and $1 \%$ levels. 
Table A6: Perceived reasons for why bride price payments increase with education in Zambia

\begin{tabular}{lccc}
\hline Reasons why bride price increases with education & $\begin{array}{c}(1) \\
\text { Unprompted } \\
\text { reason }\end{array}$ & $\begin{array}{c}(2) \\
\text { Prompted } \\
\text { reason }\end{array}$ & $\begin{array}{c}(3) \\
\text { Prompted } \\
\text { not reason }\end{array}$ \\
\hline Improves the bride's skills in the house & 212 & 476 & 716 \\
& $15.1 \%$ & $33.9 \%$ & $51 \%$ \\
Improves the bride's knowledge and skills as a mother & 171 & 600 & 625 \\
& $12.25 \%$ & $42.98 \%$ & $44.77 \%$ \\
Improves the woman's earning potential & 207 & 713 & 468 \\
Improves the literacy of children & $14.91 \%$ & $51.37 \%$ & $33.72 \%$ \\
& 85 & 725 & 573 \\
Bride's parents should to be compensated for investments & $6.15 \%$ & $52.42 \%$ & $41.43 \%$ \\
& 777 & 448 & 179 \\
Is associated with her parents being rich & $55.34 \%$ & $31.91 \%$ & $12.75 \%$ \\
Other reasons & 104 & 507 & 785 \\
& $7.45 \%$ & $36.32 \%$ & $56.23 \%$ \\
\hline
\end{tabular}

Notes: This table reports respondents' answers when asked why bride price increases with education. The data were collected by the authors as part of a special module implemented in the first wave of the ZFPS (Fall 2014). The sample comprises 715 couples interviewed in peri-urban Lusaka. An observation is an individual, either male or female. Respondents were first asked why bride price payments increase with education in Zambia unprompted and then were asked about specific reasons and could either agree or disagree. The unprompted responses are reported in column 1 and the prompted responses in columns 2 and 3. 


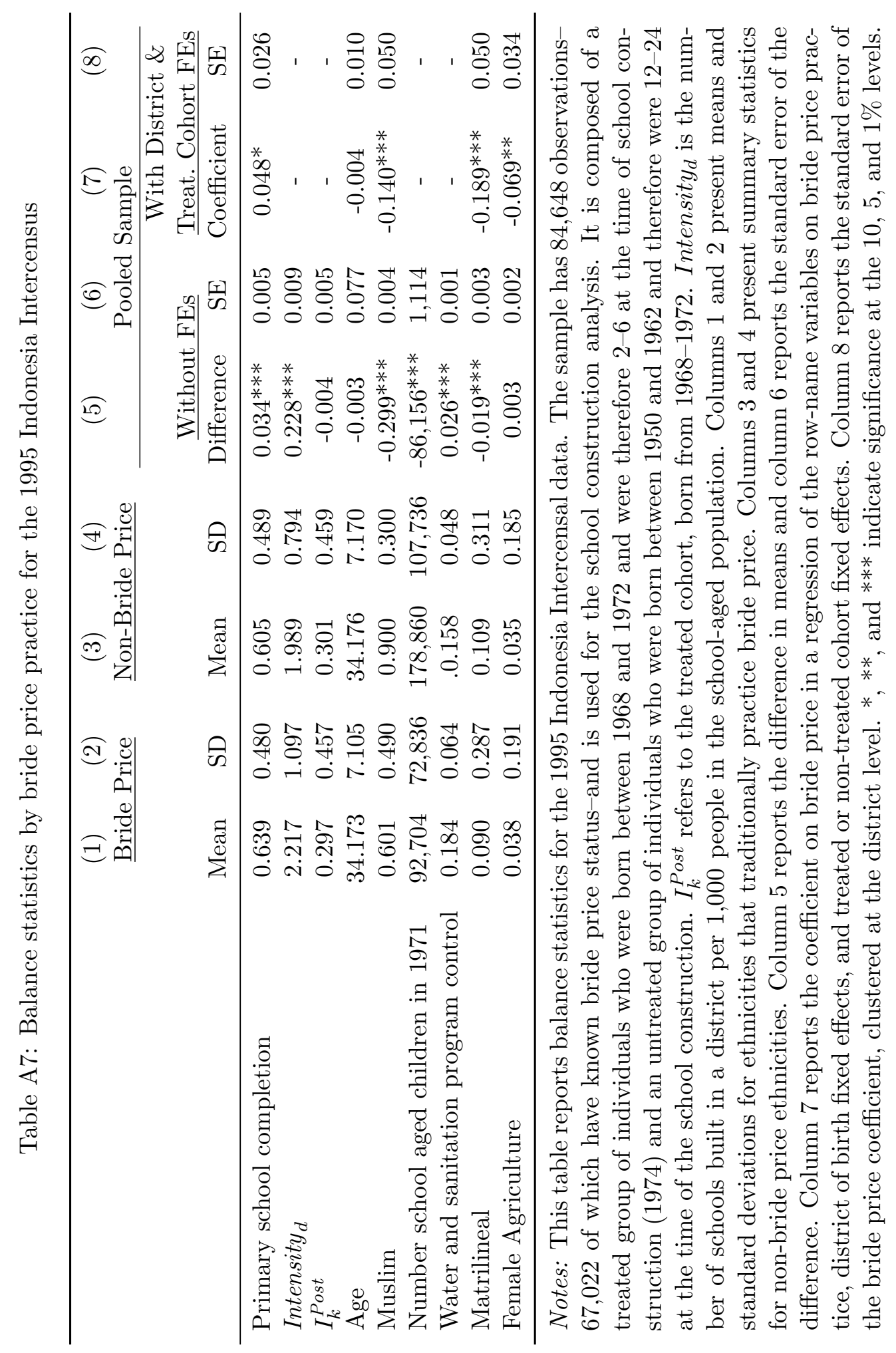


Table A8: Effect of bride price by religion in Indonesia school construction sample

(1)

Dep Var: Indicator Variable for Completion of Primary School

\begin{tabular}{|c|c|}
\hline$I_{k}^{\text {Post }} \times$ Intensity $_{d} \times I(\text { Muslim })_{i} \times I_{e}^{\text {BridePrice }}$ & $\begin{array}{c}0.023 \\
(0.018)\end{array}$ \\
\hline$I_{k}^{\text {Post }} \times$ Intensity $_{d} \times I(\text { Muslim })_{i}$ & $\begin{array}{l}-0.003 \\
(0.012)\end{array}$ \\
\hline$I_{k}^{\text {Post }} \times$ Intensity $_{d} \times I(\text { NonMuslim })_{i} \times I_{e}^{\text {BridePrice }}$ & $\begin{array}{c}0.047^{* * *} \\
(0.015)\end{array}$ \\
\hline$I_{k}^{\text {Post }} \times$ Intensity $_{d} \times I(\text { NonMuslim })_{i}$ & $\begin{array}{l}-0.011 \\
(0.010)\end{array}$ \\
\hline Ethnicity $\mathrm{FE} \times I_{k}^{\text {Post }}$ & $\mathrm{Y}$ \\
\hline 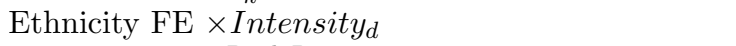 & $\mathrm{Y}$ \\
\hline District $\mathrm{FE} \times I_{e}^{\text {BridePrice }}$ & $\mathrm{Y}$ \\
\hline Duflo Controls $\times I_{e}^{\text {BridePrice }}$ & $\mathrm{Y}$ \\
\hline Muslim & $\mathrm{Y}$ \\
\hline Muslim $\times I_{k}^{\text {BridePrice }}$ & $\mathrm{Y}$ \\
\hline Muslim $\times$ Intensity ${ }_{d} \times I_{k}^{\text {Post }}$ & $\mathrm{Y}$ \\
\hline Duflo Controls & $\mathrm{Y}$ \\
\hline District FE & $\mathrm{Y}$ \\
\hline Cohort FE & $\mathrm{Y}$ \\
\hline$F$-test (joint significance of bride price effects) & 7.26 \\
\hline Number of observations & 65,403 \\
\hline Clusters & 240 \\
\hline Adjusted $\mathrm{R}^{2}$ & 0.187 \\
\hline
\end{tabular}

Notes: This table reports estimates of the effect of the INPRES school construction program on primary school completion, allowing for differences by religion (Muslim or not) and traditional bride price practice. Data on religion and educational attainment come from the 1995 Indonesia Intercensal Survey. Bride price data are from the Ethnographic Atlas (Murdock, 1967) and LeBar (1972). The F-test tests the joint significance of $I_{k}^{\text {Post }} \times$ Intensity $_{d} \times I(\text { Muslim })_{i} \times I_{e}^{\text {BridePrice }}$ and $I_{k}^{\text {Post }} \times$ Intensity $_{d} \times I(\text { NonMuslim })_{i} \times I_{e}^{\text {BridePrice }}$. The Duflo controls consist of cohort fixed effects interacted with the number of school-aged children in the district in 1971, cohort fixed effects interacted with the enrollment rate in 1971, and cohort fixed effects interacted with the regency-level implementation of a water and sanitation program under INPRES. These are the same controls as used in Duflo (2001). Standard errors are clustered at the birth district level. *, **, and $* * *$ indicate significance at the 10,5 , and $1 \%$ levels. 
Table A9: Bride price and the INPRES school expansion with effects by age in 1974

\begin{tabular}{|c|c|}
\hline & $\begin{array}{c}\text { Dep Var: Indicator Variable for } \\
\text { Completion of Primary School }\end{array}$ \\
\hline$I_{e}^{\text {BridePrice }} \times I\left(\text { Age }_{1974}=22 \text { to } 24\right)_{i}$ & $\begin{array}{c}0.004 \\
(0.014)\end{array}$ \\
\hline$I_{e}^{\text {BridePrice }} \times I\left(\text { Age }_{1974}=19 \text { to } 21\right)_{i}$ & $\begin{array}{c}0.009 \\
(0.017)\end{array}$ \\
\hline$I_{e}^{\text {BridePrice }} \times I\left(\text { Age }_{1974}=16 \text { to } 18\right)_{i}$ & $\begin{array}{c}0.013 \\
(0.011)\end{array}$ \\
\hline$I_{e}^{\text {BridePrice }} \times I\left(\text { Age }_{1974}=10 \text { to } 12\right)_{i}$ & $\begin{array}{c}0.004 \\
(0.013)\end{array}$ \\
\hline$I_{e}^{\text {BridePrice }} \times I\left(\text { Age }_{1974}=7 \text { to } 9\right)_{i}$ & $\begin{array}{c}0.007 \\
(0.010)\end{array}$ \\
\hline$I_{e}^{\text {BridePrice }} \times I\left(\text { Age }_{1974}=4 \text { to } 6\right)_{i}$ & $\begin{array}{c}0.029^{* * *} \\
(0.010)\end{array}$ \\
\hline$I_{e}^{\text {BridePrice }} \times I\left(\text { Age }_{1974}=1 \text { to } 3\right)_{i}$ & $\begin{array}{l}0.031^{*} \\
(0.016)\end{array}$ \\
\hline$I_{e}^{\text {BridePrice }} \times I\left(\text { Age }_{1974}=-2 \text { to } 0\right)_{i}$ & $\begin{array}{l}0.026^{* *} \\
(0.011)\end{array}$ \\
\hline$I_{e}^{\text {BridePrice }} \times I\left(\text { Age }_{1974}=-5 \text { to }-3\right)_{i}$ & $\begin{array}{c}0.053^{* * *} \\
(0.020)\end{array}$ \\
\hline$I_{e}^{\text {NoBridePrice }} \times I\left(\text { Age }_{1974}=22 \text { to } 24\right)_{i}$ & $\begin{array}{l}-0.004 \\
(0.011)\end{array}$ \\
\hline$I_{e}^{\text {NoBridePrice }} \times I\left(\text { Age }_{1974}=19 \text { to } 21\right)_{i}$ & $\begin{array}{l}-0.011 \\
(0.010)\end{array}$ \\
\hline$I_{e}^{\text {NoBridePrice }} \times I\left(\text { Age }_{1974}=16 \text { to } 18\right)_{i}$ & $\begin{array}{l}-0.011 \\
(0.010)\end{array}$ \\
\hline$I_{e}^{\text {NoBridePrice }} \times I\left(\text { Age }_{1974}=10 \text { to } 12\right)_{i}$ & $\begin{array}{l}-0.010 \\
(0.010)\end{array}$ \\
\hline$I_{e}^{\text {NoBridePrice }} \times I\left(\text { Age }_{1974}=7 \text { to } 9\right)_{i}$ & $\begin{array}{l}-0.008 \\
(0.010)\end{array}$ \\
\hline$I_{e}^{\text {NoBridePrice }} \times I\left(\text { Age }_{1974}=4 \text { to } 6\right)_{i}$ & $\begin{array}{l}-0.015 \\
(0.011)\end{array}$ \\
\hline$I_{e}^{\text {NoBridePrice }} \times I\left(\text { Age }_{1974}=1 \text { to } 3\right)_{i}$ & $\begin{array}{l}-0.002 \\
(0.012)\end{array}$ \\
\hline$I_{e}^{\text {NoBridePrice }} \times I\left(\text { Age }_{1974}=-2 \text { to } 0\right)_{i}$ & $\begin{array}{l}-0.004 \\
(0.012)\end{array}$ \\
\hline$I_{e}^{N o B r i d e P r i c e} \times I\left(\text { Age }_{1974}=-5 \text { to }-3\right)_{i}$ & $\begin{array}{c}0.011 \\
(0.012)\end{array}$ \\
\hline$F$-test for Bride Price Coeff. & 3.37 \\
\hline$F$-test for Non-Bride Price Coeff. & 1.12 \\
\hline Number of observations & 117,191 \\
\hline Clusters & 253 \\
\hline Adjusted $\mathrm{R}^{2}$ & 0.193 \\
\hline
\end{tabular}

This table reports the coefficients and standard errors from the regressions plotted in Figure 3 (the estimated relationships between school construction and primary school completion for different 3-year birth cohorts). Standard errors are clustered at the level of an individual's district of birth. ${ }^{*},{ }^{* *}$, and ${ }^{* *}$ indicate significance at the 10,5 , and $1 \%$ levels. 


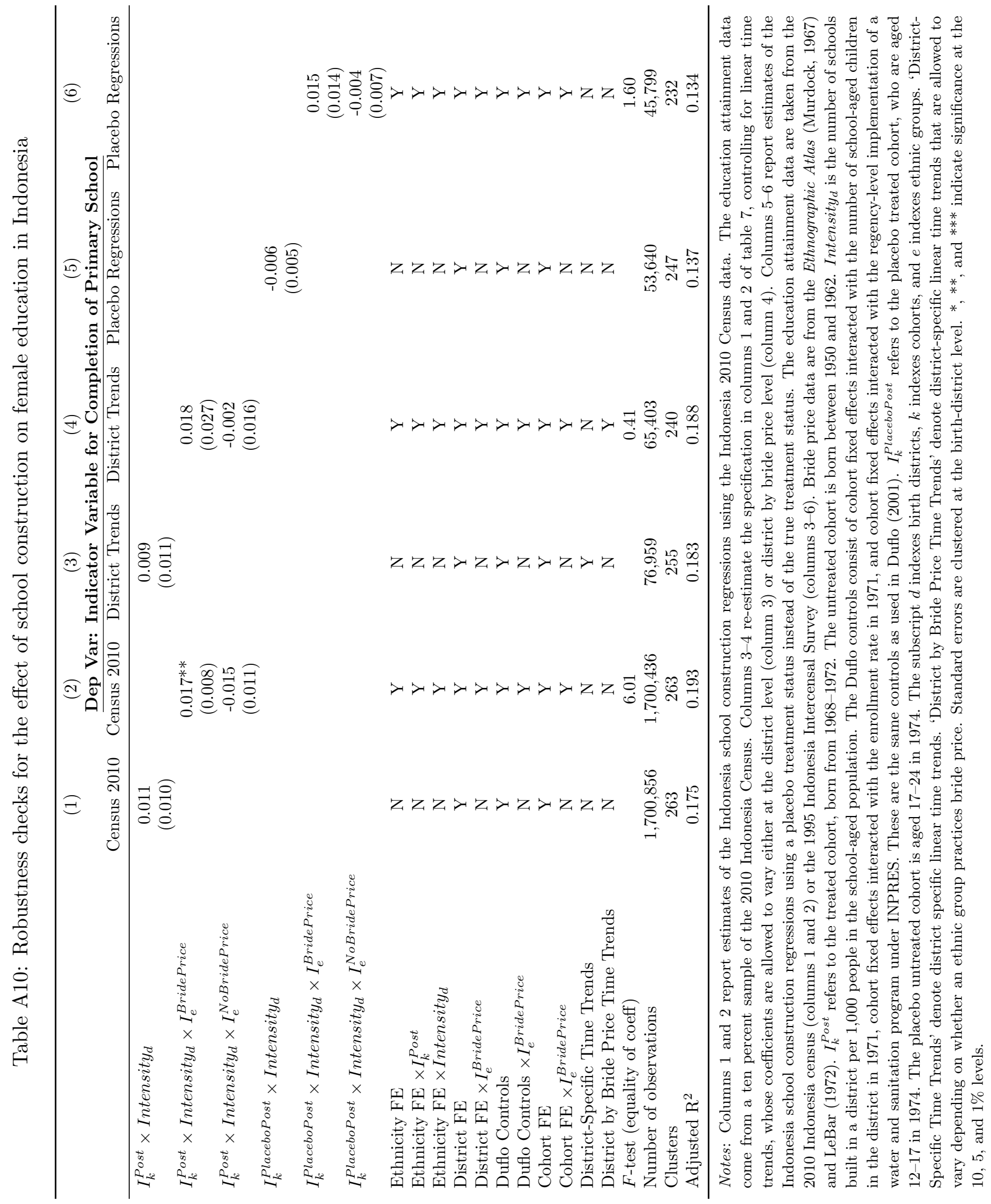




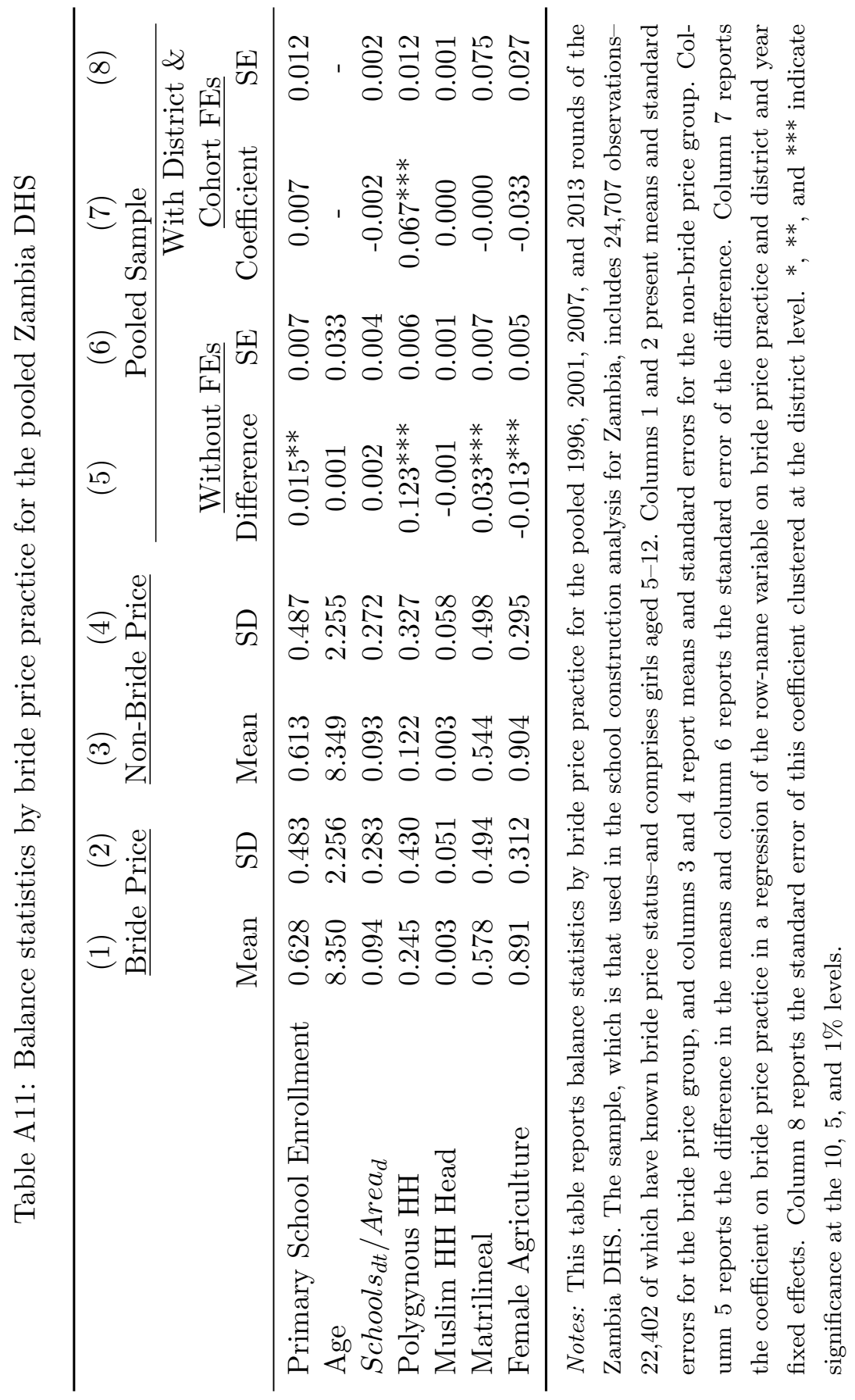


Table A12: Robustness checks for the effect of school construction on female education in Zambia

\begin{tabular}{|c|c|c|c|c|}
\hline \multirow[t]{2}{*}{ Dep Var: Indicator } & $\begin{array}{c}(1) \\
\text { Variable }\end{array}$ & $\begin{array}{c}(2) \\
\text { for Comp }\end{array}$ & $\begin{array}{l}(3) \\
\text { etion of Prir }\end{array}$ & $\begin{array}{c}(4) \\
\text { lary School }\end{array}$ \\
\hline & $\begin{array}{c}\text { District } \\
\text { Trends }\end{array}$ & $\begin{array}{l}\text { District } \\
\text { Trends }\end{array}$ & $\begin{array}{c}\text { Placebo } \\
\text { Regressions }\end{array}$ & $\begin{array}{c}\text { Placebo } \\
\text { Regressions }\end{array}$ \\
\hline Schools $_{d t} /$ Area $_{d}$ & $\begin{array}{c}0.022 \\
(0.126)\end{array}$ & & $\begin{array}{c}0.064 \\
(0.074)\end{array}$ & \\
\hline Schools $_{d t} /$ Area $_{d} \times I_{e}^{\text {BridePrice }}$ & & $\begin{array}{c}0.492^{* * *} \\
(0.176)\end{array}$ & & $\begin{array}{c}0.294^{* *} \\
(0.118)\end{array}$ \\
\hline Schools $_{d t} /$ Area $_{d} \times I_{e}^{\text {NoBridePrice }}$ & & $\begin{array}{l}-0.127 \\
(0.173)\end{array}$ & & $\begin{array}{l}-0.014 \\
(0.095)\end{array}$ \\
\hline Schools $_{d, t+1} /$ Area $_{d}$ & & & $\begin{array}{l}-0.063 \\
(0.083)\end{array}$ & \\
\hline Schools $_{d, t+1} /$ Area $_{d} \times I_{e}^{\text {BridePrice }}$ & & & & $\begin{array}{c}-0.227^{*} \\
(0.116)\end{array}$ \\
\hline Schools $_{d, t+1} /$ Area $_{d} \times I_{e}^{\text {NoBridePrice }}$ & & & & $\begin{array}{l}-0.012 \\
(0.105)\end{array}$ \\
\hline Age FE & $\mathrm{Y}$ & $\mathrm{Y}$ & $\mathrm{Y}$ & $\mathrm{Y}$ \\
\hline Age $\mathrm{FE} \times I_{e}^{\text {BridePrice }}$ & $\mathrm{N}$ & $\mathrm{Y}$ & $\mathrm{N}$ & $\mathrm{Y}$ \\
\hline Ethnicity by Year FE & $\mathrm{Y}$ & $\mathrm{Y}$ & $\mathrm{Y}$ & $\mathrm{Y}$ \\
\hline Ethnicity by District FE & $\mathrm{Y}$ & $\mathrm{Y}$ & $\mathrm{Y}$ & $\mathrm{Y}$ \\
\hline District-Specific Time Trends & $\mathrm{Y}$ & $\mathrm{N}$ & $\mathrm{N}$ & $\mathrm{N}$ \\
\hline District by Bride Price Time Trends & $\mathrm{N}$ & $\mathrm{Y}$ & $\mathrm{N}$ & $\mathrm{N}$ \\
\hline District $\mathrm{FE} \times I_{e}^{\text {BridePrice }}$ & $\mathrm{N}$ & $\mathrm{Y}$ & $\mathrm{N}$ & $\mathrm{N}$ \\
\hline$F$-test (equality of coeff) & & 5.69 & & \\
\hline Number of observations & 22,191 & 22,191 & 12,370 & 12,370 \\
\hline Clusters & 71 & 71 & 70 & 70 \\
\hline Adjusted $\mathrm{R}^{2}$ & 0.400 & 0.402 & 0.393 & 0.393 \\
\hline
\end{tabular}

Notes: Columns 1 and 2 re-estimate the effects of school construction in Zambia controlling for district-specific linear time trends, which are allowed to vary by bride price status. The regressions use girls aged 5-12 at the time of the survey in the pooled Zambia DHS surveys from 1996, 2001, 2007, and 2013. The subscript $d$ indexes districts, $k$ indexes cohorts, $e$ indexes ethnic groups, and $t$ indexes survey rounds. Columns 3-4 report estimates of the differential impact of present and future school construction in Zambia on bride price and non-bride price females. For these columns, we are unable to include the 2013 DHS, since we do not know how many schools will be built in the future. The treatment variable, Schools $s_{d t}$, is the number of schools built in a district $d$ by year $t$ (the survey round of the DHS). This is normalized by the area of the district, Area . Schools $_{d, t+1}$ is the number of schools built by 2001 in 1996 , the number of schools built by 2007 in 2001, and the number of schools built by 2013 in 2007. 'District-Specific Time Trends' denote district specific linear time trends. 'District by Bride Price Time Trends' denote district-specific linear time trends that are allowed to vary depending on whether an ethnic group practices bride price. Standard errors are clustered at the district level. *, **, and $* * *$ indicate significance at the 10,5 , and $1 \%$ levels. 
Table A13: Testing for differential returns to education for bride price and non-bride price women in Indonesia and Zambia

\begin{tabular}{|c|c|c|c|c|c|c|}
\hline & \multicolumn{3}{|c|}{ Indonesia } & \multicolumn{3}{|c|}{$\begin{array}{c}(5) \\
\text { Zambia }\end{array}$} \\
\hline & Employment & $\ln$ (Wage) & Wealth Index, 0-1 & Employment & Wealth Index, $0-1$ & Child Stunting \\
\hline$I_{i}^{\text {Primary }}$ & $\begin{array}{c}-0.059^{* * *} \\
(0.004) \\
{[0.002]}\end{array}$ & $\begin{array}{c}0.280^{* * *} \\
(0.014) \\
{[0.000]}\end{array}$ & $\begin{array}{c}0.121^{* * *} \\
(0.004) \\
{[0.000]}\end{array}$ & $\begin{array}{c}0.046^{* * *} \\
(0.013) \\
{[0.000]}\end{array}$ & $\begin{array}{c}0.097^{* * *} \\
(0.006) \\
{[0.000]}\end{array}$ & $\begin{array}{c}-0.044^{* * *} \\
(0.007) \\
{[0.002]}\end{array}$ \\
\hline$I_{i}^{\text {JuniorSecondary }}$ & $\begin{array}{c}0.091^{* * *} \\
(0.016) \\
{[0.000]}\end{array}$ & $\begin{array}{c}0.827 * * * \\
(0.028) \\
{[0.000]}\end{array}$ & $\begin{array}{c}0.163^{* * *} \\
(0.006) \\
{[0.000]}\end{array}$ & $\begin{array}{c}0.024 \\
(0.013) \\
{[0.108]}\end{array}$ & $\begin{array}{c}0.234^{* * *} \\
(0.005) \\
{[0.000]}\end{array}$ & $\begin{array}{c}-0.050^{* * *} \\
(0.005) \\
{[0.002]}\end{array}$ \\
\hline$I_{i}^{\text {SeniorSecondary }}$ & $\begin{array}{c}0.177^{* * *} \\
(0.019) \\
{[0.000]}\end{array}$ & $\begin{array}{c}0.183^{* * *} * \\
(0.015) \\
{[0.000]}\end{array}$ & $\begin{array}{c}0.053^{* *} \\
(0.012) \\
{[0.022]}\end{array}$ & $\begin{array}{c}0.217^{* * *} \\
(0.018) \\
{[0.000]}\end{array}$ & $\begin{array}{c}0.180^{* * *} \\
(0.014) \\
{[0.000]}\end{array}$ & $\begin{array}{c}-0.076^{* * *} \\
(0.014) \\
{[0.002]}\end{array}$ \\
\hline$I_{i}^{\text {Primary }} \times I_{e}^{\text {BridePrice }}$ & $\begin{array}{l}-0.001 \\
(0.017) \\
{[0.952]}\end{array}$ & $\begin{array}{c}0.157 \\
(0.094) \\
{[0.104]}\end{array}$ & $\begin{array}{l}-0.005 \\
(0.008) \\
{[0.600]}\end{array}$ & $\begin{array}{c}0.007 \\
(0.034) \\
{[0.856]}\end{array}$ & $\begin{array}{c}-0.017 \\
(0.013) \\
{[0.298]}\end{array}$ & $\begin{array}{c}0.054 \\
(0.026) \\
{[0.140]}\end{array}$ \\
\hline$I_{i}^{\text {JuniorSecondary }} \times I_{e}^{\text {BridePrice }}$ & $\begin{array}{c}0.050 \\
(0.031) \\
{[0.348]}\end{array}$ & $\begin{array}{l}-0.152 \\
(0.082) \\
{[0.073]}\end{array}$ & $\begin{array}{c}-0.023^{*} \\
(0.009) \\
{[0.062]}\end{array}$ & $\begin{array}{c}0.023 \\
(0.018) \\
{[0.270]}\end{array}$ & $\begin{array}{l}-0.013 \\
(0.009) \\
{[0.222]}\end{array}$ & $\begin{array}{c}0.002 \\
(0.019) \\
{[0.994]}\end{array}$ \\
\hline$I_{i}^{\text {SeniorSecondary }} \times I_{e}^{\text {BridePrice }}$ & $\begin{array}{l}-0.026 \\
(0.054) \\
{[0.672]}\end{array}$ & $\begin{array}{l}-0.026 \\
(0.042) \\
{[0.539]}\end{array}$ & $\begin{array}{l}-0.025 \\
(0.024) \\
{[0.432]}\end{array}$ & $\begin{array}{c}0.018 \\
(0.026) \\
{[0.486]}\end{array}$ & $\begin{array}{l}-0.008 \\
(0.026) \\
{[0.758]}\end{array}$ & $\begin{array}{l}-0.015 \\
(0.030) \\
{[0.642]}\end{array}$ \\
\hline$I_{e}^{\text {BridePrice }}$ & $\begin{array}{l}-0.029 \\
(0.027) \\
{[0.289]}\end{array}$ & $\begin{array}{l}-0.020 \\
(0.032) \\
{[0.542]}\end{array}$ & $\begin{array}{l}-0.014 \\
(0.108) \\
{[0.748]}\end{array}$ & $\begin{array}{l}-0.051 \\
(0.041) \\
{[0.336]}\end{array}$ & $\begin{array}{c}0.020 \\
(0.019) \\
{[0.304]}\end{array}$ & $\begin{array}{c}-0.045^{*} \\
(0.021) \\
{[0.054]}\end{array}$ \\
\hline District by Year FE & $\mathrm{Y}$ & $\mathrm{Y}$ & $\mathrm{Y}$ & $\mathrm{Y}$ & $\mathrm{Y}$ & $\mathrm{Y}$ \\
\hline Age Controls & $\mathrm{Y}$ & $\mathrm{Y}$ & $\mathrm{Y}$ & $\mathrm{Y}$ & $\mathrm{Y}$ & $\mathrm{Y}$ \\
\hline $\begin{array}{l}\text { Effect of } \mathrm{BP} \text { for women with average } \\
\text { education for sample }\end{array}$ & $\begin{array}{l}-0.030 \\
(0.033)\end{array}$ & $\begin{array}{c}0.080 \\
(0.059)\end{array}$ & $\begin{array}{l}-0.018 \\
(0.020)\end{array}$ & $\begin{array}{c}-0.037^{* * *} \\
(0.011)\end{array}$ & $\begin{array}{l}-0.001 \\
(0.018)\end{array}$ & $\begin{array}{c}0.010 \\
(0.008)\end{array}$ \\
\hline$F$-test of bride price interact coeffs & 4.96 & 1.39 & 3.30 & 1.10 & 1.35 & 2.33 \\
\hline Number of observations & 88,049 & 12,547 & 88,039 & 19,671 & 17,145 & 21,946 \\
\hline Clusters & 40 & 31 & 40 & 30 & 30 & 30 \\
\hline Adjusted $\mathrm{R}^{2}$ & 0.106 & 0.506 & 0.413 & 0.099 & 0.498 & 0.053 \\
\hline $\begin{array}{l}\text { Notes: This table reports estimates of the rel } \\
\text { The samples consist of women aged } 25-45 \text {, wi } \\
\text { donesia, educational attainment and labor me } \\
\text { child health outcomes data are taken from the } \\
\text { tor employees. } I_{i}^{\text {Primary }} \text { is an indicator varial } \\
\text { is an indicator variable equal to } 1 \text { if an indivi } \\
\text { one if the woman has any post-secondary edu } \\
\text { any college or university education. The row } \\
\text { of interest for a woman with the mean level } \\
\text { attending junior secondary school in Zambia. } \\
\text { procedure with } 1000 \text { draws are reported in s } \\
\text { significance at the } 10,5 \text {, and } 1 \% \text { levels accorc }\end{array}$ & $\begin{array}{l}\text { ationship between } \\
\text { th the exception o } \\
\text { arket outcomes da } \\
1996,2001,2007 \text {, } \\
\text { le that equals on } \\
\text { dual has complet } \\
\text { cation, which is n } \\
\text { "Effect of BP for } \\
\text { f education for th } \\
i \text { indexes a wom } \\
\text { quare brackets. S }\end{array}$ & $\begin{array}{l}\text { education and } \\
\text { ta column } 6 \text {, wh } \\
\text { and } 2013 \text { Dem } \\
\text { if individual } i \\
\text { ed junior secon } \\
\text { ot necessarily a } \\
\text { women with ave } \\
\text { e sample. This } \\
\text { an between the } \\
\text { tandard errors, }\end{array}$ & $\begin{array}{l}\text { other outcomes for bric } \\
\text { ich includes all children } \\
\text { m the } 1995 \text { Intercensal } \\
\text { graphic and Health Sur } \\
\text { has completed primary } \\
\text { dary school and attende } \\
\text { t the university level, w } \\
\text { rage education for samp } \\
\text { is an } 63.4 \% \text { chance of p } \\
\text { ages of } 25 \text { and } 45, e \text { her } \\
\text { clustered at the ethnici }\end{array}$ & $\begin{array}{l}\text { le price and non- } \\
\text { ages } 0-5 \text {. Age co } \\
\text { data. For Zambi } \\
\text { veys. Wage data } \\
\text { school and atten } \\
\text { d upper secondar } \\
\text { hile in Indonesia } \\
\text { le" reports the e } \\
\text { rimary school co } \\
\text { ethnicity. p-valı } \\
\text { ty level, are repo }\end{array}$ & $\begin{array}{l}\text { ride price women in Ind } \\
\text { trols consist of age and a } \\
\text { educational attainment } \\
\text { Indonesia are only repo } \\
\text { ed junior secondary scho } \\
\text { school. In Zambia, } I_{i}^{\text {Ser }} \\
\text { Senior Secondary equals or } \\
\text { imated effect of bride pr } \\
\text { sletion in Indonesia and } \\
\text { ted in parentheses. * } *\end{array}$ & $\begin{array}{l}\text { ge squared. For In- } \\
\text { labor market, and } \\
\text { rted for formal sec- } \\
\text { ol, } I_{i}^{\text {Junior Secondary }} \\
\text { iiorSecondary equals } \\
\text { le if the person has } \\
\text { ice on the outcome } \\
\text { a } 31.7 \% \text { chance of } \\
\text { d cluster bootstrap } \\
* \text {, and *** indicate }\end{array}$ \\
\hline
\end{tabular}




\section{Appendix E: Appendix Figures}

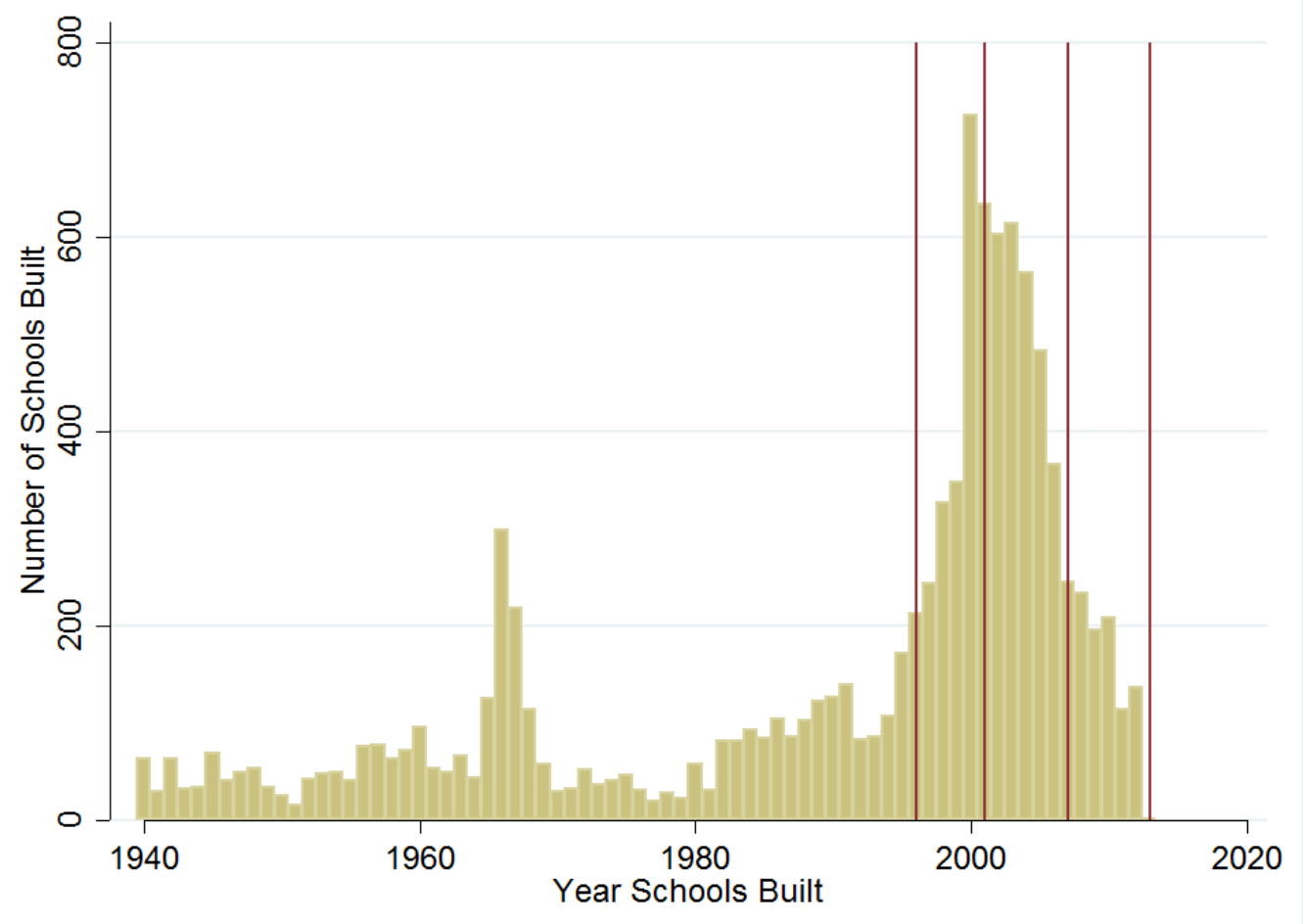

Figure A1: Number of schools constructed each year in Zambia (Ministry of Education, Government of Zambia). Vertical red lines indicate the years of the four rounds of the DHS. 


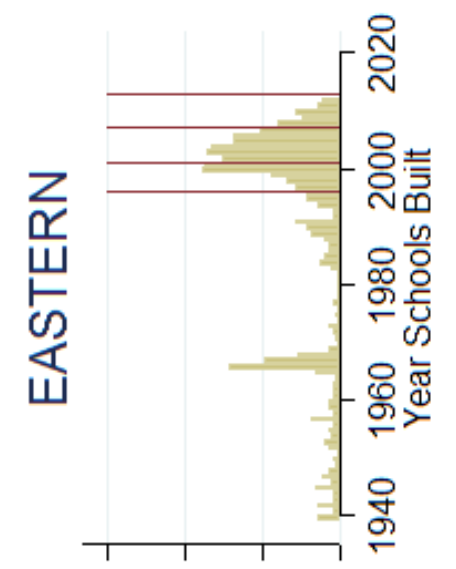

OSL OOL OS O t!!ng s|Oouगs to dequnN

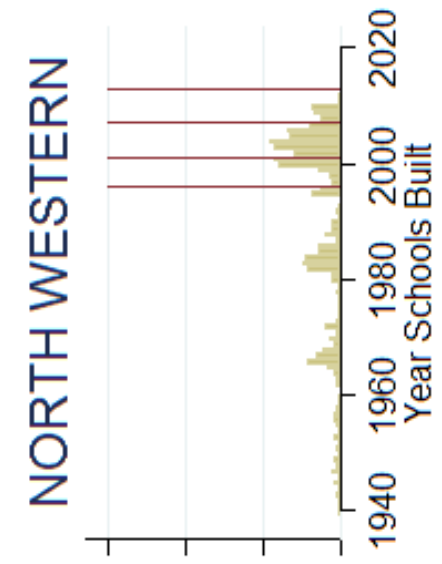

OSL OOL OS O H!ng s loouगs to dequnN

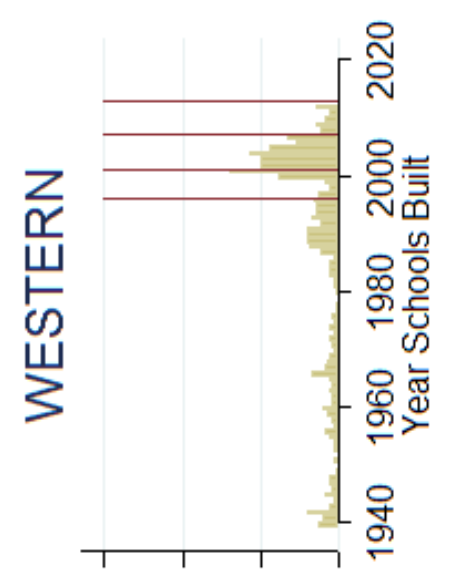

OSL OOL OS O t!!ng s|004ग्S to dəqunN

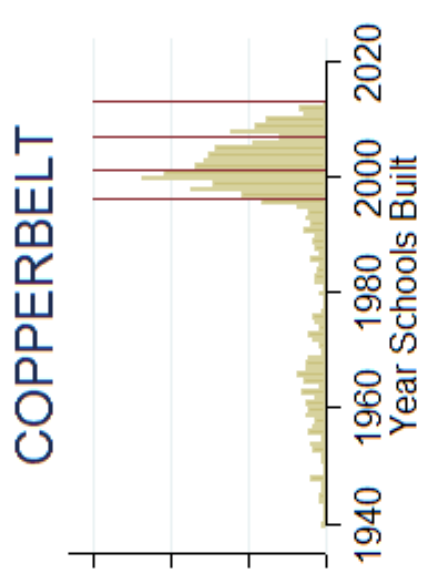

OSL OOL OS O H!ing s|004गS to dequnN

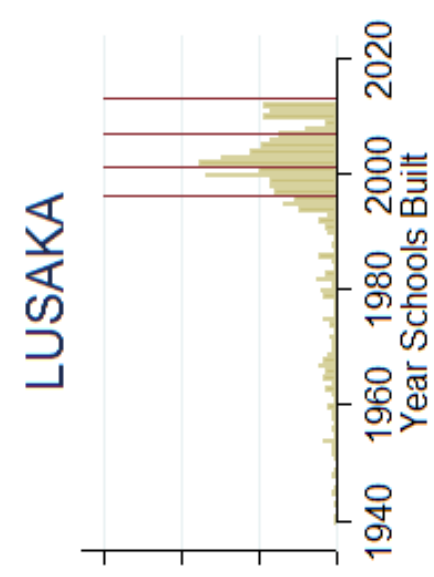

OSL OOL OS O H!!ng s|OOपगS to dequnN

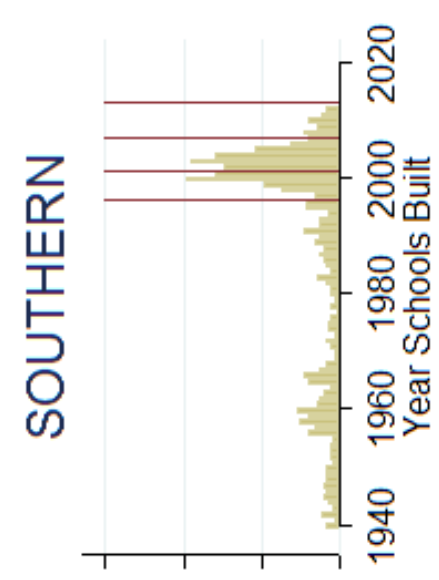

OSL OOL OS O t!!ng s|004गS to dequnn
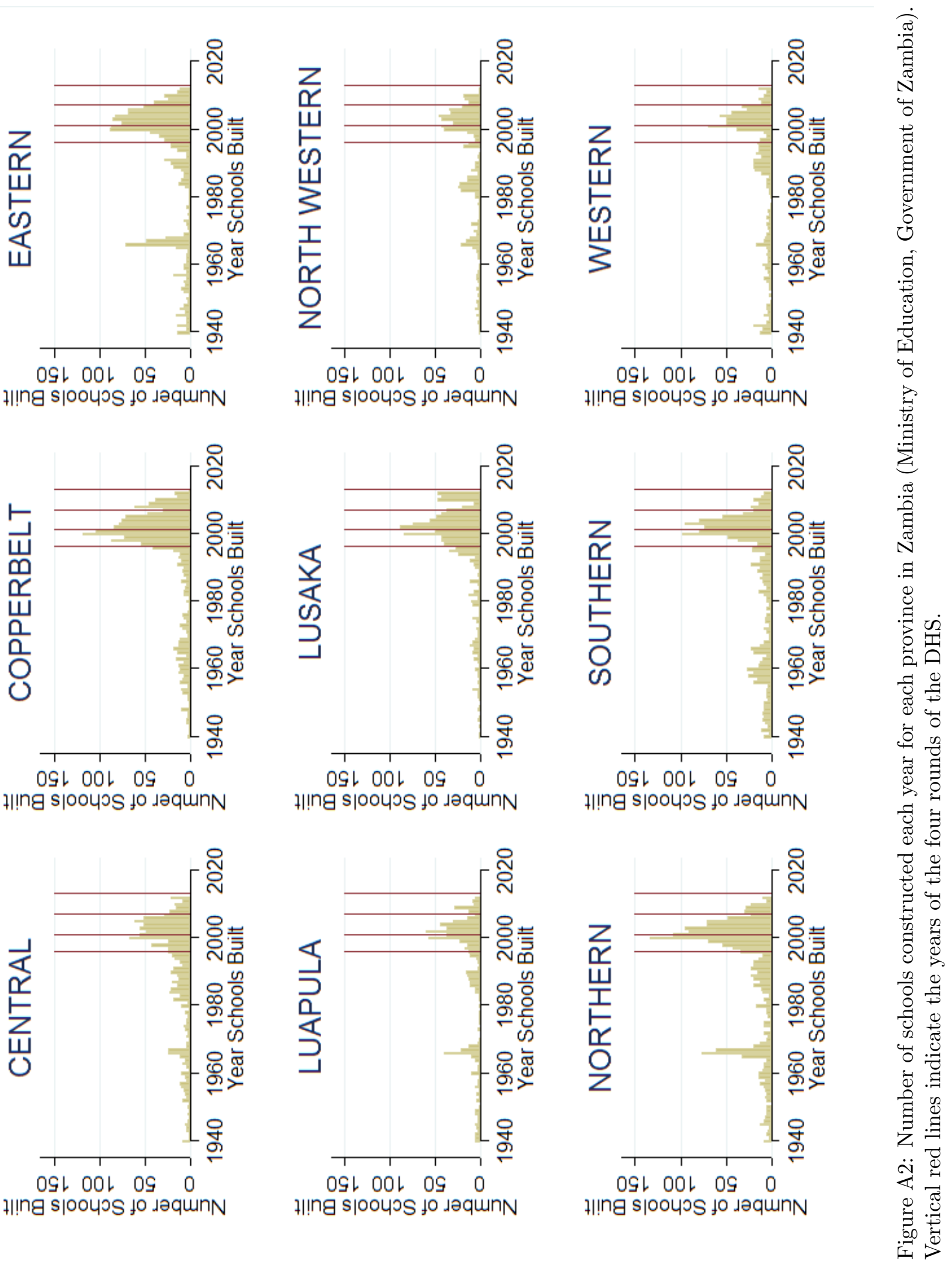


\section{References}

Alesina, Alberto, Paola Giuliano, and Nathan Nunn, "On the Origins of Gender Roles: Women and the Plough," Quarterly Journal of Economics, 2013, 128 (2), 155-194.

Duflo, Esther, "Schooling and Labor Market Consequences of School Construction in Indonesia: Evidence from an Unusual Policy Experiment," American Economic Review, 2001, 91 (4), 795813.

Gordon, Raymond G., Ethnologue: Languages of the World, 15th Edition, SIL International, 2005 .

LeBar, Frank M., Ethnic Groups of Insular Southeast Asia. Volume 1: Indonesia, Adaman Islands, and Madagascar, New Haven: Human Relations Area Files Press, 1972.

Minnesota Population Center, "Integrated Public Use Microdata Series, International: Version $6.1, " 1995$.

Murdock, George Peter, Africa: Its Peoples and Their Cultural History, New York: McGrawHill Book Company, 1959.

_ , Ethnographic Atlas, Pittsburgh: University of Pittsburgh Press, 1967.

Schapera, Isaac, A Handbook of Tswana: Law and Custom, Oxford: Oxford University Press, 1938.

Strauss, J., F. Witoelar, B. Sikoki, and A.M. Wattie, "The Fourth Wave of the Indonesian Family Life Survey (IFLS4): Overview and Field Report," 2009.

_, K. Beegle, B. Sikoki, A. Dwiyanto, Y. Herawati, and F. Witoelar, "The Third Wave of the Indonesian Family Life Survey (IFLS): Overview and Field Report,” 2004.

Whiteley, Wilfred and J. Slaski, Bemba and Related Peoples of Northern Rhodesia, London: International African Institute, 1950.

Willis, Roy, The Fipa and Related Peoples of South-West Tanzania and North-East Zambia, London: International African Institute, 1966. 